NACHBARSCHAFTSZENTRUM \& GEMEINSCHAFTSSCHULE an der alten Feuerwache in Anger-Crottendorf, Leipzig 


\section{Über den Autor}

Norma Brecht hat nach ihrem Politikwissenschaftsstudium mit der Vertiefung Stadtgeografie an der Universität Leipzig Architektur an der HTWK Leipzig studiert. Im Rahmen von Lehraufträgen, als wissenschaftliche Mitarbeiterin oder als Beauftragte im Rahmen von Modellprojekten der Stadt Leipzig weiß Sie beide Fachbereiche miteinander zu kombinieren. Zur Zeit arbeitet sie im Büro cowerk architektur und ist in verschiedenen stadtpolitischen Gruppen aktiv.

\section{Bibliografische Information der Deutschen Nationalbibliothek}

Die Deutsche Nationalbibliothek verzeichnet diese Publikation in der Deutschen Nationalbibliografie. Detaillierte bibliografische Daten sind im Internet unter http://dnb.de abrufbar.

Der Text dieses Werks ist unter der Creative-Commons-Lizenz CC BY 4.0 International veröffentlicht. Den Vertragstext der Lizenz finden Sie unter

https://creativecommons.org/licenses/by/4.0/. Die Abbildungen sind von dieser Lizenz ausgenommen, hier liegt das Urheberrecht beim jeweiligen Rechteinhaber.

(C) 2019 Norma Brecht

\section{Herausgeber}

Open-Access-Hochschulverlag

Hochschule für Technik, Wirtschaft und Kultur Leipzig

Karl-Liebknecht-Str. 132

04277 Leipzig, Deutschland

Druck \& Bindung in Deutschland und den Niederlanden

Gedruckt auf säurefreiem Papier 


\section{NACHBARSCHAFTSZENTRUM \& GEMEINSCHAFTSSCHULE an der alten Feuerwache in Anger-Crottendorf, Leipzig}

1 AUFGABE.

Zur Lösung eines Nutzungskonflikts

2 DER ORT.

Anger-Crottendorf'sches Allerlei -

Das Stadtbild und seine Bewohner_innen

3 RAUMPROGRAMM.

Drei Akteure formulieren das Raumprogramm

4 BESTAND.

Die alte Feuerwache und deren Nebengebäude

5 ENTWURF.

Die Stadt als Schule.

5.1 KONZEPT. Die Stadt als Schule

5.2 STÄDTEBAU. Zur Stadt öffnen, Plätze definieren

5.3 RAUMORGANISATION. Horizontal und Vertikal

5.4 BAUKONSTRUKTION. Raster Tragwerk

5.5 GESTALTUNG. Fassade und Ansichten

5.6 MODELLE

6 FAZIT.

Wenn drei sich streiten 


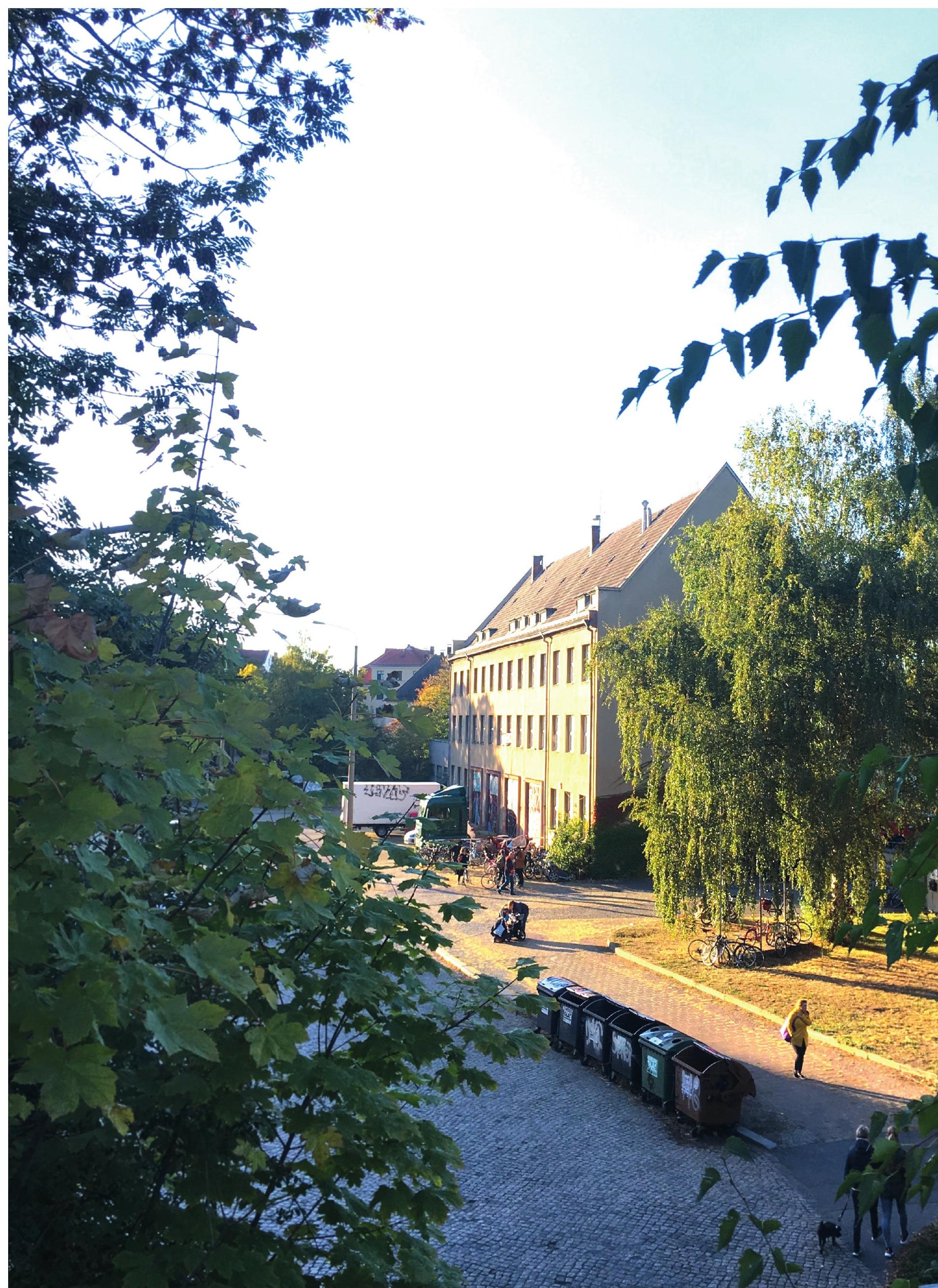



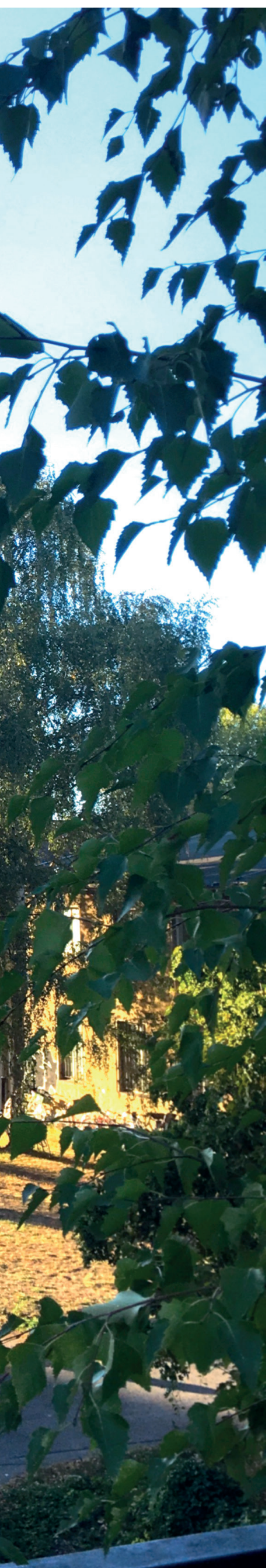

\section{ZUR LÖSUNG EINES NUTZUNGSKONFLIKTS}

\begin{abstract}
Als sich 2015 ankündigte, dass die Branddirektion für ihre Feuerwache im Leipziger Osten einen neuen Standort benötigte und somit ihr damals genutztes Gebäude frei werden würde, bemühte sich die Stadt Leipzig um eine mögliche Nachnutzung des Areals. Das zuständige Amt für Stadterneuerung und Wohnungsbauförderung (ASW) veranstaltete verschiedene Workshops, deren Ergebnis ein Nutzungskonzept für den Bestand hervorbringen sollte. Der im Nachgang gegründete Verein Ostwache Leipzig e.V. setzt sich seit 2016 für ein Nachbarschaftszentrum in der ehemaligen Feuerwache ein. Gleichzeitig prüft die Stadt Leipzig für die Liegenschaft der alten Feuerwache sowie zusätzlich auf zwei im Norden angrenzenden Grundstücken einen Schulneubau. Auf diesen beiden Grundstücken befinden sich seit über 40 Jahren etwa 170 stark genutzte Garagen. Für diesen Nutzungskonflikt zwischen Nachbarschaftszentrum, eines nötigen Schulneubaus und vorhandenen Garagen soll in der Arbeit eine Lösung entworfen werden.
\end{abstract}

DOI - Kapitel 1: http://doi.org/10.33968/9783966270144-01 


\section{DREI AKTEURE VOR ORT}

1. Ostwache Leipzig e.V.

2. Stadt Leipzig

3. Garagenverein Mehr Gewerbe!
Zurzeit formulieren also drei Akteure Interessen für den Standort rund um die Feuerwache und sind auf verschiedene Weise vor Ort aktiv. Sie haben berechtigten Grund für die Formulierung ihres Anspruchs an den Stadtteil: Die Interessen des Ostwache e.V. und des Garagenvereins kollidieren nicht. Die Stadt Leipzig muss jedoch dem Versorgungsauftrag ihrer wachsenden Bevölkerung gerecht werden und deshalb neue Schulen schaffen. Sie prüft das Areal als möglichen Standort. Gerade die Bewohner_innen von kleinen Wohnungen im Geschosswohnungsbau haben den Anspruch auf die ansonsten fehlenden Stellplätze. Der Garagenverein Bahndamm e.V. verwaltet hier 170 Garagen. Der Ostwache e.V. hat mit seiner umfangreichen Arbeit in der Nachbarschaft und im Stadtteil gezeigt, dass er als kulturelle Einrichtung und Nachbarschaftszentrum nicht mehr wegzudenken ist.

\section{SOZIAL \& NICHT KOMMERZIELL NUTZUNGSLÜCKEN IM STADTTEIL}

In Anger-Crottendorf fehlt es vor allem an sozialen, kulturellen und gewerblichen Angeboten. Denn im 2,5 km östlich vom Leipziger Zentrum gelegenen Stadtteil wird vor allem gewohnt und gegärtnert. Im Rahmen von verschiedenen Befragungen des Ostwache e.V. und Workshops der Stadt Leipzig konnten verschiedene Nutzungswünsche herausarbeitet werden: Es fehle an Gastronomie und unkommerziellen Angeboten, wie Sport- und Kultureinrichtungen. Aus der Analyse des Ostwache e.V. ist deshalb die Idee entstanden, dass ein Kultur- und Bildungszentrum für, mit und im Stadtteil entstehen soll.

THESE I. Eine qualitativ hochwertige Nachnutzung des Areals „alte Feuerwache" verbindet die Interessen aller im Prozess beteiligten Akteure und trägt entscheidend dazu bei, die Lebensqualität für die Bewohner_ innen in Anger-Crottendorf zu steigern und die alte Feuerwache als Treffund Ankerpunkt im Stadtteil etablieren.

Ziel der Arbeit ist es, einen möglichen Konsens und Interessensausgleich zwischen den handelnden Parteien vorzuschlagen, indem ein Entwurf erarbeitet wird, der die Interessen aller Parteien vereint: Dem Verein Ostwache e.V. soll die Möglichkeit gegeben werden, als Stadtteilverein auf dem Areal aktiv zu werden und die Stadt Leipzig soll gleichzeitig in der Lage sein, ihren Auftrag zur Sicherung von Schulstandorten gerecht zu werden.

Dabei wird davon ausgegangen, dass jegliche Aussagen, Annahmen und Forderungen der Parteien sachlich und politisch nicht hinterfragt werden können. Für die Garagennutzung und Stellplätze soll mindestens eine Ausgleichsfläche vorgeschlagen werden.

THESE II: Um den Konsens zu ermöglichen, müssen sowohl verschiedene Akteure einbezogen als auch räumliche Synergieeffekte genutzt werden. Das kann nur dann gelingen, wenn Nachbarschaftszentrum, Schule und Parken gemeinsam funktionieren. In staatlicher Trägerschaft deutscher Schulen sind solche Nutzungsmischungen selten möglich. Deshalb soll ein alternatives pädagogisches Schulkonzept herangezogen werden, um diese Nutzungsmischung zu ermöglichen - egal in welcher Trägerschaft. 
DIE STADT ALS SCHULE.

NACHBARSCHAFTSZENTRUM

UND GESAMTSCHULE AN EINEM ORT

Der Nutzungsschwerpunkt des Standorts liegt bei den verschiedenen Akteuren im Bereich Bildung und Kultur. Die Stadt und der Verein haben hier das Ziel eine Nutzungslücke zu füllen.

Ziel der vorliegenden Masterarbeit ist es, ein Zentrum zu schaffen, dass diese beiden Nutzungen - Schule und Nachbarschaftszentrum - miteinander verbindet. Beide Funktionen sollen gemeinsam gedacht werden und (nach außen) in den Stadtteil Anger-Crottendorf wirken.

Um zu zeigen, dass beide Nutzungskonzepte "Schule" und „Nachbarschaftszentrum" miteinander in Einklang gebracht werden können, soll das Raumprogramm einer Freinet-Gesamtschule mit dem Raumprogramm des Ostwache e.V. verbunden und zusammengebracht werden.

Das Bildungskonzept der französischen Reformpädagog_innen Elise und Celeste FreiFreinet-Pädagogik Stadt als Schule net beruht auf der Annahme, dass Kinder und Jugendliche selbstbestimmt lernen, wenn man sie dazu befähigt. Dabei ist das Erstellen und Publizieren eigener Werke und Produkte Bestandteil des Lernens. Im deutschsprachigen Raum wurde Freinet-Pädagogik u.a. unter dem Slogan "die Stadt als Schule" umgesetzt. Das praktische Lernen in Betrieben, Firmen und sozialen Einrichtungen ist Teil des Lehr- und Lernplans. Die Schule geht somit über die Grenzen des Gebäudes bewusst hinaus und gleichzeitig werden die selbsterlernten Inhalte und Erfahrungen der Schüler_innen wieder in den Schulbetrieb zurück getragen.

THESE III. Der pädagogische Ansatz „Stadt als Schule” macht die Synergie der verschiedenen Akteure möglich. Wenn die Räume des Nachbarschaftszentrums und die der Schule gemeinsam und ganztags genutzt werden können, kann ein neuer Treffpunkt in, mit und für Anger-Crottendorf entstehen.

Für das Ziel der Stadt Leipzig, dass Nachbarschaftszentrum und Schule an einem Ort funktionieren sollen, soll diese Arbeit ein Lösungsvorschlag sein. Die vorliegende Broschüre stellt diesen Entwurf vor und dokumentiert meinen Weg als Verfasserin zu diesem Ziel.

Zu Beginn wird der Stadtteil Anger-Crottendorf sowie deren sozialräumlichen Veränderungen und Stadtentwicklungstendenzen dargestellt. Die drei Akteure vor Ort werden vorgestellt und meinen Kontakt zu ihnen chronologisch nachgezeichnet. Um eine Nutzungssynergie herzustellen, werden die Ziele der einzelnen Akteure und deren Anforderungen an das Raumprogramm miteinander verbunden und mit Hilfe von vier Grundsätzen alternativer Pädagogik zur "Stadt als Schule” als Konzept miteinander verknüpft. Mit diesem Konzept wurde vom Städtebau bis zur Innenarchitektur entworfen. Für das städtebauliche Konzept wurden drei räumliche Defizite vor Ort festgestellt und durch die Bebauung zweier Gebäude drei Freiräume entwickelt. Der L-Förmige Schulneubau wird über einen Mittelgang erschlossen, der aufgrund des baukonstruktiven Entwurfs zum Lernflur mit Leseecken und Nischen wird. Die Lernräume sind im Cluster organisiert. Die Klassenzimmer sind hinter einer bespielbaren Pfosten-Riegel-Fassade als Lernateliers entworfen. Die Schüler_innen können sich hier die Räume für sich und ihr individuelles Lernen aneignen.

Nachbarschaftszentrum und Schule können durch die Öffnung beider konzepte an einem Ort funktionieren.

Schule

Nachbarschaftszentrum 


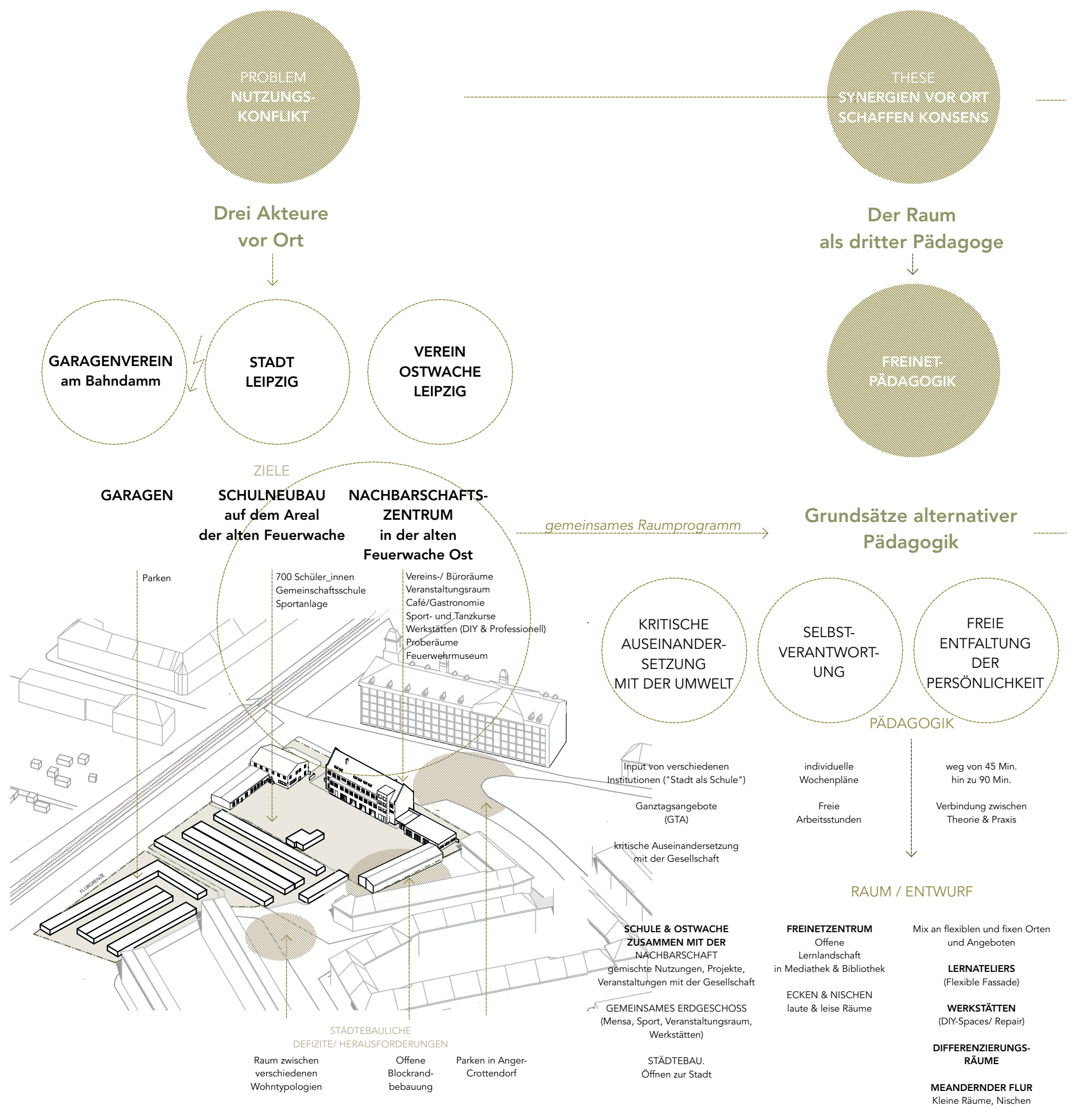




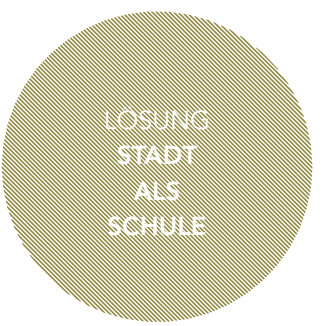

Die Nachbarschaft als vierte Pädagogin

SCHULNEUBAU NACHBARSCHAFTS-

Ost
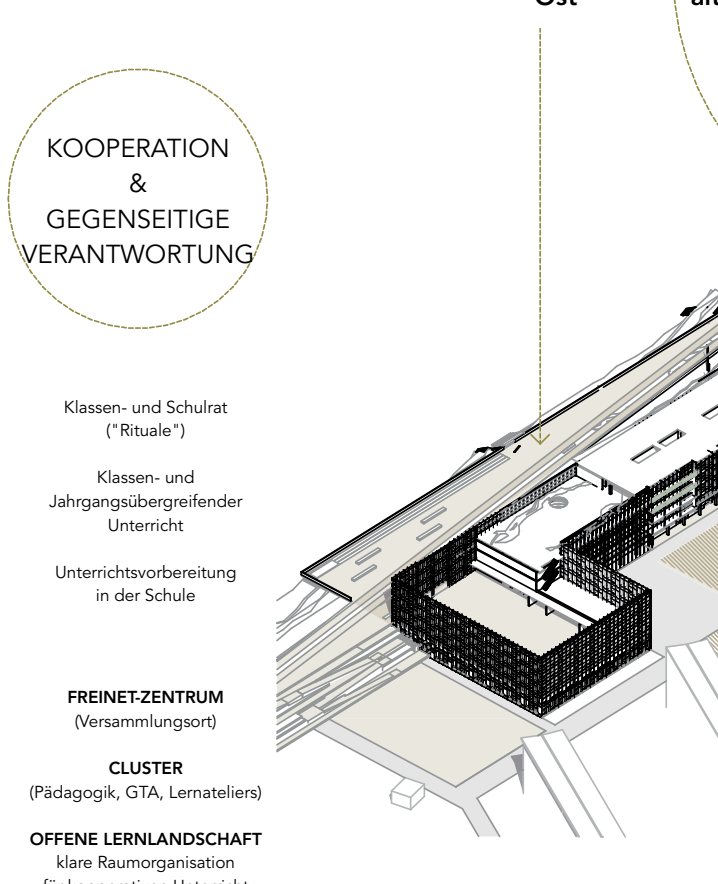

Klassen- und Schulrat ("Rituale")

Klassen- und

Jahrgangsübergreifender Unterricht

Unterrichtsvorbereitun in der Schule

FREINET-ZENTRUM

(Versammlungso

$$
\text { CLUSTER }
$$

(Pädagogik, GTA, Lernateliers)

OFFENE LERNLANDSCHAFT klare Raumorganisation für kooperativen Unterricht
und gemeinsame Arbeit auf dem Areal der ZENTRUM ten Feuerwache in der alten

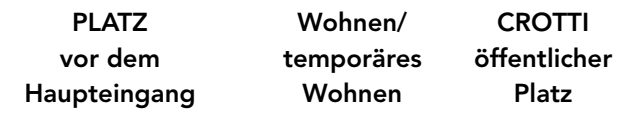

PARKEN / LAGERN Feuerwache Ost
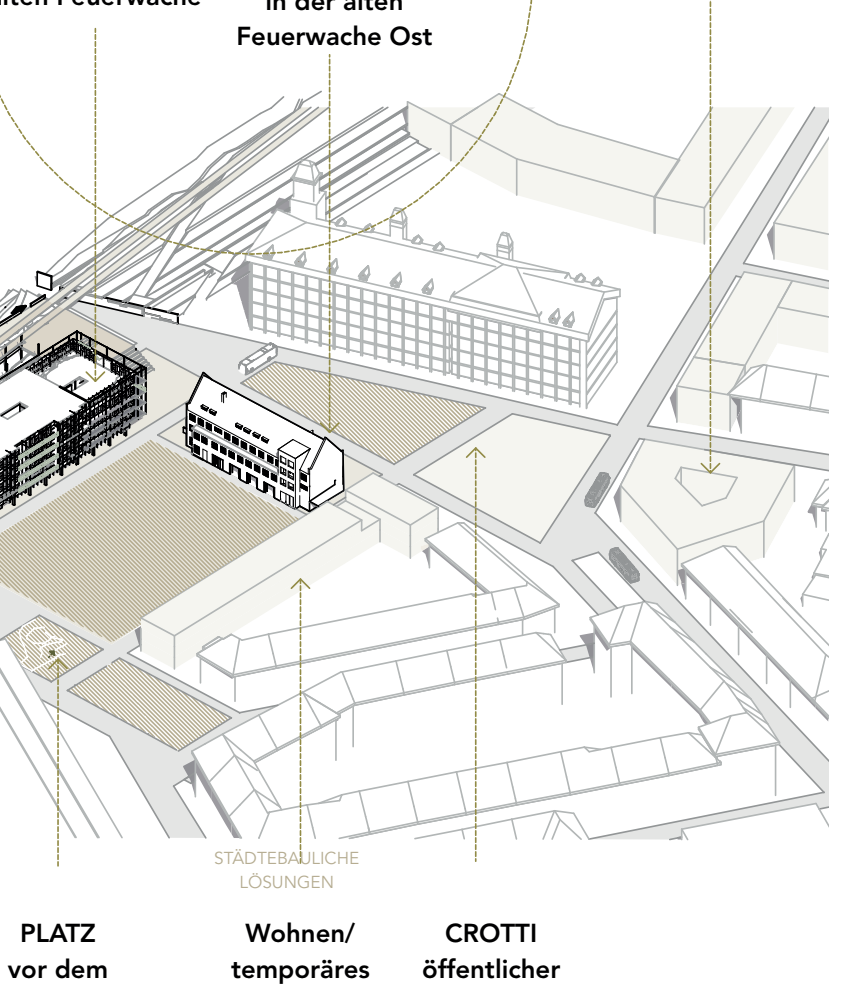

Platz

GESAMT

ENTWURFSKONZEPT

Problem-These-Argument Diagramm 


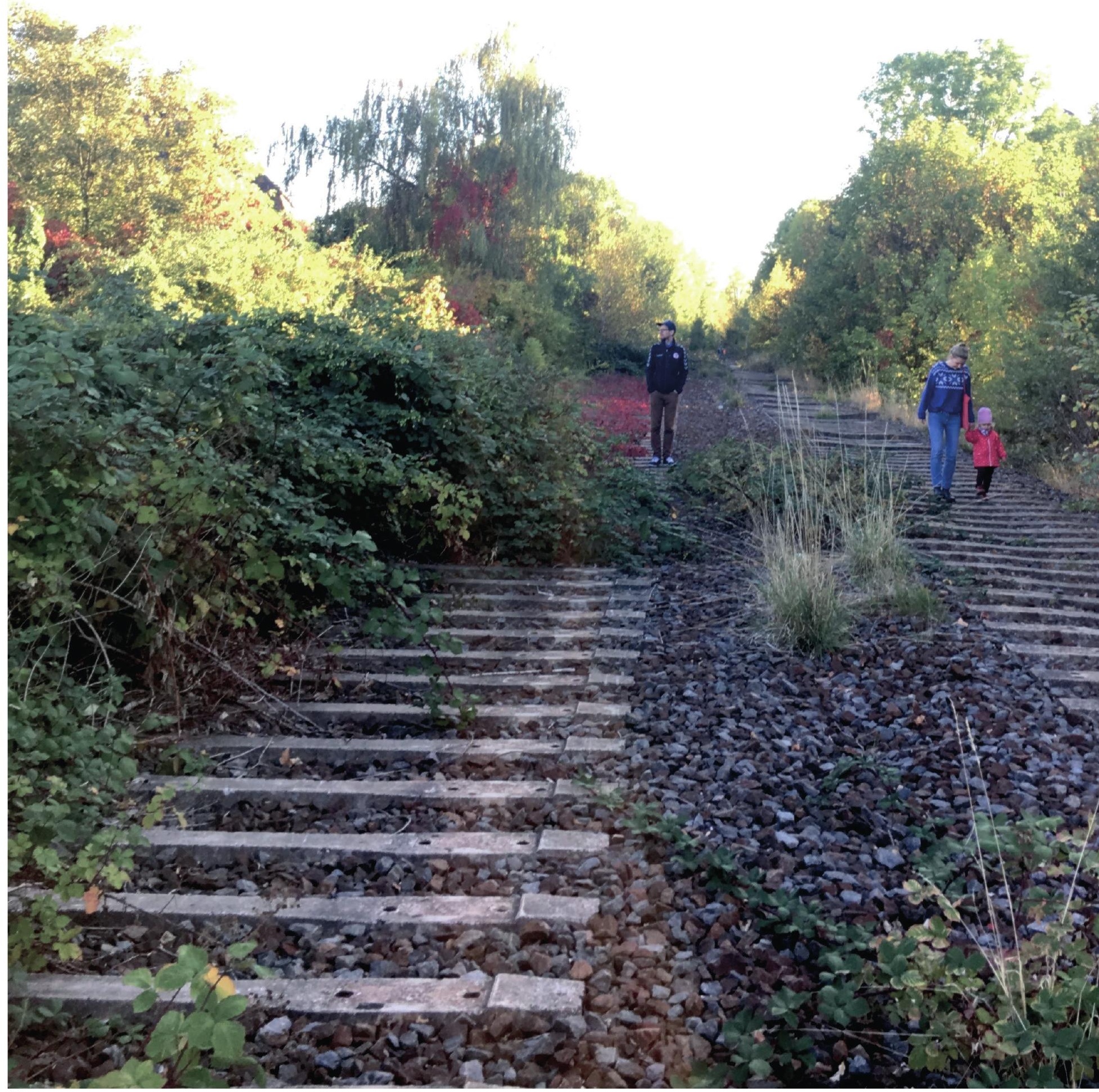




\title{
ANGER-CROTTENDORF'SCHES ALLERLEI
}

\author{
DAS STADTBILD \& SEINE BEWOHNER_INNEN
}

Aufgrund der steigenden Bevölkerungszahlen kommt es zu stadträumlichen Veränderungen. Auch der Stadtteil Anger-Crottendorf im Leipziger Osten verändert sich in diesem Rahmen. Die Mieten steigen schneller als das Haushaltseinkommen. Zwischen privaten Grünflächen und Wohngebäuden ist der Bedarf nach neuen gewerblichen und sozialen Angeboten hoch.

DOI - Kapitel 2: http://doi.org/10.33968/9783966270144-02 


\section{VERÄNDERUNG IM STADTTEIL - JÜNGER, TEURER, DIVERSER}

Es ist privat.

Kleingarten \& Wohnen
Es ist grün und feucht in Anger-Crottendorf. Es verwundert nicht, dass hier viele Kleingärtner_innen ihren Platz gefunden haben. Dank der Rietzschkenaue lieferten vor der Industrialisierung das Dorf Crottendorf und die sogenannten Kohldörfer Lebensmittel in die nah gelegene Stadt Leipzig. Dort im Osten der Stadt, wo heute in Schrebergärten-Kolonien das private Grün gepflegt wird, wurde früher Leipzig ernährt.

Große Kleingartenanlagen entlang der ehemaligen Bahntrasse charakterisieren heute den Stadtteil, es handelt sich hierbei vor allem um private Günflächen. Zwar sind aus zwei ehemaligen Villengärten - wie der Ramdohrscher Park oder Lieselotte-Hermann-Park - kleine öffentliche Parkanlagen entstanden. Der in diesem Verhältnis 13 ha große Stünzer Park gehört zu dem größten öffentlichen Grünanlagen (Werner 2011, S. 49). Jedoch unterscheiden sie sich von der Qualität der Grünflächen anderer Leipziger Stadtteile.

Die Kleingartenkolonien werden durch den verwilderten Bahndamm von der ehemaligen Bahntrasse zwischen Anger-Crottendorf und Sellerhausen durchstoßen. Dieser Bahndamm verspricht Aufwertungspotenial für den Stadtteil.

\section{PARKBOGEN OST}

Es wird öffentlich. Stadtentwicklung \& Aufwertung
Gerade wegen der vergleichsweise wenigen Grünflächen soll die ehemalige Bahntrasse, die Anger-Crottendorf zerteilt, mittelfristig als Fuß- und Radweg "Parkbogen Ost” (PBO) ausgebaut werden, welcher die gesamten Stadtteile des Leipziger Ostens als Nord- und Südachse miteinander verbindet. Der PBO soll auch ein Naherholungsgebiet für den Leipziger Osten werden. Schon jetzt lädt der verwachsene Bahndamm zumindest Personen, die gut zu Fuß sind, zum Schlendern ein. Die Stadt Leipzig sieht in der Masterplanung mehrere Zu- und Abgänge zum Parkbogen Ost vor. Großes Vorbild ist die Entwicklung der High Line in New York (Stadt Leipzig 2018a).

Die Aufwertung des Bahndamms zur Grünanlage und die Verkehrsverbindung der Stadtteile werden den Stadtteil in den nächsten Jahren verändern. Auch andere Neubau- projekte und Sanierungstätigkeiten nehmen Einfluss auf die bauliche und voraussichtliche demographische Veränderung von Anger-Crottendorf.

\section{QUARTIERSSCHULE}

Infrastrukturell rüstet die Stadt nach. Das ASW plant in der Hermann-Liebmann-Straße einen Doppelschulstandort als Schulkomplex mit 4-Zügiger Oberschule und 4Zügigem Gymnasium Fertigstellung ist voraussichtlicht 2019 (Stadt Leipzig 2018b).

\section{AUFWERTUNG \& VERDRÄNGUNG}

Ebenso hat eine zunehmende Sanierungstätigkeit im Bestand Einfluss auf das Wohnungsmarktangebot. Die Stadt Leipzig prüft für den Stadtteil die Einführung einer Erhaltungssatzung, da hier durch das große Aufwertungspotential die Gefahr der Verdrängung von alteingesessenen Bewohner_innen besonders groß ist. In der Voruntersuchung durch die Landeseigene Planungsgruppe (LPG) wird beschrieben, dass die Modernisierung von bewohntem Bestand zur Verdrängung der Bewohner_innen führen kann und entsprechend sieht die LPG Handlungsbedarf. Zwar seien hier „gefestigtere Bevölkerungsstrukturen” zu finden, jedoch ändert sich die „Zusammensetzung der Wohnbevölkerung, (...) [was] auch durch den starken Anstieg des monatlichen Nettoeinkommens " (LPG et al. 2017, S. 63) verursacht wird.

Es sind vor allem die privatwirtschaftlich organsierten gründerzeitlichen Wohnbestände, in denen das Verdrängungspotenzial durch Umwandlung in Eigentumswohnungen hoch ist. Da die genossenschaftlich organisierten Bestände umfassend saniert wurden, gibt es hier kaum Aufwertungspotential (LPG et al. 2017, S. 63).

Hinzu kommen Kernsanierungen oder Umwandlungen von Leerständen, wie beispielsweise die Fabrik „Polygraph Karl-Krause".

Die Maschinenfabrik für Druck- und Papierverarbeitung 
wurde 1983 auf dem Areal zwischen ZweinaundorferstraBe und Theodor-Neubauer-Straße errichtet. Mit der Vergrößerung der Fabrik stieg auch die Bewohner_innenzahl (Werner 2011, S. 47) und somit auch die Bautätigkeit im Stadtteil.

Heute ist nur noch der Rohbar des ehemaligen Verwaltungsgebäude erhalten, aber stark sanierungsbedüftig. Es wird von einem Immobilienentwickler zu Wohnraum umgenuzt werden (Dolphin Trust GmbH 2017). Für das gesamte Gelände der Karl-Krause-Fabrik ist ein städtebaulicher Entwurf geplant. Die Sanierung der Fabrik und der dazugehörigen Fläche scheitert zurzeit an der Vermarktung. Es sollte aber aufgrund der aktuellen Marktlage nur eine Frage der Zeit sein, bis sich ein Investor findet.

Allgemein nimmt die Kauftätigkeit im Neubau und im Bestand zu. Die Kauftätigkeit steigt in allen Stadtteilen des Leipziger Ostens an, da hier die Preise im Vergleich zum Rest der gründerzeitlich geprägten Stadteile Leipzig noch niedrig sind (LPG et al. 2017, S. 18). Vor allem der Verkauf von unsanierten Mehrfamilienhäusern hat sich zwischen 2011 und 2015 verdoppelt und nimmt kontinuierlich zu. Auch der Verkauf von bereits sanierten Eigentumswohnungen nimmt zu, wobei nur ein Drittel der Eigentümer_innen aus Leipzig kommt.

\section{JUNG \& ARM}

Das Aufwertungspotential und die Neubautätigkeit trifft in Anger-Crottendorf auf ein sich veränderndes, aber armes Milieu. Hier besteht ganz besonders die Gefahr der Verdrängung ärmerer Milieus.

Anger-Crottendof wächst. Einige Bevölkerungsprognosen sprechen in den Jahren 2016 - 2030 stadtweit sogar von einem Bevölkerungszuwachs von ca. $27 \%$. Im Vergleich zu den anderen Stadtteilen des Leipziger Ostens wächst AC unterdurchschnittlich mit 5-10\%, „was dem geringen Leerstand und \{der\} wenig\{en\} Bautätigkeit im Gebiet geschuldet" (LPG et al. 2017, S. 16) ist.

Doch Anger-Crottendorf wird jünger, bleibt dabei aber relativ arm. Wie in ganz Leipzig wird auch die Bevöl- kerung in Anger-Crottendorf aufgrund der starken Geburtenzunahme jünger (LPG et al. 2017, S. 17). Neben Volkmarsdorf ist Anger-Crottendorf einer der am schnellsten verjüngten Stadtteile ganz Leipzigs (Stadt Leipzig 2018, S. 8). Jedoch bleibt der Leipziger Osten und Anger-Crottendorf ein vergleichsweise einkommensschwacher Stadtteil. Während in ganz Leipzig die Arbeitslosenquote in den letzten 10 Jahren von 18\% auf 9\% gesunken ist, liegt sie im Leipziger Osten noch bei über 30\% (LPG et al. 2017, S. 17).

Ähnlich bleibt die Mietpreisbelastungsquote bei ca. 31\%. Denn das Netto-Haushaltseinkommen von $1.600 €$ im Monat liegt etwas unter dem Leipziger Durchschnitt, während die Mieten steigen. „Die höchsten Nettokaltmieten von bis zu 6,90 Euro/qm werden in den innerstädtischen Ortsteilen des Stadtbezirks Mitte erreicht. Die westlich, südlich und südöstlich angrenzenden Ortsteile folgen mit Nettokaltmieten von 5,50 bis 6,00 Euro/qm" im Leipziger Osten sind es "unter 4,80 Euro/qm (Volkmarsdorf) bis 5,50 Euro/qm" (LPG et al. 2017, S. 19). Das noch geringe Mietniveau steigt an und zeigt eine höhere Dynamik als in der Gesamtstadt (LPG et al. 2017, S. 63).

Die umfassende Sanierung der leer stehenden Häuser ist nahezu abgeschlossen. Man rechnet hier mit der „zweiten Modernisierungswelle". Nach der ersten umfassenden Sanierungswelle der 1990er Jahre werden vermehrt bewohnte Häuser saniert. Einzeleigentümer bekommen Kaufangebote von großen Investoren. Diese Entwicklung ist im gesamten Leipziger Osten zu beobachten, da hier "große Potenziale zur Gewinnmaximierung bestehen, da die Kaufpreise und das Mietniveau niedrig und die möglichen Wiederveräußerungserlöse hohe Gewinnmagen ermöglichen" (LPG et al. 2017, S. 19).
Erhaltungssatzung gegen die zweite Modernisierungswelle 


\subsection{STÄDTEBAU}

\section{WBS70, REFORMBAU UND GRÜNDERZEIT}

Alle hier genannten städtebaulichen und sozialen Veränderungen betreffen auf verschiedene Weise das zu bearbeitende Areal der alten Feuerwache.

Bewegt man sich aus der Innenstadt Leipzig Richtung Osten zur alten Feuerwache in Anger-Crottendorf wird es vor allem ruhiger. Der Straßenlärm und Gewerbebetrieb von Reudnitz-Thonberg lässt abrupt hinter der Breiten Straße nach, welche den Stadtteil gemeinsam mit der Wurzner Straße im Westen begrenzt.

Die ehemaligen Kohlgärten und die nur spärlich erhaltene Bebauung sind Zeugnisse der historischen Nutzung. Das Dorf Anger war schon früh von städtischer Bebauung geprägt. Doch erst nach der Zusammenlegung mit Crottendorf und späteren Eingemeindung 1889 (Briel/Krüger 1999, S. 2) wird der Stadtteil schnell von gründerzeitlicher Blockrändern bebaut und so mit den Nachbarstadtteilen verbunden. Die Grenzen zwischen den Stadtteilen sind kaum mehr erkennbar (Briel/Krüger 1999, S. 2).

Trotzdem ist Anger-Crottendorf vor allem durch seine Nutzung charakterisiert. Denn hier wird vorrangig gewohnt und gegärtnert. Gen Norden hin trennen die Bernhardstraße und Kleingartenanlagen Anger-Crottendorf von Sellerhausen und Volkmarsdorf. Gleisanlagen und große Anlagen von Kleingartenvereinen lassen die Grenze nach Osten hin diffus erscheinen. Im Gegensatz zum Süden, hier grenzt Wohnbebauung entlang der Mierendorfstraße an Stünz an (LPG et al. 2017, S. 50).

Im Stadtteil wird vor allem im mehrgeschossigen Wohnungsbau gewohnt. Dieser ist vorrangig durch drei Baustrukturen charakterisiert: Erstens dem industriell gefertigten Geschosswohnungsbau der DDR, zweitens den Reformbauten der Weimarer Republik und schließlich die bis zu fünfgeschossige Gründerzeitbebauung (LPG et al. 2017, S. 63). Die Blockränder und Zeilen werden von Sonderbauten unterbrochen - wie beispielsweise Kaufhallen, eine Kirche, Schulen oder eben die Feuerwache selbst.
Die städtebauliche Struktur um die alte Feuerwache und die beiden angrenzenden Flurstücke werden durch diese drei Wohntypologien geprägt, deshalb soll die Beschreibung der Nachbarschaft des zu bebauenden Grundstücks und des Charakters Anger-Crottendorfs gemeinsam samt deren Defizite sowie Vorzüge erfolgen:

1. WBS 70 Platten / Geschosswohnungsbau der DDR

2. Reformbau der $1920 / 30$ er

3. Gründerzeit 


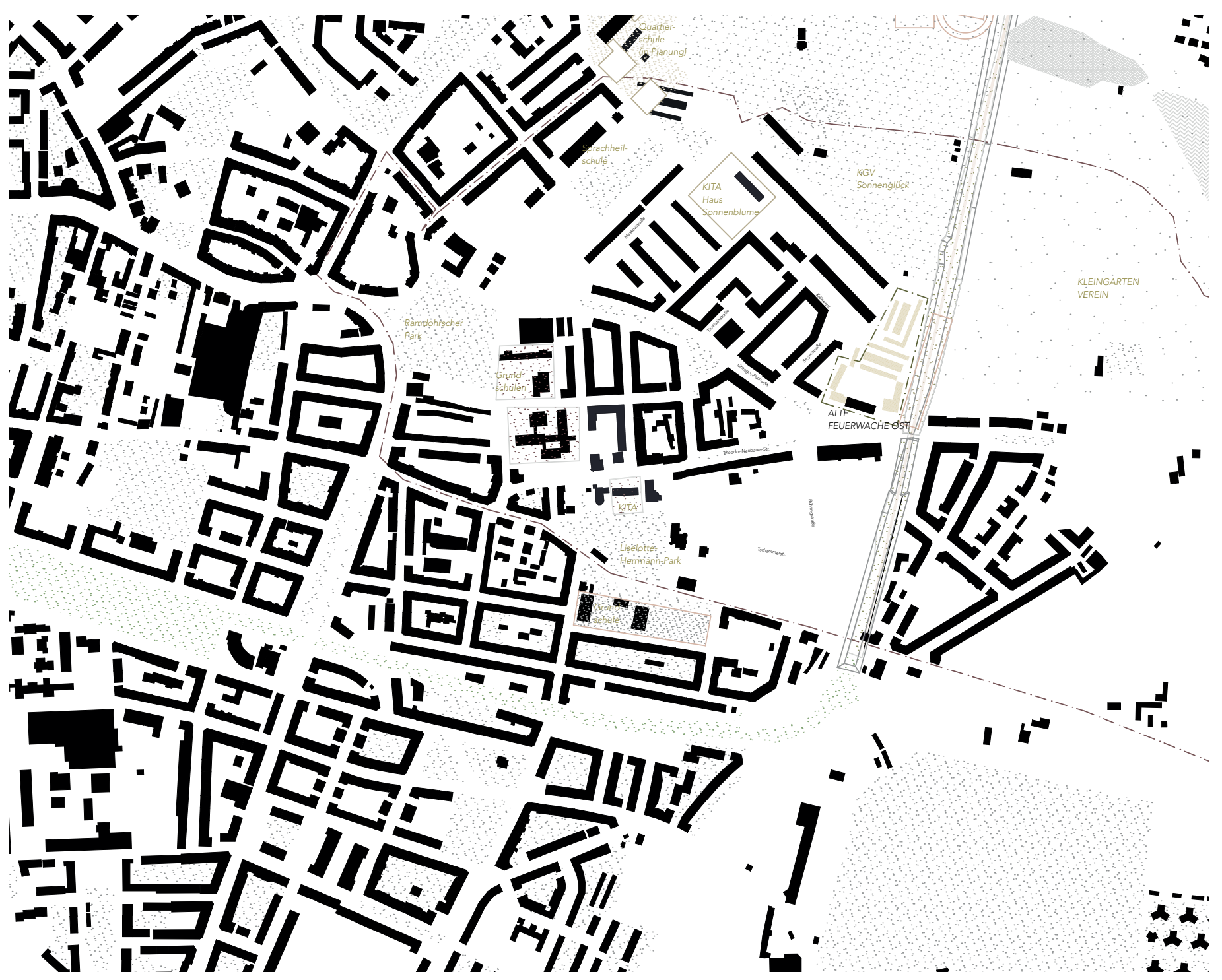




\section{WBS70 PLATTENBAUTEN GELEITEN DEN WEG}

Zwei sechsgeschossige industriell gefertigte Geschosswohnungsbauten der DDR (WBS70) entlang der Hanns-Eisler-Straße und der Herrmann-Straße treffen im Nord-Osten auf das Grundstück. Die in Reihe stehenden Plattenbauten lassen aufgrund ihrer Fabrikation keine Straßendurchbrüche zu, sondern beschreiben eine StraBenachse, die jedoch nicht durch einen Zielpunkt definiert wird. So wirkt die Bebauung hier wie eine Abgrenzung nach Norden hin.

Die Blöcke geleiten aber die Verbindungstraße zwischen Feuerwache und der neu entstehenden Quartiersschule und der hier ggf. gemeinsam genutzten Sportanlagen. Trotz der städtebaulichen Grenze liegt hier ein Verkehrspunkt mit zunehmender Bedeutsamkeit.

\section{REFORMBAU IM BLOCK}

Zweitens prägt genossenschaftlicher Wohnungsbau im Blockrand oder in der Zeile der 1910er und 1930er Jahre den Stadtteil zwischen Hans-Eisler-Straße, Segerstraße und Neumannstraße. Im Westen der Feuerwache reicht eine nicht-geschlossene genossenschaftliche Blockrandbebauung dieser Typologie an das Grundstück heran. Die bewusst geplanten Vorgärten stehen unter Denkmalschutz (Briel/Krüger 1999, S. 2) und prägen eine ruhige Wohnanlage. Der nicht geschlossene Blockrand rahmt den südlichen Teil des Grundstückes zwar ein, definiert hier aber keine klaren Räume (DEFIZIT I)

\section{GRÜNDERZEIT DER WACHSENDEN GROSSTADT DER LETZTEN JAHRHUNDERTWENDE}

Gründerzeitliche Blockrandbebauung definiert südlich der Zweinaundorfer Straße und rund um die Stegerwaldund Wichernstraße im Osten sowie im Norden entlang der Bernhardstraße Anger-Crottendorfs Stadtbild. Die Art und Weise der Bebauung Anger-Crottendorfs ist deshalb so heterogen, da die Überbauung während der Jahrhundertwende schon im Gange war, bevor sich der Bebauungsplan 1913 „regulierend auf die Bautätigkeit der mitunter nicht bäuerlichen Grundstückseigentümer in Crottendorf auswirken konnte" (Briel/Krüger 1999, S. 46). 
DREI STÄDTEBAULICHE DEFIZITE

Dort, wo alle drei Stadtstrukturen im Nordosten des Areals aufeinandertreffen, bilden Sie einen undefinierten Freiraum aus (DEFIZIT II).

Die drei dominierenden Städtebaustrukturen werden durch Grünanlagen unterschiedlicher Qualitäten und Gemeinde- oder Sondernutzungen unterbrochen. Einige geplanten Freiräume und Plätze sind mit dem Bebauungsplan 1913 identisch, andere Strukturen widersprechen der Planung (Briel/Krüger 1999, S. 52 ff.).

Sogar die 1937 eingeweihte Feuerwache (Briel/Krüger 1999, S. 26) platziert sich auf einem geplanten Straßenverlauf, begrenzt aber "unfreiwillig” den dreieckigen Platz, den sie im Süden gemeinsam mit dem Verlauf der Theodor-Neubauer und Gregor-Fuchs-Straße bildet. Das Gelände der Feuerwache wird über diesen Platz erschlossen, welcher aktuell als Parkplatz genutzt wird.

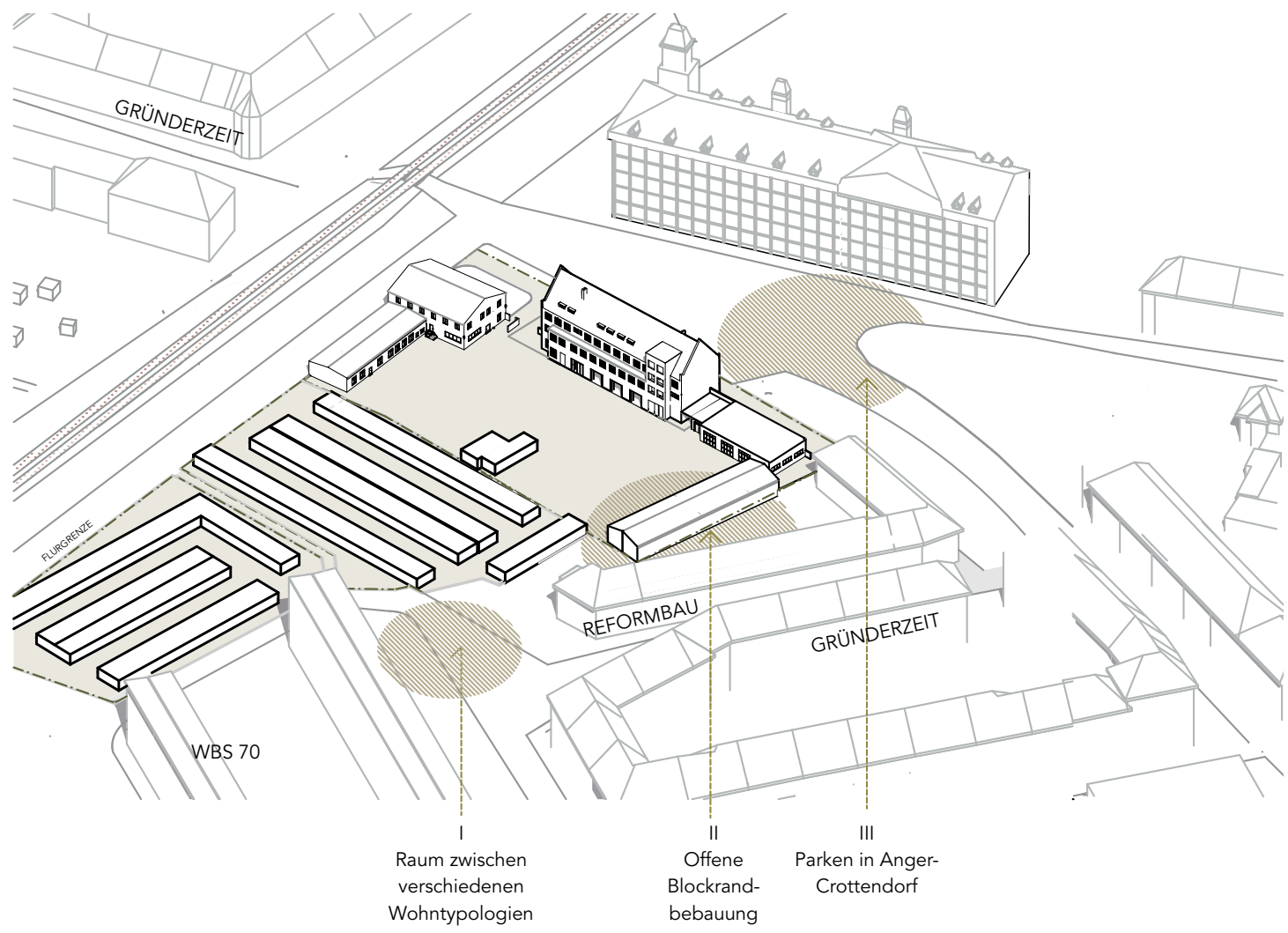

Dieser Freiraum wird zwar durch die Straßenverläufe definiert, er ist aber baulich und somit räumlich nicht gefasst. Zwar kann man die im Süden des Platzes ehemalige Krausfabrik (Polygraph) - ein 6 geschossiger Industriebau - als städtebauliches Gegenüber bezeichnen, jedoch wirkt der Platz im Westen durch einen unvollständigen Kopfpunkt eines Blockrandes offen (DEFIZIT III).
Städtebauliche Defizite (eigekreist) \& Wohngebäudetypologie am Standort (eigene Darstellung) 


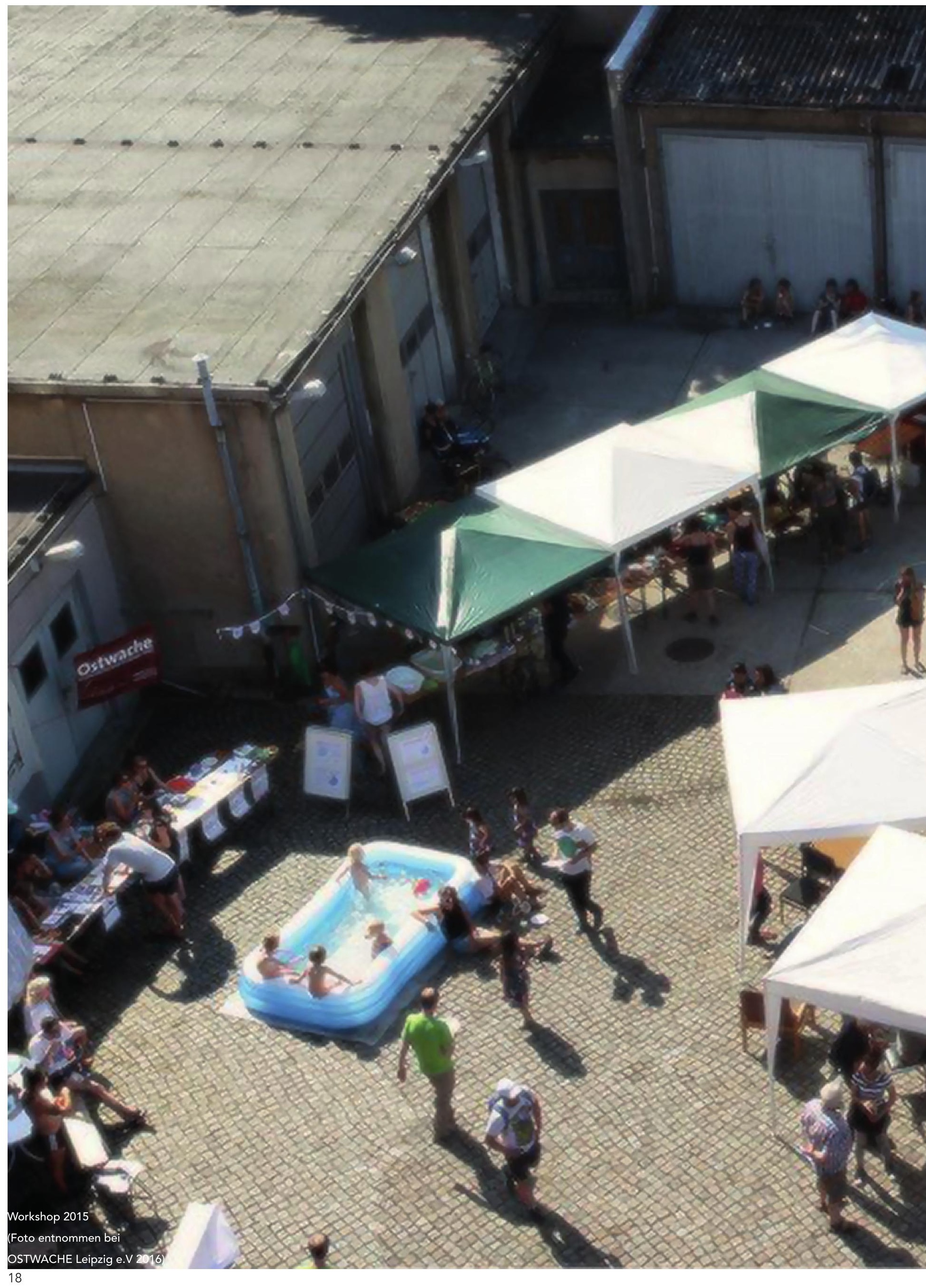


„Wenn das mit der

Ostwache nicht klappt, wandere ich aus!"

Mitglied des Ostwache

Leipzig e.V.

\section{DREI AKTEURE VOR ORT FORMULIEREN DAS RAUMPROGRAMM}

Für diese Arbeit relevant sind vor allem drei Akteure. Sie werden hier kurz vorgestellt und mein Kontakt während des Arbeitsprozesses zu ihnen dargestellt. Sie formulieren auf verschiedene Art und Weise Ziele für den Standort, welche die Grundlage des Raumprogramms der Arbeit bilden.

DOI - Kapitel 3: http://doi.org/10.33968/9783966270144-03

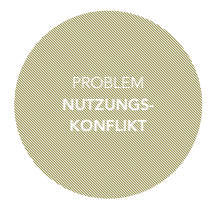

Drei Akteure vor Ort
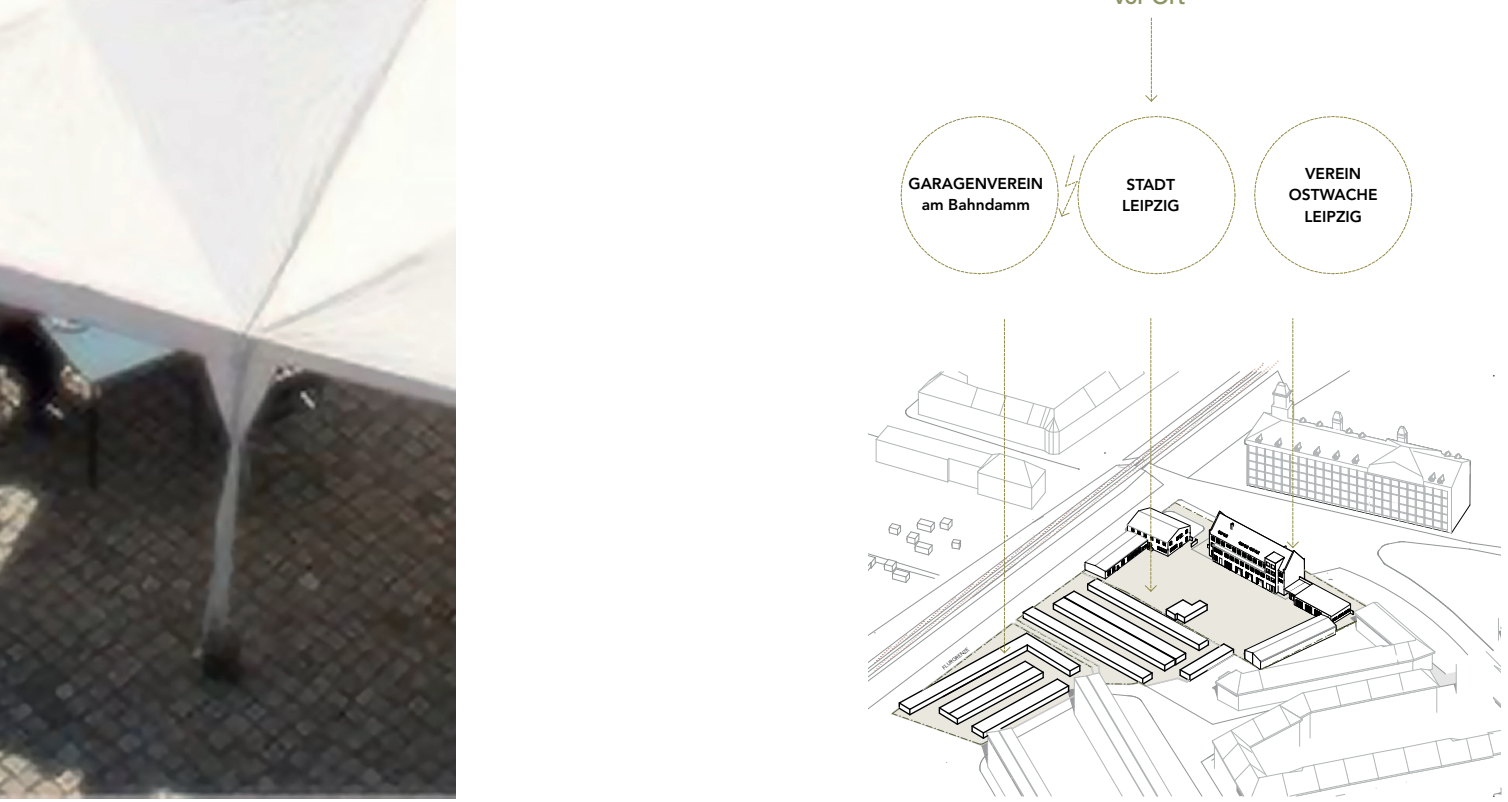


\section{OSTWACHE LEIPZIG E.V. \& EINE AKTIVE NACHBARSCHAFT}

Es ist vor allem dem Ostwache e.V. zu verdanken, dass man in der Nachbarschaft schon heute von einem bald entstehenden Nachbarschafts- und Kulturzentrum in der alten Feuerwache gesprochen wird. Der Verein ging 2016 aus der "Interessengemeinschaft Ostwache" hervor, die wiederum 2015 nach den vom ASW initiierten Workshops und der Konzeptwerkstatt zur Weiter- und Umnutzung des Gebäudes der alten Feuerwache entstand. Im

Rahmen dieser Workshops- und Gesprächsrunden erarbeitete der Verein mögliche Nutzungen für die Feuerwache. Es sollen soziale und gewerbliche, kommerzielle und nicht kommerzielle Nutzungen Raum finden. Ihr Anspruch dabei ist immer, dass sie nicht für oder mit der Nachbarschaft, sondern aus ihr heraus planen. Ihr bei der Stadt Leipzig vorgelegtes Konzept beinhaltet Nutzungs- und Finanzierungsideen sowie Rechtsformen. Die Ostwache soll ein Anlaufpunkt für die Nachbarschaft sein und basisdemokratisch als Genossenschaft organisiert werden.

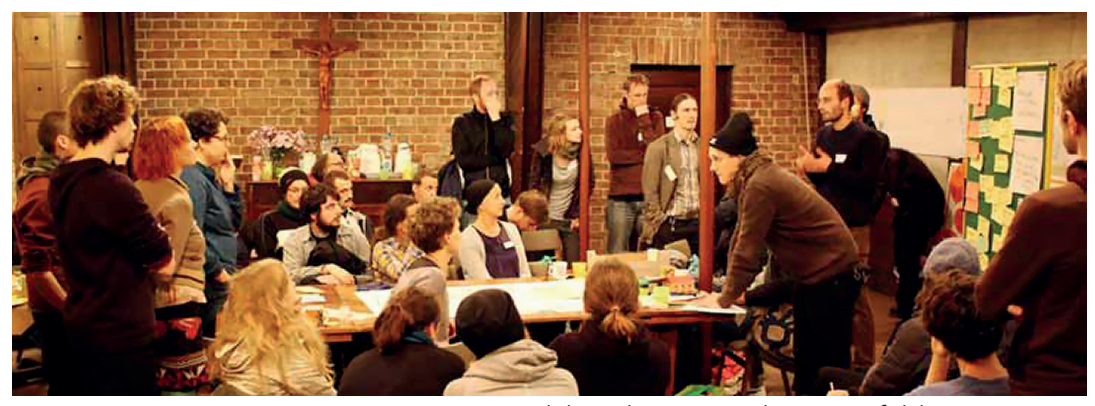

Workshop 2015

(Foto entnommen bei OSTWACHE Leipzig e.V 2016)

Sie nennen dabei die Samtweberei Krefeld, ExRotaprint in Berlin oder die alte Feuerwache Köln als Referenzen (Seehausen 2015, S. 221) für ihre Arbeit.

Viel Arbeit ist bereits in die Idee eines neuen Nachbarschaftszentrums geflossen. Einzelne Vereinsmitglieder arbeiten seit über drei Jahren unbezahlt für das neue Zentrum. Sie organisieren Feste, bieten Rundgänge an, sprechen mit der Presse, der Stadt und vor allem den Menschen im Stadtteil. „Wenn das hier nicht klappt, wandere ich aus" berichtet mir ein Mitglied des Vereins Ostwache e.V. während meines dreimonatigen Bearbei- tungszeit.

Seit September 2018 kann der Verein eine alte Tischlerei in den Nebengebäuden der Ostwache offiziell zwischennutzen und ist nun auch räumlich im Stadtteil sichtbar (Ostwache Leipzig e.V. 2018a) Die Ostwache ist nun kaum mehr wegzudenken (Leipziger Internet Zeitung/ Freitag 2016). Die Nachfrage ist groß: Über 40 Vereine und Institutionen haben bereits Interesse zur Anmietung von Räumen in der Ostwache geäußert. Zur Zeit versucht der Verein durch die Akquise von Fördermitteln die Sanierung des Bestandes und somit auch die Nutzung der Räume realistisch und ökonomisch zu gestalten.

Dafür wurde auch eine Entwurfsplanung benötigt, welche ich im Rahmen meiner Masterarbeit leisten wollte. Auf einem der alle zwei Wochen stattfindenden Treffen der Ostwache habe ich im August 2018 dem Verein angeboten im Rahmen der Arbeit Pläne zu zeichnen, die ggf. für die weitere Planung genutzt werden konnten. „Du machst dann also das, was wir sagen?" fragt mich ein Mitglied des Ostwache e.V. während unserer ersten Begegnung. Die Stimmung ist positiv und gut. Es beruhigte jedoch einige, dass man das am Ende nicht so machen muss, wie ich es zeichnen werde. Einige Mitglieder im Verein äußerten Bedenken zur Überplanung der Garagengrundstücke. Man wollte nicht in Verbindung mit der Verdrängung der Garagennutzer_innen gebracht werden, sondern bemüht sich um Akzeptanz seiner zukünftigen Nachbar_innen. Aber trotzdem: Wir nutzen die Chance. Sie als Verein und ich für meinen Abschluss (Ostwache Leipzig e.V. 2018b).

Ich hatte vor allem mit der Bau-AG des Vereins Kontakt. Während der Vorbereitungen für ihr Herbstfest konnte ich gemeinsam mit einigen Mitgliedern des Vereins ein grobes Aufmaß des Bestandsgebäudes machen und war zum ersten Mal vor Ort. Später stand ich vor allem mit Noriko Minkus des Ostwache e.V. im Austausch zur Planung. Mit ihr habe ich Zwischenstand und schließlich das Ergebnis besprochen. Während der Vereinsweihnachtsfeier habe ich die Pläne vorgestellt und es wurde zum Glühwein diskutiert.

Der Verein möchte einen neuen Treffpunkt für An- 
ger-Crottendorf und den Leipziger Osten schaffen. Dabei ist ihm der Bezug zum Stadtteil besonders wichtig. Deshalb haben sie 2015-2016 Anwohner_innen zu ihren Wünschen für den Stadtteil befragt. Im Ergebnis konnte festgestellt werden, dass es kaum Räume für nachbarschaftliche Begegnung gibt. Meist genannte Antworten waren: "Begegnungsort für alle Generationen, Spielplätze, Sporträume und Sportangebote (auch für ältere Menschen), Cafés und Kneipen, kleine Einkaufsmöglichkeiten, Räume für Kulturveranstaltungen" (Ostwache Leipzig e.V. 2017). Eine umfangreichere Bedarfsanalyse für den Standort im Auftrag der Stadt liegt momentan nicht vor, weshalb dem Konzept der Ostwache e.V. Beachtung gebührt. Werden die Angebote, die vom Ostwache e.V. recherchiert und erarbeitet wurden, umgesetzt, wird die alte Feuerwache ein wichtiger Treff- und Ankerpunkt im Stadtteil (THESE I).

Um das erste Ziel dieser Arbeit zu erreichen, sollen die vorgeschlagene Nutzungen des Ostwache e.V. räumlich umgesetzt werden. Denn durch die Ergänzung fehlender und damit vor allem sozialer Nutzungen im Stadtteil, wird die alte Feuerwache "gezwungenermaßen" zum Anlaufpunkt:

- Möglichst viele Seminar- und Büroräume für Vereine (z.B. für Beratung, Büroarbeit)

- ein großer Veranstaltungsraum für Kino, Vorträge, Tanzveranstaltung, Märkte etc.

- Ein Café bzw. Gastronomie. Hier soll ein Ankermieter ein Mittagsangebot mit maximal 2 Gerichten anbieten

- Sport- und Tanzkurse, sowie Veranstaltungen

- Werkstätten (z.B. für Tischler_innen, fürs Töpfern)

- Probenräume für Bands

- Feuerwehrmuseum

\section{GARAGENVEREIN AM BAHNDAMM ANGER-CROTTENDORF E.V.}

Zwei der im Norden gelegene Grundstücke werden zurzeit als Garagenhof genutzt. Hier werden ca. 170 Garagen vom Garagenverein verwaltet. Bis zur Fertigstellung der Arbeit hatte ich keinen Kontakt zu den Garagennutzer_innen. Dies hatte vor allem den Grund, dass die Stadt Leipzig den Standort noch prüft und ich hier „keine schlafenden Hunde wecken" wollte. Die Stadt Leipzig hat hier eine Kommunikationsstrategie, die im Rahmen der Masterarbeit weder analysiert, noch hinterfragt werden soll.

Im Rahmen der Arbeit bin ich (nach der Information der Stadt Leipzig), davon ausgegangen, dass die Garagennutzer_innen hier Parken und Lagern wollen:

- Mindestens 170 Stellplätze (überdacht)

- Ggf. Lagerräume

\section{STADT LEIPZIG}

Im September und Oktober 2018 habe ich zu den Sachbearbeiterinnen Marlen Försterling und Heide Luckmann Kontakt aufgenommen. Aus den Gesprächen mit beiden ging hervor, dass vor dem Hintergrund der wachsenden Bevölkerungszahlen an allen Schulformen Bedarf bestehe. Ein Neubau lohne sich v.a. für Schulen mit einer Größe von mindestens 4 Klassen pro Jahrgang. Die Schule soll, wenn möglich, auch mit dem geplanten Ostwache-Projekt zusammen funktionieren, sofern der Bedarf der Schulnutzung dies zulässt. Auch für die Garagennutzung würden zurzeit Ausweichflächen geprüft (Luckmann 2018; Försterling 2018).

- Parksituation in Leipzig (Stellplätze)

- 4-5 Zügige Schule (ca. 700 Schüler*) 


\section{EIN GEMEINSAMES RAUM- PROGRAMM ERGIBT SYNERGIE}

Reformpädagogik macht Synergien möglich

Gemeinschaftsschule

4 Jahrgänge

5-10. Klasse

2 Jahrgänge 11.-12. Klasse lebendigen Ortes. Ausgleichfläche angeboten werden. mit möglicher Abiturklassen entschieden.
Um ein Nutzungskonzept entwickeln zu können, dass dem der Ostwache e.V. und dem Auftrag der Stadt Leipzig zur Sicherung von Schulstandorten gerecht wird, soll eine Nutzungsmischung allen Zielanforderungen der drei Akteure vorgeschlagen werden. Es ist davon auszugehen, dass dieses Ziel vor allem mit einem reformpädagogischen Ansatz verwirklicht werden kann (THESE II). Ganztätige und durch verschiedene Gruppen genutzte Orte sind nicht nur unter ökonomischen Gesichtspunkten sinnvoll, sondern ermöglichen auch die Entstehung eines

Um darüber hinaus Konflikte möglichst gering zu halten und notwendige Stellplätze für Stadtteil zu erhalten, soll für die Garagennutzung/ Stellplätze mindestens eine

Da die Stadt Leipzig zum Zeitpunkt der Einreichung des Masterarbeitsthemas noch kein Ergebnis der Prüfung der Liegenschaft vorgelegt hatte, habe ich mich selbst für eine Schule für Schüler_innen zwischen der 5.-10. Klassen

Hypothetisch soll also am Standort eine Gemeinschaftsschule entstehen. Hier sollen ca. 700 Schüler_innen von der 5.-12. Klasse von 60 Lehrer_innen unterrichtet werden. Die Sekundarstufe I (5.-10 Klasse) ist mit 4 Klassen pro Jahrgang und die Abiturklassen (11.-12. Klasse) mit 2 Jahrgängen berechnet.

Das hat zwei Gründe: Erstens findet man im Stadtteil vor allem Grundschulen und Kindertageseinrichtungen vor, weshalb eine weiterführende Schule den Standort ergänzt. Zweitens soll eine erste Gemeinschaftsschule in Leipzig entstehen. Zwar wird im nahe gelegenen Volkmardorf zurzeit eine weiterführende Schule (Doppelstandort) (Quartiersschule Ihmelstraße) errichtet. Es handelt sich hier jedoch um einen Doppelstandort eines Gymnasiums und einer Oberschule mit jeweils getrenntem Unterricht. An einer Gemeinschaftsschule lernen Kinder und Jugendliche bis zur 10. Klasse gemeinsam und werden nicht nach der vierten Klasse nach ihrer Leistung sepa- riert. In Sachsen gibt es dieses Konzept lediglich in freier Trägerschaft (Waldorfschulen, Montessori-Schulen, Internationalschool etc.), jedoch fordern bereits mehrere Initiativen die Einführung von Gemeinschaftsschulen in staatlicher Trägerschaft (Grothe 2018).

Damit Schule und Nachbarschaftszentrum miteinander funktionieren, soll das Raumprogramm einer Freinet-Gesamtschule mit dem Raumprogramm des Ostwache e.V. verbunden und zusammengedacht werden (THESE II). 


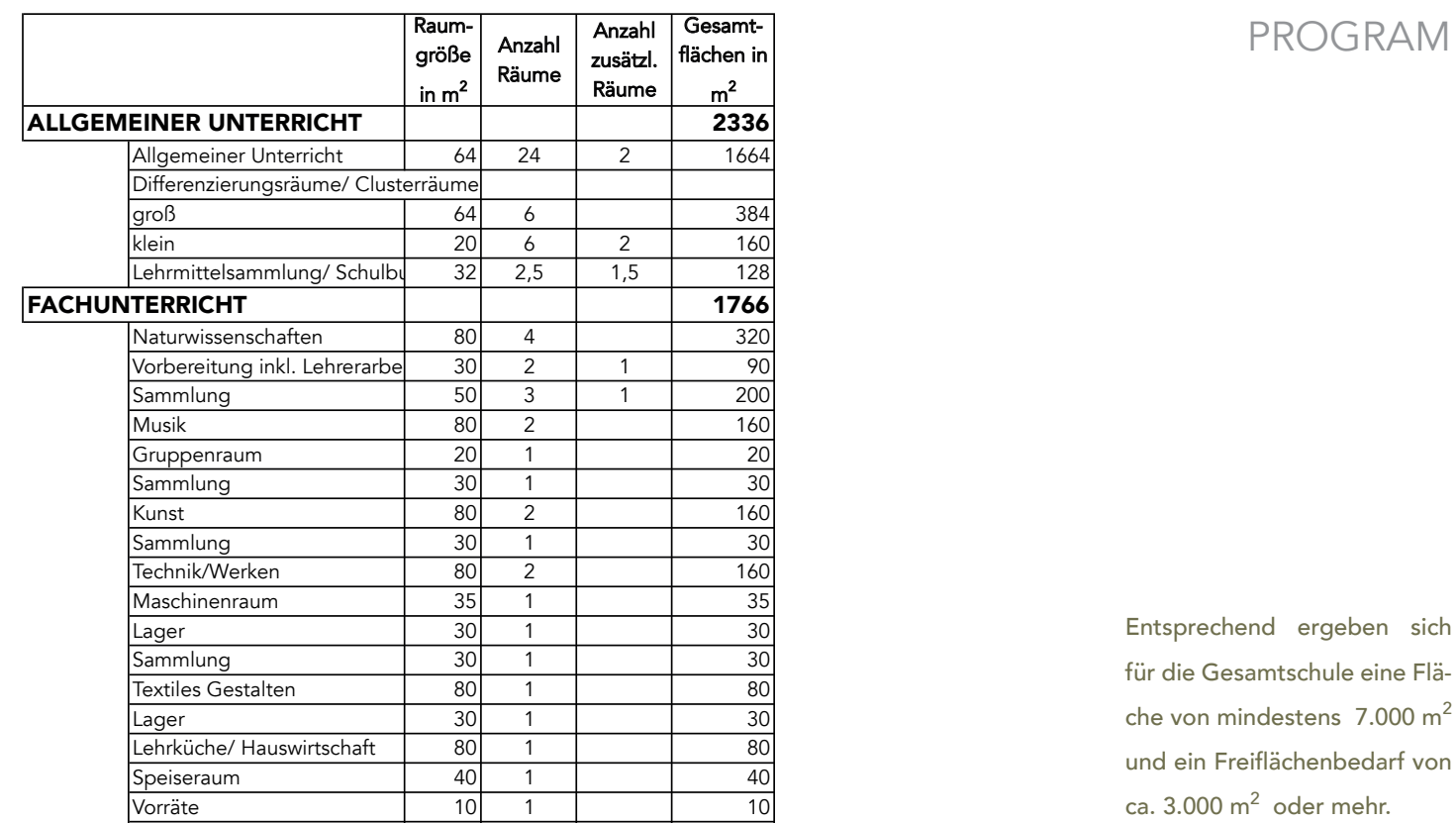

\begin{tabular}{l|l|}
\hline Außensport-Anlagen (Quartierschule) \\
\hline VERWALTUNG
\end{tabular}

Informatik

Informatik groß

Serverrraum

Laderaum für Laptop-Klassen

Bibliothek

Therapie/Ergoraum

Pflegeraum/ Sanitär

SPORT

\begin{tabular}{l} 
Regieraum \\
\hline Gerateraum \\
\hline
\end{tabular}

Geräteraum

\begin{tabular}{|l|l|l|l|}
\hline & 50 & 2 & \\
\hline
\end{tabular}

\begin{tabular}{|l|r|r|r|r|}
\hline Umkleide/Duschen Jungen & 35 & 3 & & 105 \\
\hline
\end{tabular}

Umkleide/Duschen

Lehrkräfte

WC-Anlagen

Putzmittelraum

Schulleitung

erw. Schulleitung

Stellvertretende Schulleitung

Didaktischer Lehrer

Funktionsstellen

Schulassistenten

Sekretariat

Kopierer

Materiallager

Archiv

Krankenzimmer

Krankenzimmer-Sanitätsraum

Lehrerzimmer/Lehrerestation

Gaderobe

Teeküche

Sozialarbeiter

Beratungslehrer

Schränke Schüler

GTA

\begin{tabular}{|l|l}
\hline MENSA & Mensa \\
\hline
\end{tabular}

Küchenbereich

Cafeteria/Schülercafe (ggf.)

\begin{tabular}{l|l}
15 & 2
\end{tabular}

\begin{tabular}{|l|l}
\hline 5 & \\
\hline & \\
\hline & 1 \\
\hline
\end{tabular}

2

\begin{tabular}{l|l|}
2 & \\
\hline 1 &
\end{tabular}

\begin{tabular}{l|l}
\hline 30 & \\
\hline 15 & \\
\hline 15 & \\
\hline 15 & \\
\hline 20 & \\
\hline 10 & \\
\hline 10 & \\
\hline 10 & \\
\hline 10 & \\
10 & \\
\hline 20 & \\
70 & \\
10 & \\
\hline 15 & \\
15 & \\
15 & \\
\hline 80 & \\
\hline
\end{tabular}

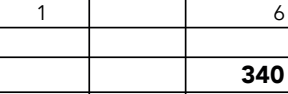

340

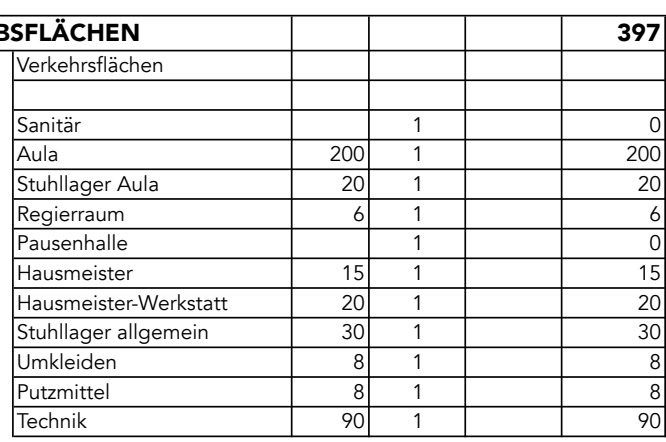

GESAMT SCHULE

.

\section{.}

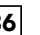

92




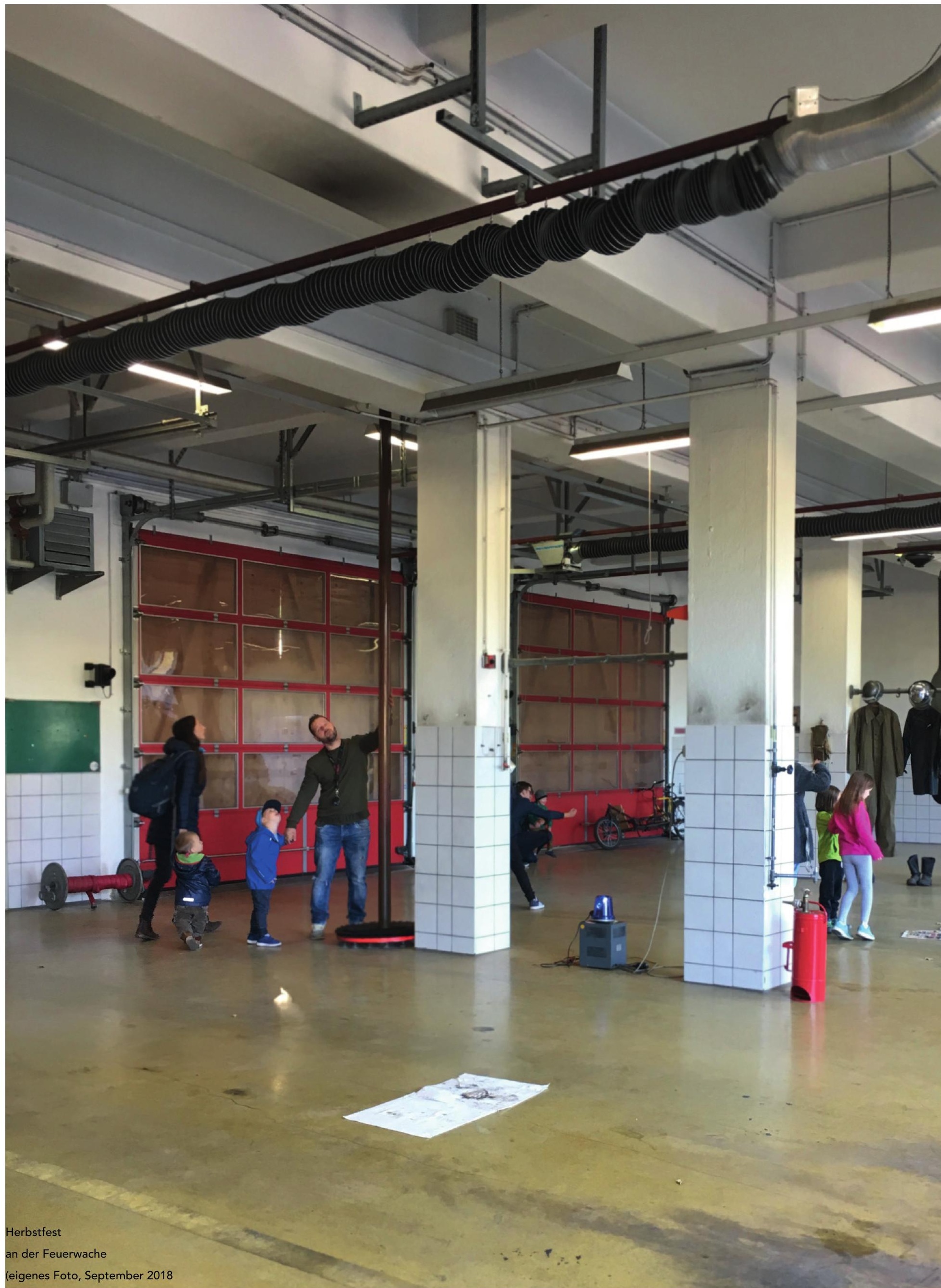




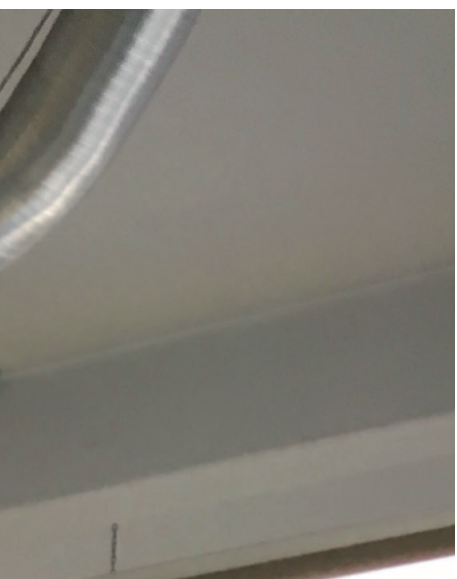

\section{DIE ALTE FEUERWACHE UND DEREN NEBENGEBÄUDE}

Das Hauptgebäude der alten Feuerwache kann genutzt werden. Sanitäreinrichtungen sowie Einrichtung für die Barrierefreiheit müssen angepasst und modernisiert werden. Um den bisher als Garage dienende Raum im Erdgeschoss flexibel nutzen zu können, muss er als Innenraum ertüchtigt werden.

Die Nebengebäude sind als Zwischennutzungen brauchbar, jedoch wird sich eine Sanierung hier voraussichtlich nicht lohnen.

DOI - Kapitel 4: http://doi.org/10.33968/9783966270144-04 

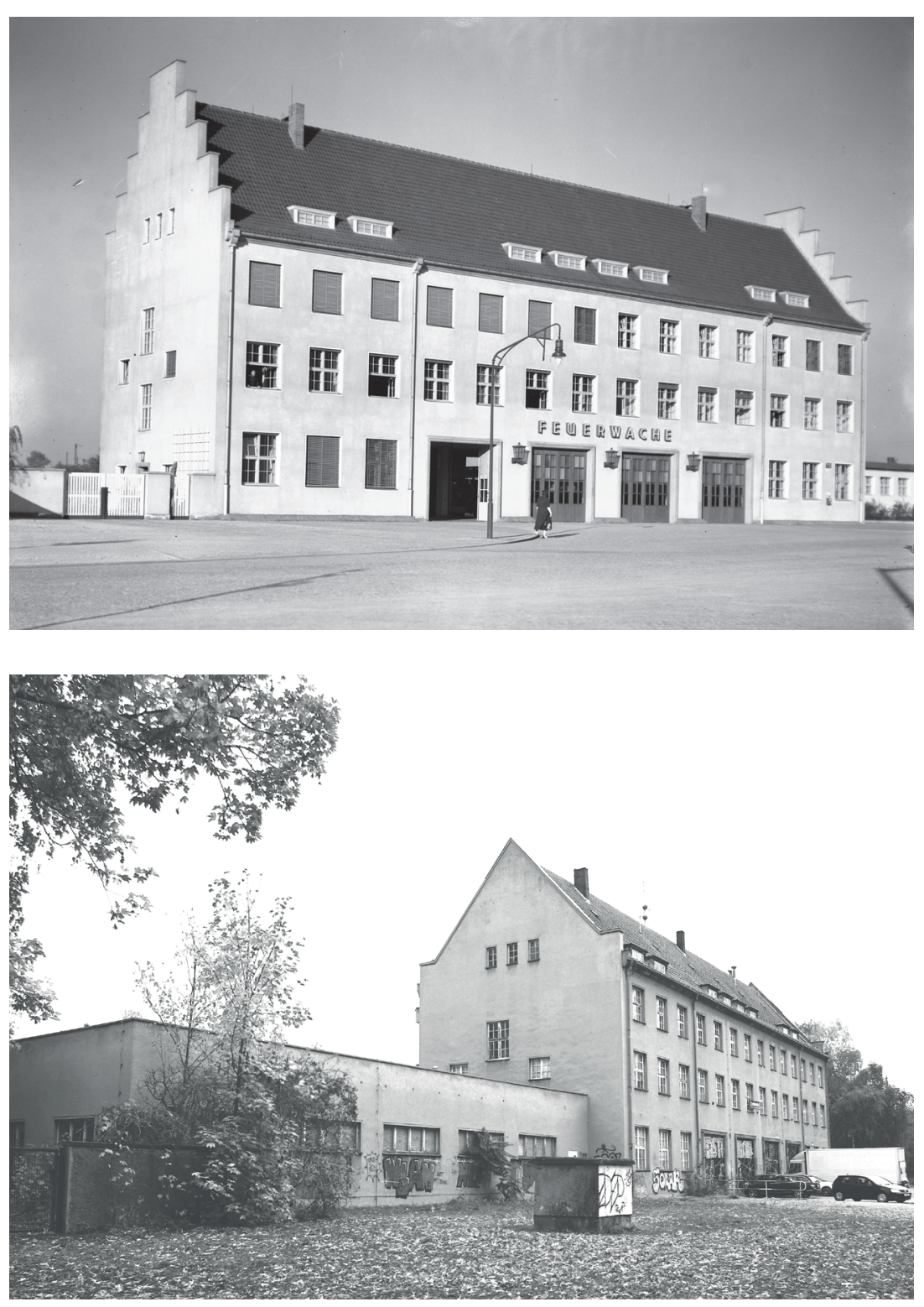

oben: Straßenperspektive kurz nach der Eröffnung 1937

(Stadtarchiv Leipzig)

unten: Straßenperspektive

2018 (eigenes Foto)

\section{HAUPTGEBÄUDE FÜR DIE HAUPTNUTZUNG}

Zwei Elemente der zwischen 1936 und 1937 errichteten Feuerwache Ost sind typologisch als Feuerwehr: Ihre vier gleichgroßen Einfahrten für Löschfahrzeuge, die durch das Gebäude hindurch auf den Hof fahren konnten. Aufgrund der gleichwertigen Einfahrten ist straßenseitig kein Haupteingang ablesbar. Sowie der Schlauchturm, in und an dem früher die Löschschläuche getrocknet und Rettungsübungen gemacht wurden. Konventionell ist er entweder mit dem Hauptgebäude verbunden oder freistehend. Hier ist der Schlauchturm Hofseitig mit dem Gebäude verbunden

Es handelt es sich um einen dreigeschossigen Stahlbetonskelettbau, dessen Stützen in einem Raster von 3,15 $\mathrm{m}$ bzw. 6,30 verteilt sind. Schon für die Nutzung einer Feuerwehr waren die Stützen und Unterzüge überdimensioniert. Das Gebäude ist auch in Vorbereitung eines Luftangriffs gebaut wurden. Deshalb ist das gesamte Kellergeschoss als Luftschutzbunker ausgebildet und bietet sich aufgrund seiner Geräumigkeit auch für andere Nutzungen an.

Das Erdgeschoss weist eine Deckenhöhe von knapp 5 Metern auf, sodass vier Löschfahrzeuge hier Raum finden konnten. Die Last der Innenkonstruktion wird über einen Mittelgang abgetragen. Der Stahlbetonskelettbau, dessen Außenmauerwerkswände zur Aussteifung und Lastabtragung des Satteldaches relevant sind, ist aufgrund seiner typologischen und konstruktiven Merkmale als Kulturdenkmal gelistet. Seiner vormals offenen Bebauung, der geputzte Lochfassade mit Porphyrtuffgewände und sein Satteldach weisen ihm eine bauliche und ortsgeschichtliche Bedeutung zu (Landesamt für Denkmalpflege Sachsen 2018).

Da das Gebäude noch bis 2015 als Feuerwehrzentrale genutzt wurde, ist es als solches noch im Stadtteil etabliert. Es ist demnach auch komplett nutzbar und muss nur teilweise modernisiert und an die neue Nutzung angepasst werden. 

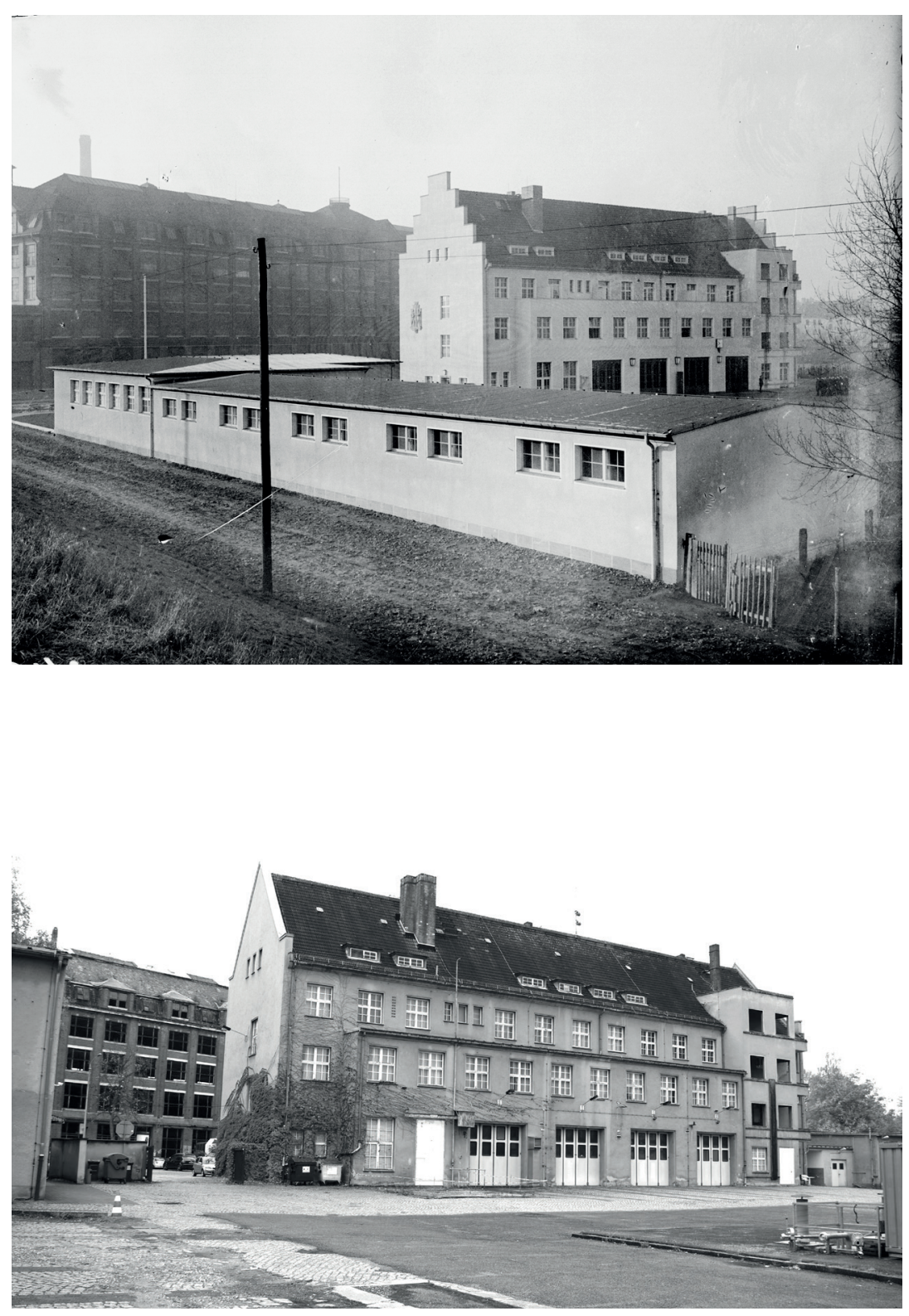

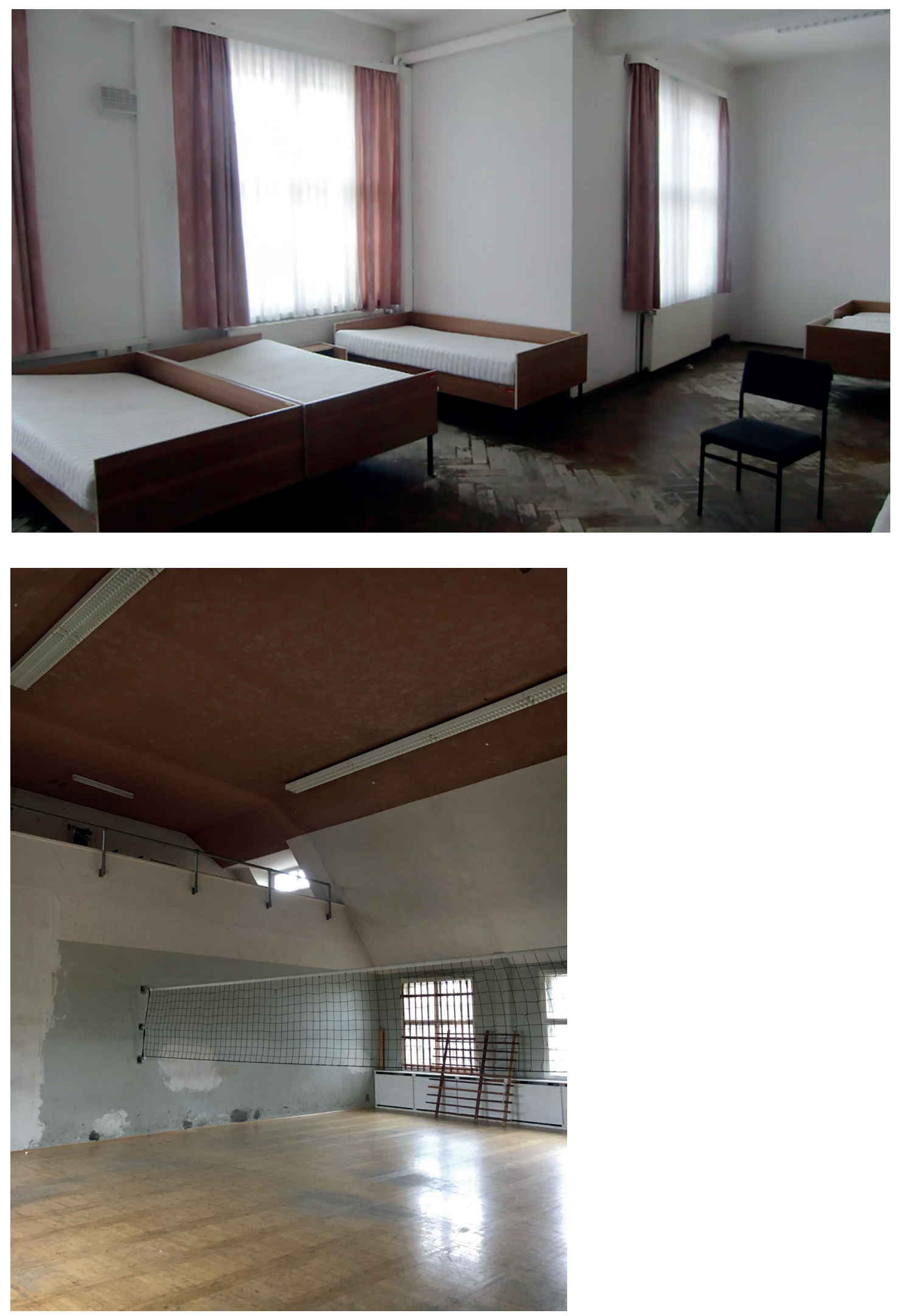

oben: ehemalige Schlafraum der Feuerwehr (entnommen bei OSTWACHE e.V. 2017)

unten: Alte Turnhalle im 2. OG des Hauptgebäudes

(eigenes Foto)

rechts: Nebengebäude

(eigene Fotos) 


\section{NEBENGEBÄUDE \\ FÜR ZWISCHENNUTZUNGEN}

Abgesehen von der Lagerhalle sind die anderen L-förmig angeordneten Gebäude rechts- und links neben dem Hauptgebäude zu einem späteren Zeitpunkt entstanden. Die ein- bis maximal zweigeschossigen Gebäude sind unter denkmalschutzrechtlichen Gesichtspunkten nicht schützenswert und teilweise aufgrund von Bauschäden (u.a. Asbest) nur bedingt nutzbar. Zum großen Teil besteht hier Sanierungs- oder Modernisierungsbedarf.

Auf der Westseite des Areals befinden sich 10 große Garagen für Löschfahrzeuge sowie ehemalige KFZ-Werkstätten und eine Tischlerei, welche bisher straßenseitig erschlossen werden kann und seit Oktober 2018 vom Verein Ostwache e.V. genutzt werden darf.

Das auf der Ostseite gelegene, zu DDR-Zeiten errichtete Verwaltungsgebäude, ist auf den Grundmauern der ehemaligen Lagerhalle der Feuerwache errichtet worden.

Die aktuelle Bebauung bildet in einem $U$ einen Hof Richtung Norden - also in Richtung der Garagengrundstücke - aus.

Im Norden schließen sich zwei Grundstücke an. Die zwei Grundstücke mit eingeschossiger Garagennutzung kommen für den Schulneubau in Betracht. Sie beherbergen zur Zeit etwa 170 Stellplätze.
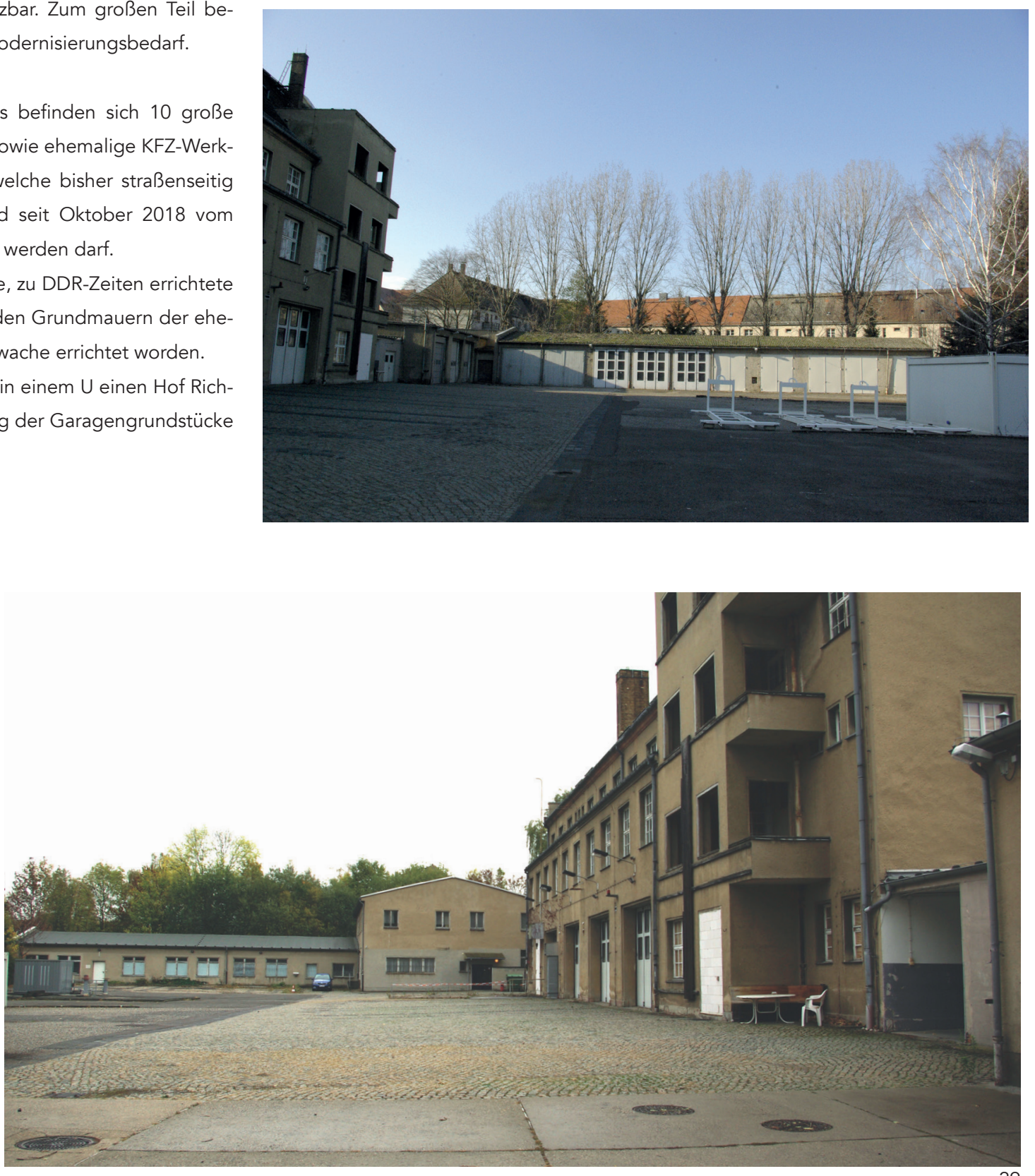
NEUBAU

BGF $13.700 \mathrm{~m}^{2}$

GRZ $0,17 \mathrm{~m}^{2}$

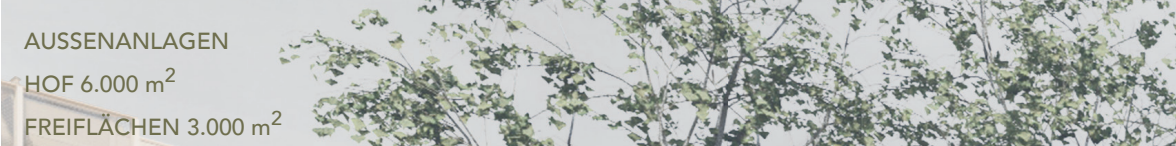

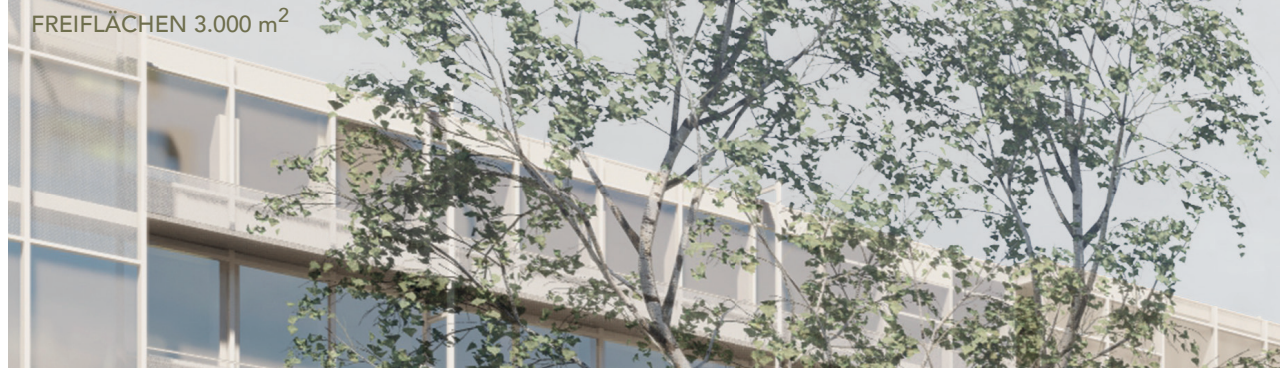

1 4.

(1)

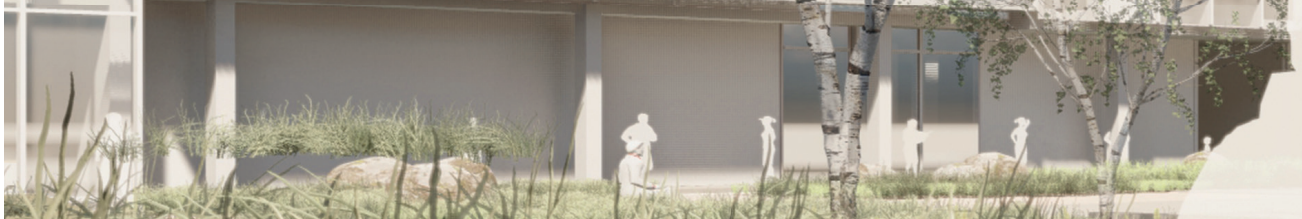

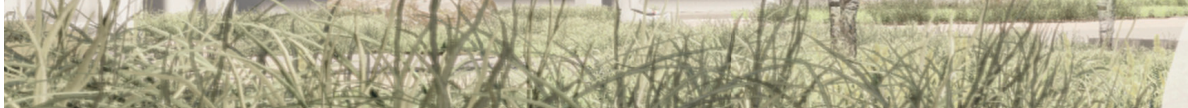

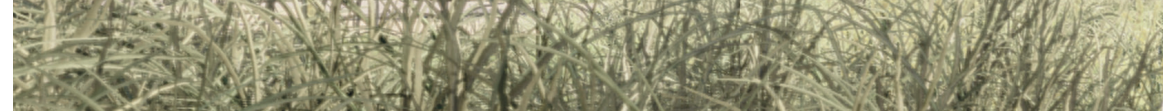

(25)

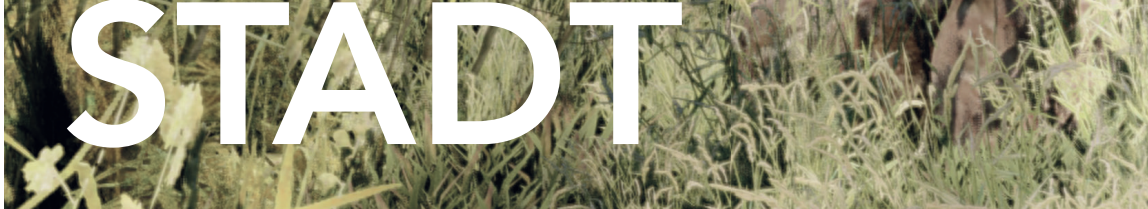

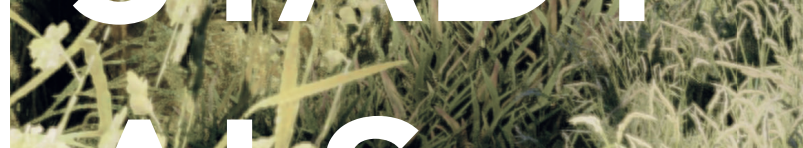

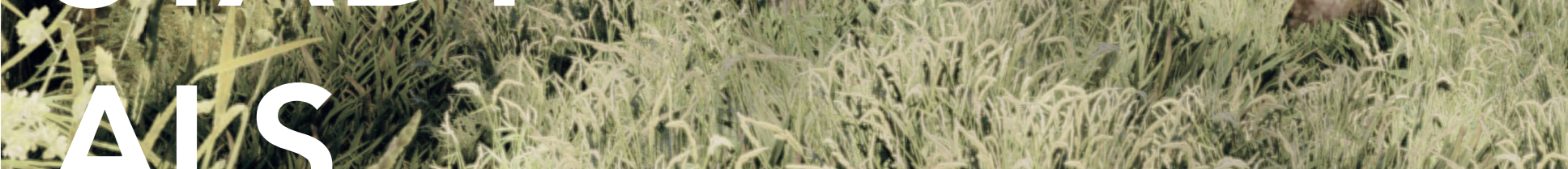

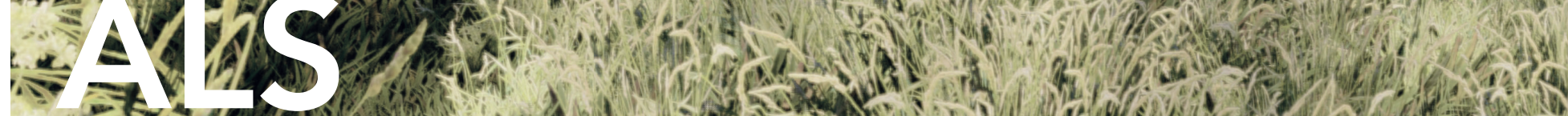

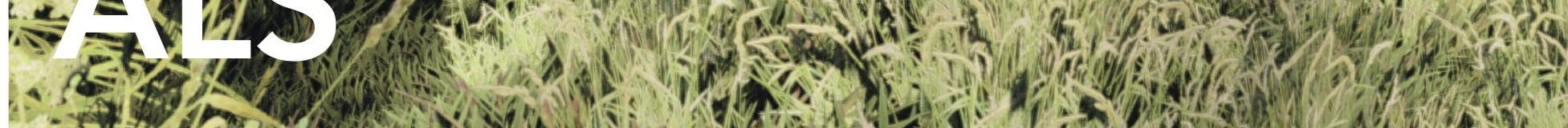
X.

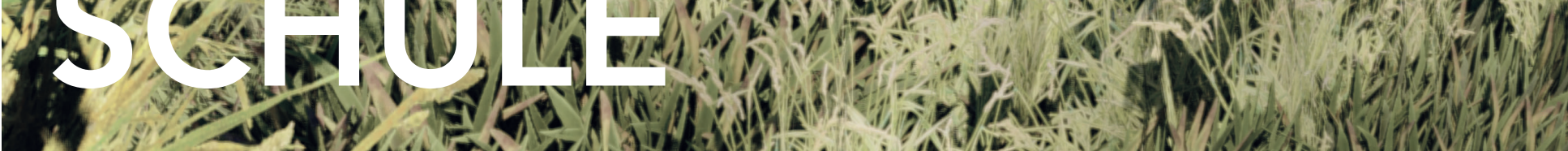
2. 


\section{$5.1 \quad$ KONZEPT}

\section{DIE STADT ALS SCHULE ZUR FREINET-PÄDAGOGIK IM DEUTSCHSPRACHIGEN RAUM}

Das Konzept beruht auf der Annahme, dass Lernende wissbegierig und lernwillig sind und sie durch das Feedback ihrer Umgebung natürlich lernen. Wie das Erlernen der eigenen Muttersprache lernt man durch Praxisbezug in der "Stadt als Schule" fast ganz nebenbei (Glänzel 2012, S. 170 ff.).

Die Schule öffnet sich zur Stadt und die Stadt kommt durch die Erfahrungen der Schüler_innen wieder in die Schule. So könnte man kurz das Konzept der „Stadt als Schule" beschreiben.

Verschiedene internationale Beispiele beschreiben die "Stadt als Schule" oder „Educational City" als duales System, in dem Kinder, aber vor allem Jugendliche in verschiedenen Betrieben, Einrichtungen oder anderen Institutionen praktische Erfahrung sammeln und diese in die Schule tragen. In Tel Aviv bringt beispielsweise eine Nachbarschaftsschule die Stadtgesellschaft durch Praktika und Mentor_innenprogrammen zusammen (Jaqueline Simon/Toni Simon 2013). Ähnlich schlägt der deutsche Pädagoge Hartmut Glänzel das Lern- und Lehrprinzip im deutschsprachigen Raum vor (Glänzel 2012, S. 183). In einem Modellprojekt konnte er an Mittelschulen etablieren, dass Jugendliche an 2-3 Tagen in der Woche in Betrieben arbeiten, um ihre Lust am Lernen zu wecken. Glänzel beschreibt das als natürliche Lernmethode am Beispiel der eigenen erprobten Praxis.

Die pädagogische Grundlage des Lehr- und Lernkonzepts bildet der Ansatz der französischen Pädagogen Céleste und Elise Freinet. Sie geben den Pädagog_innen kein Standardwerk an die Hand, sondern haben ihr Vokabular von anderen Konzepten entliehen. Die Pädagogik beruht auf einer Sammlung von Texten und hat damit einen narrativen Charakter. Sie geben den Hochschulen und Schulen lediglich den Rat zur Seite das Konzept stetig zu hinterfragen und weiterzuentwickeln (Bruns 2011, S. $21 \mathrm{ff}$.).
Das Paar publizierte als Freinet verschiedene Texte über Reformpädagogik. Der Anspruch beider war es dabei immer, ihre theoretischen Ansätze auch in der Praxis erprobt zu haben. Die Selbstorganisierung von Lehrer_innen spielt hier eine große Rolle. Selbstorganisierte Weiterbildungen, Workshops und Tagungen sind deshalb Teil der Ausbildung. Praxis und Theorie sind miteinander verflochten und reflektieren sich gegenseitig (Hansen-Schaberg 2012, S. 4 ff.). Gerade deshalb sind Konzepte wie „die Stadt als Schule" relevant für die praktische Umsetzung von Freinet-Pädagogik.

In Schulen, die nach Freinet lehren, kommt dies besonders durch eine Druckerpresse zum Ausdruck. In der schuleigenen Druckerei produzieren Kinder und Jugendliche ihre eigenen Texte. Gedichte für den Deutschunterricht, Verhaltensregeln für den Klassenrat oder Texte für die eigene Schulzeitung. (Dietrich 1995, S. 14 f.) Heute sind es vor allem Computer, die an diese Stelle gerückt sind. Relevant bleibt, dass Schüler_innen die Produktion und Verteilung ihrer eigenen Texte erleben .

In verschiedenen alternativpädagogischen Ansätzen spielt die Selbstverantwortung und das Selbsterlenen eine wichtige Rolle. Kinder und Jugendliche haben durch Erfolgserlebnisse und Spaß am Lernen Fortschritte in ihrer Bildungerfahrung.

Céleste und Elise Freinet werden als kommunistische Sozialist_innen und Demokrat_innen beschrieben, deren Ziel es war Schüler_innen als Demokrat_innen und zur Mündigkeit zu erziehen (Bruns 2011, S. 61 ff.). Aus dieser Grundhaltung ergeben sich Vier Grundprinzipien der Freinetpädagogik (Bruns 2011, S. 33), die unter Bezug verschiedener anderer Quellen (vgl. u.a. Burow 2018; Kahl 2004; Jaqueline Simon/Toni Simon 2013; Kovermann 2012; Dietrich 1995; Bundesverband der Freien Alternativschulen 2011; Hansen-Schaberg 2012; Schlemminger 2005) ergänzt wurden: 


\section{VIER GRUNDPRINZIPIEN ALTERNATIVER SCHULKONZEPTE}

\section{DIE FREIE ENTFALTUNG DER PERSÖNLICHKEIT.}

Kinder- und Jugendliche sollten sich frei ausdrücken können. Darüber hinaus wird Lernen als lebenslanger Prozess begriffen, der eine soziale und emanzipatorische Erfahrung ist.

\section{KRITISCHE AUSEINANDERSETZUNG MIT DER UMWELT.}

Die Öffnung des Unterrichts für verschiedene Formate und Akteure hilft dabei, nicht in einer Blase, sondern eng mit der Praxis zu lernen. Dabei helfe vor allem praktische Arbeit auch außerhalb schulischer Einrichtungen.

\section{SELBSTVERANTWORTUNG.}

Jede_r erstellt einen individuellen Arbeits- und Wochenplan. Gemeinsam mit der Klasse und den Pädagog_inenn wird am Ende einer Woche oder eines Jahres erörtert, ob die Ziele erreicht wurden. Der üblich "Fragend-entwickelnde-Unterricht", nachdem die Lehrer_innen die Schüler_innen vorher vorgetragenen Lernstoff abfragen und so Schritt für Schritt an den Stoff begreifen sollen, wird in den meisten alternative Schulen abgelehnt. Dieser direkte Weg zum gesicherten Wissen wird im gleichen Tempo auf gleichem Niveau abverlangt. Im Selbstlernenden Unterricht hingegen, lernen Schüler_innen auf verschiedene Weise in unterschiedlichem Tempo.

\section{KOOPERATION UND GEGENSEITIGE VERANTWORTLICHKEIT.}

Durch demokratische Institutionen, wie den Klassenrat erleben Schüler_innen und Lehrer_innen aktive Partizipation. Die Institutionen werden nicht nur für die Auswahl von Ausflugszielen, sondern auch für alltägliche Anliegen genutzt. Im selbstmoderierten Morgenkreis wird Demokratie so zur sozialen Erfahrung.

Neben den Mitschüler_innen als erste, den Lehrer_innen als zweite wird der Raum als „dritter Pädagoge” (Müller-Barion 2008; zitiert Malaguzzi) bezeichnet. Im Rahmen der Recherche habe ich die pädagogischen und räumlichen Umsetzungsideen, den Grundsätzen nach Freinet zugeordnet und nach der Logik Chronologie der meiner Entwurfsstrategie sortiert - beginnend mit den städtebaulichen, über Grundrissorganisatorische bis hin zu innennarchitektonischen Anforderungen: 
DER RAUM ALS

DRITTER PÄDAGOGE

ARCHITEKTUR FÜR DAS LERNEN

VON MORGEN

\begin{tabular}{|c|c|c|c|}
\hline $\begin{array}{r}\text { GRUNDSÄTZE } \\
\text { ALTERNATIVER SCHULEN } \\
\text { (FREINET PÄDAGOGIK) }\end{array}$ & PÄDAGOGIK & RAUM & ENTWURF \\
\hline $\begin{array}{r}\text { KRITISCHE } \\
\text { AUSEINANDER- } \\
\text { SETZUNG } \\
\text { MIT DER UMWELT }\end{array}$ & $\begin{array}{l}\text { Input von verschiedenen } \\
\text { Instituinen (Stadt als Schule) } \\
\text { Ganztagsangebote } \\
\text { kritische Auseinandersetzung } \\
\text { mit der Gesellschaft }\end{array}$ & $\begin{array}{l}\text { Gemischte Nutzungen, } \\
\text { Projekte } \\
\text { \& Veranstaltungen } \\
\text { mit Institutionen } \\
\text { außerhalb der Schule }\end{array}$ & $\begin{array}{l}\text { SCHULE \& OSTWACHE } \\
\text { gemeinsam in der Nachbarschaft } \\
\text { gemeinsames } \\
\text { ERDGESCHOSS } \\
\text { (Mensa, Sport, Veranstaltungsraum, } \\
\text { Werkstätten) } \\
\text { STÄDTEBAU. Öffnen zur Stadt }\end{array}$ \\
\hline $\begin{array}{r}\text { KOOPERATION } \\
\text { \& GEGENSEITIGE } \\
\text { VERANTWORTUNG }\end{array}$ & $\begin{array}{l}\text { Klassen- und Schulrat } \\
\text { Klassen- und } \\
\text { Jahrgangsübergreifender } \\
\text { Unterricht } \\
\text { Lehrer_innen arbeiten in der } \\
\text { Schule }\end{array}$ & $\begin{array}{l}\text { Versammlungsort } \\
\text { Raumorganisation } \\
\text { für kooperativen Unterricht } \\
\text { (Cluster, Offene Lernlandschaft, } \\
\text { KlassenraumPlus) }\end{array}$ & $\begin{array}{l}\text { FREINET-ZENTRUM } \\
\text { (Offene Lernlandschaft in der } \\
\text { Mediathek/ Bibliothek) } \\
\text { CLUSTER } \\
\text { Pädagogische Büros }\end{array}$ \\
\hline $\begin{array}{r}\text { FREIE ENTFALTUNG } \\
\text { DER } \\
\text { PERSÖNLICHKEIT }\end{array}$ & $\begin{array}{l}\text { weg von } 45 \text { Min. hin zu längeren } \\
\text { Zeitslots } \\
\text { Verbindung zwischen } \\
\text { Theorie \& Praxis }\end{array}$ & $\begin{array}{l}\text { Lernateliers } \\
\text { Mix an flexiblen und fixen Orten } \\
\text { und Angeboten } \\
\text { Differenzierungsräume } \\
\text { Leseecken \& Nischen }\end{array}$ & $\begin{array}{l}\text { LERNATELIERS } \\
\text { (Fassade) } \\
\text { WERKSTÄTTEN } \\
\text { (DIY-SPACES) } \\
\text { DIFFERENZIERUNGSRÄUME } \\
\text { MEANDERNDER FLUR } \\
\text { OFFENE LERNLANDSCHAFT }\end{array}$ \\
\hline $\begin{array}{r}\text { SELBST- } \\
\text { VERANTWORTUNG }\end{array}$ & individuelle Wochenpläne & $\begin{array}{l}\text { Lernatelier } \\
\text { Offene Lernlandschaft }\end{array}$ & NUTZBARE FASSADE \\
\hline
\end{tabular}




\section{WERKSTÄTTEN}

Die Stadt als Schule kommt vor allem durch die räumliche Nähe zum Nachbarschafzszentrum und zur Stadt zum Tragen. Die Werkstätten (Holz, Metall, Ton, Textil, Informatik / Hackerspace, Hauswirtschaft) werden auch vom Nachbarschaftszentrum sowie von ansässigen Handwerker_innen sowie der Schule genutzt. Das breite und ganztags nutzbare Angebot von verschiedenen Werkstätten ist wichtige Schnittstelle zwischen Theorie und Praxis.

\section{VERSAMMLUNG und OFFENE LERNLANDSCHAFTEN IM FREINETZENTRUM}

An Freinet-Schulen soll Demokratie im Schulalltag erlebbar gemacht werden (Kovermann 2012, S. 244) Die Klassenräte und Morgenroutinen können dabei in eigenen Lernateliers stattfinden. Für große Versammlungen müssen auch Räumlichkeiten angeboten werden. Klassenrat und Schulrat sollen als gemeinsamer Ort stattfinden.

Ich habe mich im Entwurf für ein Freinetzentrum entschieden, das von Mensa und Mehrzweckraum bis hin zu Bibliothek und Mediathek eine offene Lern- und Erfahrungslandschaft bietet.

Offene Lernlandschaften sind in der Bibliothek bzw. im sogenannten Freinet-Zentrum zu finden. Hier gibt es keine Klassenräume mehr, sondern alle Räume sind offene Räume, in denen selbst gelernt wird.

\section{LERNATELIER}

Anstatt von klassischen Klassenzimmern und dazugehörigen Räumen für die Lehrbuchsammlung, findet man in Freinetschulen Lernräume als Ateliers (Glänzel 2012, S. 172). Hier können Schüler_innen während oder nach der Klassenstunde selbstständig lernen. Die Ateliers sind zum einen mit Lern- und Lehrmaterial ausgestattet. Zum anderen sind verschiedene Raumteilungen für die Selbst- und Gruppenarbeit möglich (Schlemminger 2005, S. 236).

Nach Freinet werden die Ateliers je nach Projekt thematisch ausgestattet. So wird beispielsweise ein Atelier zu den Redaktionsräumen der Schulzeitung. Die Verantwortlichkeit für die Ateliers liegt bei den Schüler_innen.
Sie reinigen, räumen auf, sortieren um. Dabei ist wichtig, dass eine Klasse einem Raum oder einem Cluster zugeordnet ist und sich hier einrichten kann.

\section{CLUSTER \& KLASSENRAUM-PLUS}

Die Montagsstiftung stellt drei verschiedene Modelle der Raumorganisationen für Schulen vor. Erstens den Klassenraum-Plus, bei dem an den Klassen ein oder mehrere Räume hinzugeschaltet werden können. Zweitens die Organisation von Klassenräumen im Cluster. Hier werden Räume themenbezogen oder gruppenbezogen als zusammenhängende Einheit betrachtet und drittens offene Lernlandschaften (Montagsstiftung/Bund deutscher Architekten/Verband Bildung und Erziehung 2013, S. 12 ff.). Im Rahmen der Masterarbeit habe ich mich für die Anordnung der Lernateliers im Cluster entschieden. Für Gemeinschaftsschulen kann hier klassenübergreifend Unterricht stattfinden.

\section{NISCHEN \& ECKEN} IM FLUR

Lese-, Ruhe- und Arbeitsecken sind in Schulen wichtige Rückzugsorte. Neben flexiblen Räumen braucht es klar ruhige oder kleine Räume, um auch fern des allgemeinen Trubels erleichtern das Lernen und Leben in der Schule. Die Definition von lauten und leisen Räumen ermöglicht, dass verschiedene Lerntypen hier einen Ort finen.

Die Strukturierung der Arbeit und der Arbeitsteilung verlangt klare Begrenzung und Definition von lauten und leisen Räumen (Schlemminger 2005, S. 236). (Montagsstiftung/Bund deutscher Architekten/Verband Bildung und Erziehung 2013). Im Entwurf wurde sich für verschiedene Lern- und Leseecken im Mittelgang entschlossen.

\section{MINUTEN}

Anstatt der 45 Minuten pro Unterrichtsstunde, werden an alternativen Schulen oft Zeitslots angeboten. Oft sind dabei 90 Minuten ausreichend, um das Angebot der Lehrer_innen und selbsterarbeitende Phasen gut miteinander zu verbinden. 


\subsection{STÄDTEBAU}

\section{ZUR STADT ÖFFNEN, PLÄTZE DEFINIEREN}

Auf der Grundlage meiner Berechnungen ergab sich, dass die komplette Garagenbebauung einem Schulneubau weichen muss. Die benötigte Baumasse und der Freiflächenbedarf macht ein Erhalten unmöglich.

Während der Recherche zur städtebaulichen Lösung, sind die räumliche Defizite im Stadtbild und Potentiale für den Entwurf relevant geworden. Der oben beschriebene offene Blockrand, die Platzbildung zwischen den WBS-70 Platten sowie die Platzbildung vor der Feuerwache waren hier von Relevanz. Hier sind städtebauliche Varianten entstanden, wobei die städtebaulichen Reperaturen der Defizite für die finale Entscheidung gesorgt haben. Deshalb sind drei Reperaturen vorgenommen worden, die zu einem schlüssigen städtebaulichen Konzept geführt haben.

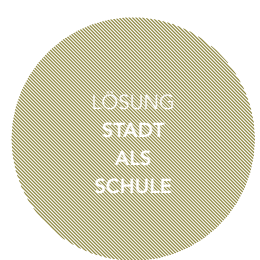

Die Nachbarschaft als vierte Pädagogin (

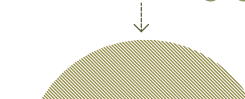

$<+\frac{1}{1}$

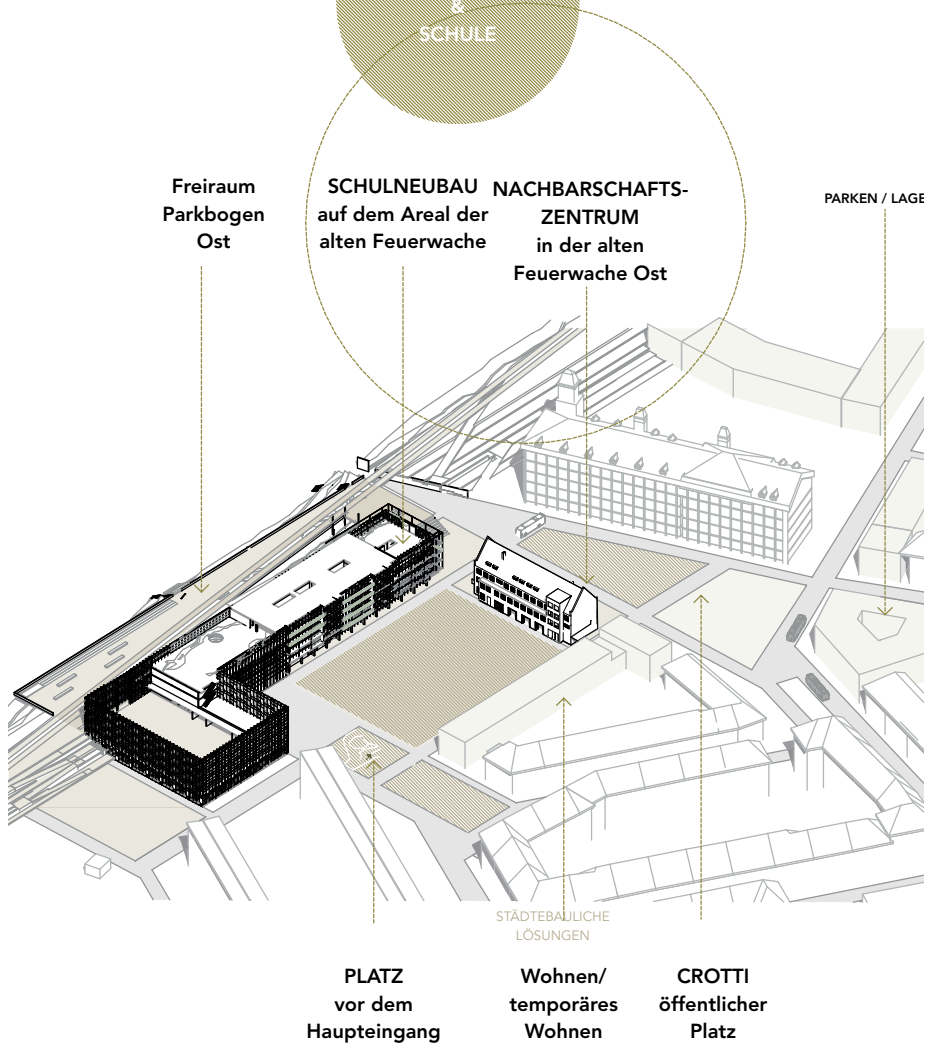

$+\frac{1}{2}$ 


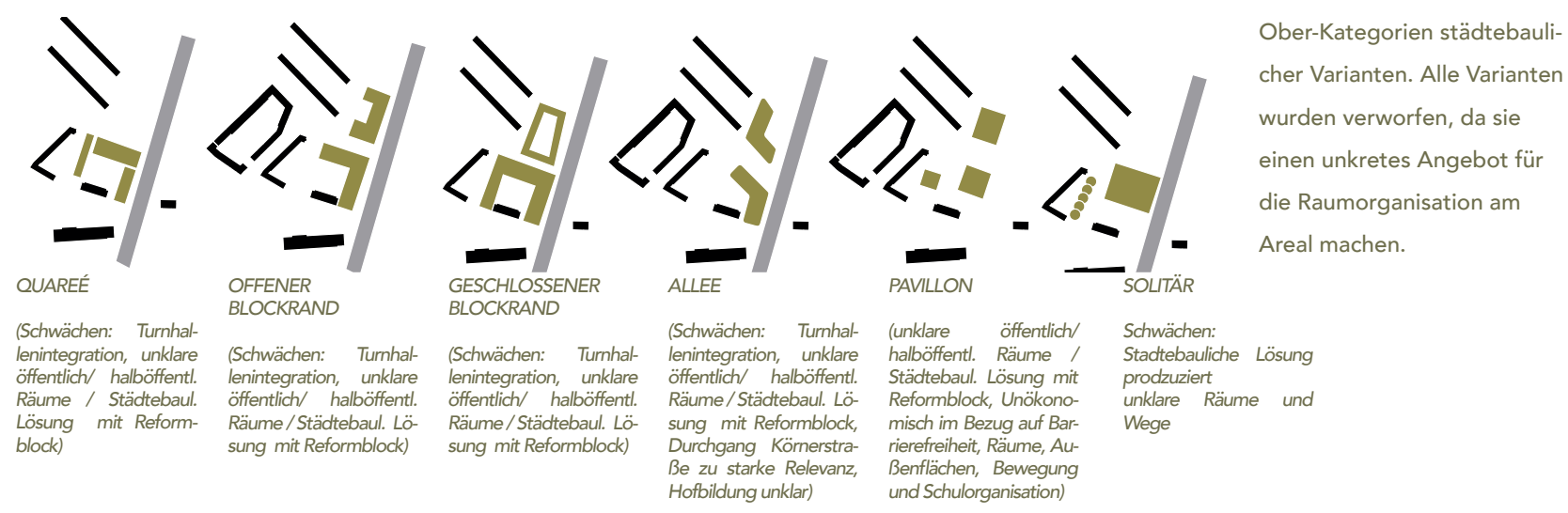

\section{FEUERWACHE FREISTELLEN}

Besonders relevant war hier der Umgang mit dem Bestandsgebäude. Die Nebengebäude (Tischlerei und Ga-

ragen) sollen abgerissen werden.

\section{BLOCK SCHLIESSEN}

Der offene Blockrand wurde mit einem Neubau geschlossen, dessen Nutzung vorerst unabhängig von der Aufgabe betrachtet wurde. Er definiert nun neue öffentliche und halböffentliche Räume. Ebenso definiert er die Freiräume im Norden neu (Defizt II). Im hier entstehenden Neubau könnte ggf. Wohnungsneubau oder Schlafplätze für temporäres Wohnformen (z.B. Hostel, Heime) oder besondere Wohnformen (wie z.B. betreutes Wohnen) etc einen Ort finden. Nach einer Neueinteilung der Flurstücke könnte dieser Teil der Liegenschaft vermarktet und so ein Teil des Areals refinanziert werden.

Die nun notwendig gewordene Erschließungsstraße definiert die Räume des Areals neu. Ebenso werden die zukünftigen Wegebeziehungen um das Areal relevant. Dafür wurde erörtert, welchen Weg die Schüler_innen zur Schule hin und von der Schule weg nehmen würden.

Die auch bereits schon notwendig gewordene neue Buslinie könnte zwischen der ehemaliger Karl-Krause-Fabrik und Feuerwache eine Halte und Wendemöglichkeit bekommen. Von hier würden die meisten Schüler_innen das Grundstück betreten. Ebenso ist damit zu rechnen, dass viele Schüler_innen entlang der Plattenbauten aus Richtung Lieselotte-Herrmann-Straße zur Schule gelangen.

Schließlich ist der zu entwickelnde Parkbogen Ost als neue Nord-Süd-Verbindung vermutlich auch ein potentieller Schulweg. Hier müssen Auf- und Abfahrten geplant und in den Stadtteil gestaltet werden. Deshalb habe ich mich für einen Schulneubau am Parkbogen entschieden und aktiv auf die Erschließungsmöglichkeit reagiert. Hier entsteht ein neuer Freiraum.

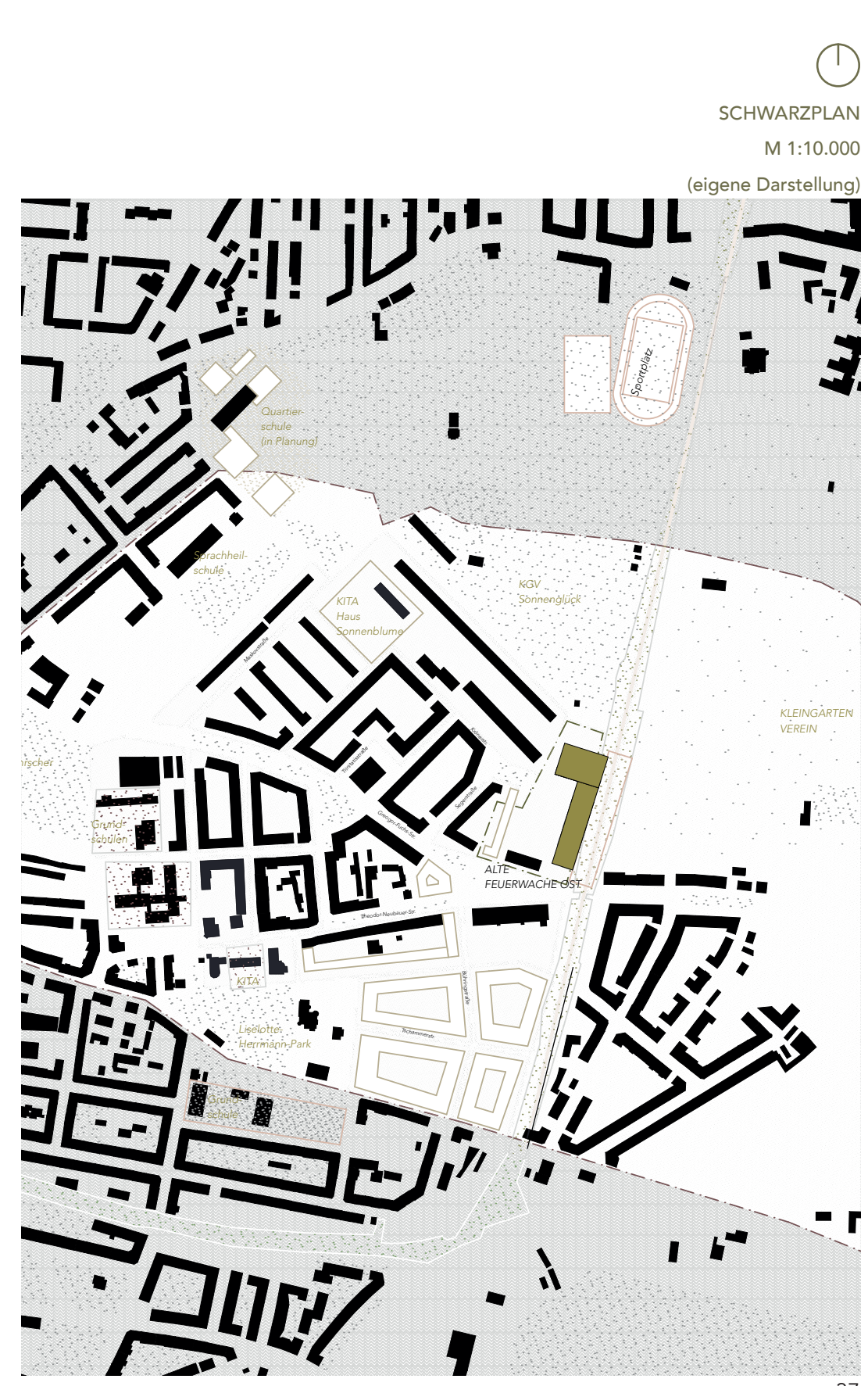




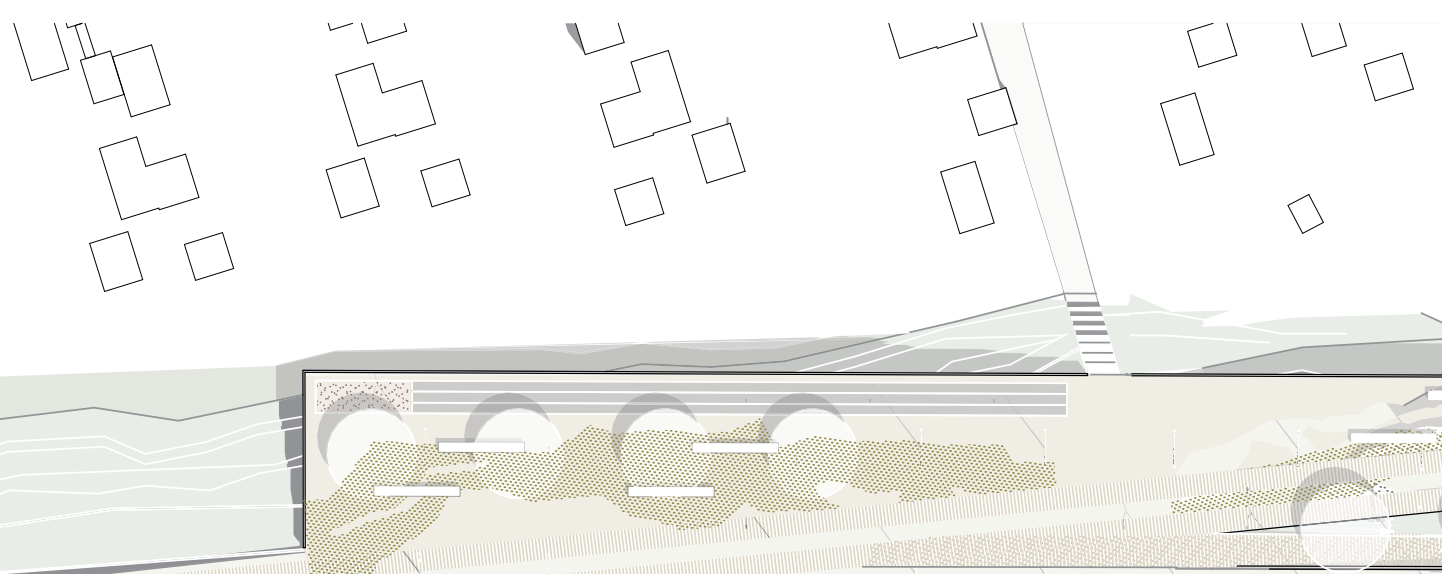




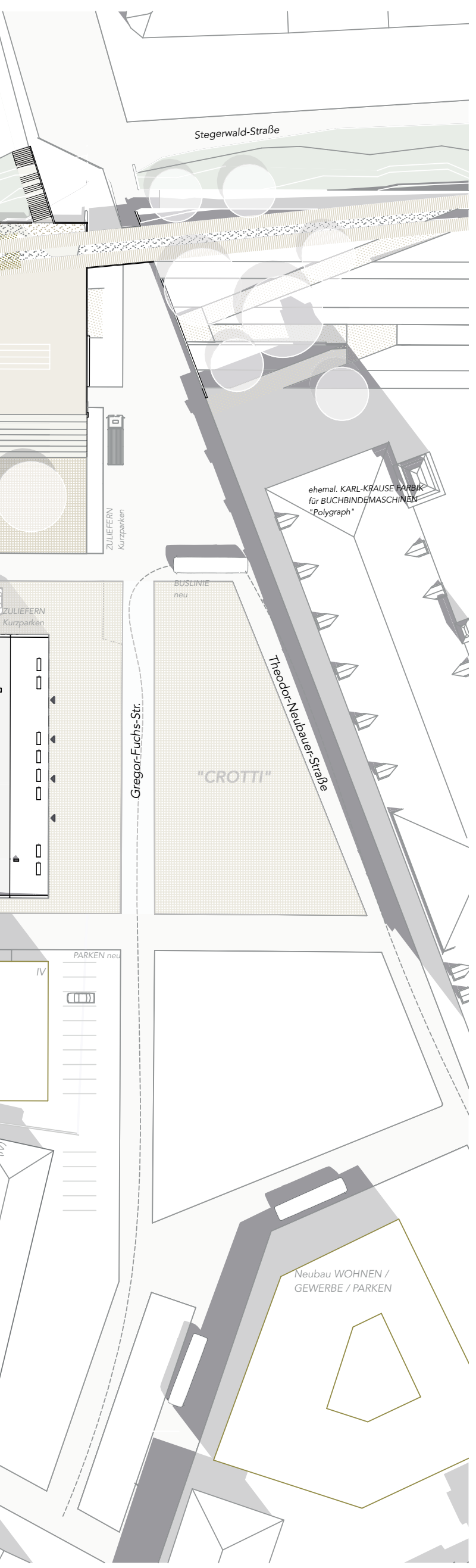

\section{PARKBOGEN OST SCHULE ÖFFNET SICH ZUR STADT}

Der Schulneubau soll entlang des Parkbogen Ost als Riegel ausgebildet werden und diesen für kurze Zeit begleiten. Hier entstehen neue Zuwegungs- und Freiraummöglichkeiten. Da der Parkbogen Ost als Rad- und Fußweg ausgebildet werden soll, habe ich mich hier entschieden, die Sportfreiräume anzuschließen.

Schließlich habe ich mich für einen Riegel entlang des Parkbogen Ost entschieden, der von diesem erschlossen wird. Die Turnhalle samt Ganztagsangebot und Musikräumen ist orthogonal zu diesem Riegel orientiert und bietet auf dem Dach der Turnhalle einen neuen Freiraum. Gleichzeitig rahmt der L-Förmige Neubau (Riegel und Turnhalle) nun den neu entstandenen Schulhof ein und grenzt ihn zur umliegenden Bebauung ab. Der Baukörper öffnet sich zur Stadt und räumt gleichzeitig den Städtebau auf, indem der dem „Anger-Crottendorf'schen” Allerlei einen Schlusspunkt setzt.

\section{PLATZBILDUNG „CROTTI”}

Neben dem neu entstandenen Hof, soll auch der Freiraum vor der Feuerwache an Bedeutung gewinnen. Der dreieckige Platz zwischen Karl-Krause-Fabrik und Feuerwache soll durch eine Bebauung der Spitze des Blockrandes schließen. Diese Eckbebauung kann beispielswiese ein Parkhaus fassen. Dieses könnte als Angebot für eine Ausgleichsfläche für die Garagennutzung des Bahndamm e.V. genutzt und ebenso die Parksituation im Stadtteil entlasten. Wenngleich einem neuen Kopfpunkt eines Platzes sicherlich auch eine weniger profane Nutzung zugute kommen würde.

Auf dem neu entstandenen öffentlichen Freiraum kann nicht nur einen Haltepunkt für öffentlichen Nahverkehr entstehen. Hier können Märkte oder Feste stattfinden. Daraus entsteht ein neuer Ort für Anger-Crottendorf der "Crotti". 


\section{$\mathrm{HOF}$}

Schulhof und Crotti werden durch den Veranstaltungsraum der alten Feuerwache miteinander verbunden. Ähnlich wie die Löschfahrzeuge der Feuerwehr durch das Gebäude hindurch fahren konnten, können zu Flohmräkten und Stadtteilfesten Besucher_innen durch das Gebäude hindurch gehen. Der Crotti wird hinter der Feuerwache als gemeinsam genutzter Schulhof weitergeführt.

Es soll keinen Zaun oder eine Mauer um das Schulgelände geben. Die Landschaftsarchitektur soll den Freiraum so zonieren, dass es eine deutliche Abgrenzung zu den öffentlichen Räumen entsteht. Ein Baumreihe entlang der neu entstehenden Durchwegung "neue Straße" und eine Hecken und Grasbepflanzung macht diese Abgrenzung deutlich. Das gleiche Motiv kehrt bei allen geplanten Freiräumen - Parkbogen Ost und Dachterassen - wieder.

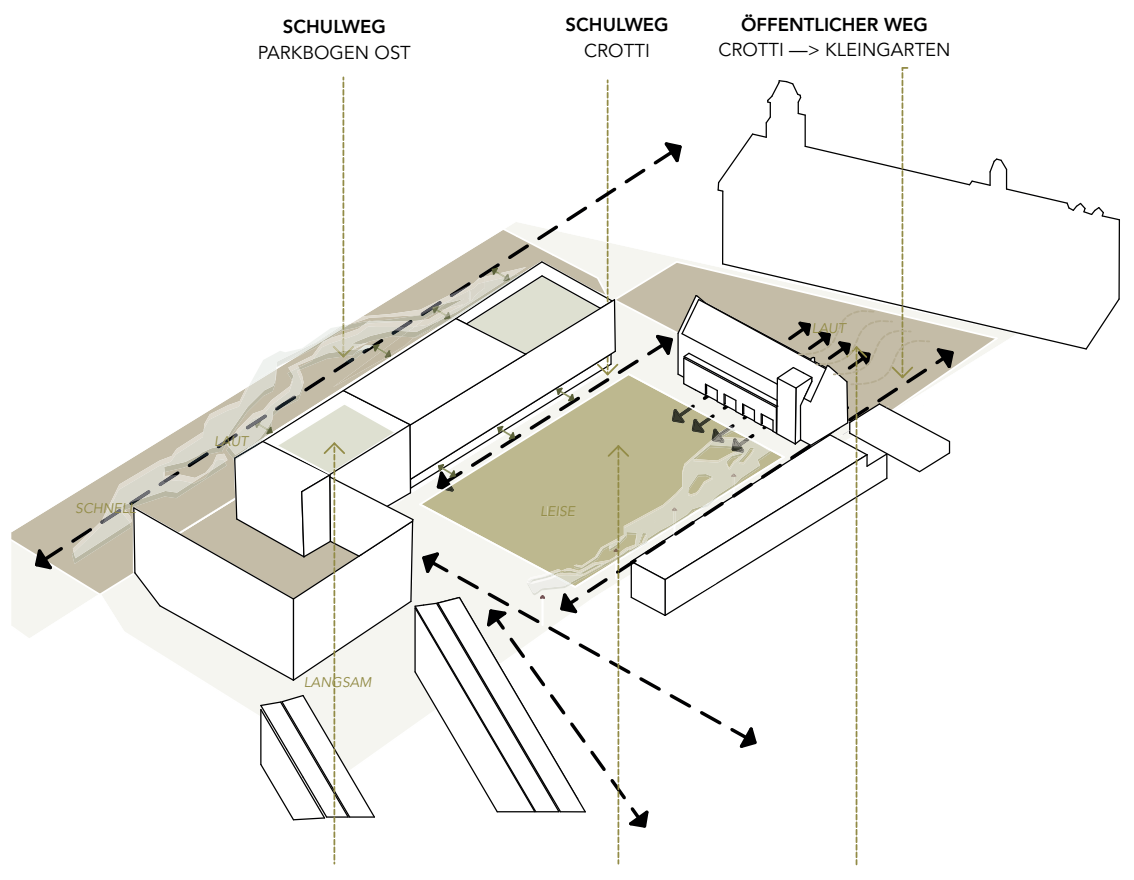




\subsection{RAUMORGANISATION}

\section{RAUMORGANISATION HORIZONTAL}

Ähnlich, wie die vertikale Raumorganisation in einer europäischen Stadt, ist auch der Schulneubau und das Nachbarschaftszentrum entworfen. In der Erdgeschosszone sind öffentliche und laute Räume, während den Obergeschossen leise und halböffentliche bzw. private Räume zugeordnet sind.

Das Hauptgebäude der Feuerwache ist für einen Schulneubau ungeeignet. Die Räume sind nicht tief genug, dass hier sinnvoll Klassenräume untergebracht werden können. Abgesehen von den Werkstätten und Küchen finden die Nutzungsanforderungen des Ostwache e.V. hier jedoch Raum. Deshalb soll die alte Feuerwache auch Hauptgebäude des Nachbarschaftszentrums werden.

\section{FEUERWACHE}

Im Erdgeschoss der Feuerwache entsteht ein großer Veranstaltungsraum, der flexibel nutzbar ist. Ein Café, Veranstaltungen und Kurse können in dem über 300m2 großen Raum Platz finden. Damit dieser Raum auch möglichst frei von Barrieren und Hindernissen ist, sollen die beiden oberen Geschosse an Vereine, Künstler_innen und Handwerker_inenn vermietet werden. Ein Vorschlag zur Aufteilung wurde mit dem Verein besprochen und entworfen. Als barrierefreie Erschließung habe ich dem Verein einen Aufzug im alten Schlauchturm vorgeschlagen. Die Trotz der gleichwertigen Treppenhäuser an der Ost und Westseite des Gebäudes, wurde sich für eine Haupterschließung auf der Westseite - an der Stadtseite - entschieden. Sanitär, Aufzug und Treppenanlagen und Café befinden sich in räumlicher Nähe. Ein ehemaliger Sportraum im Dachgeschoss der Feuerwache ist ebenso eine Besonderheit des Baus. Hier wurden Duschen und Umkleiden der Sanitäreinrichtung ergänzt. Im geräumigen ehemaligen Luftschutzkeller können Bandprobenräume Platz finden.

Das zeigt, dass das Nachbarschaftszentrum auch ohne ohne Schulneubau funktionieren kann. Jedoch steckt in der Synergie beider Orte Potential.

Das Nachbarschaftszentrum in der alten Feuerwache und

UMBAUSTRATEGIE

FREISTELLEN

Abbruch der Nebengebäude WIEDERHERSTELLEN

Laubengang Hofseitig

NEUBAU

Sanitär \& Aufzug im Schlauchturm
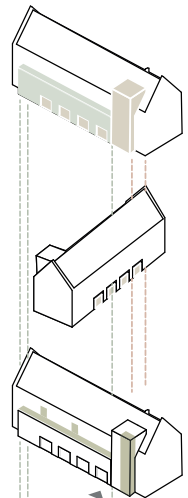

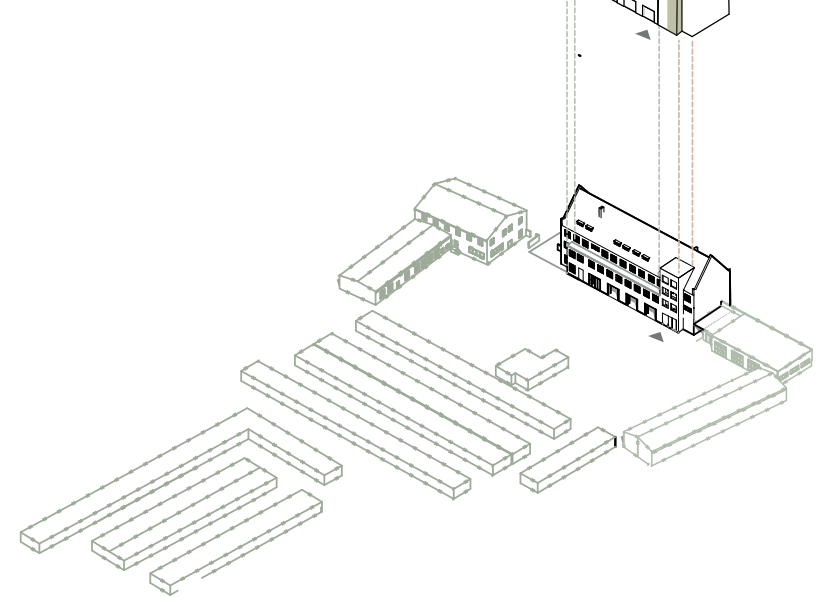


der Schulneubau sind im Erdgeschoss räumlich miteinander verbunden. Die Schüler_innen und Nachbar_innen der Ostwache teilen sich hier Werkstätten, Selbsthilfewerkstätten, Mensa, Sporthalle und eben den gemeinsamen Hof.

Die technischen Räume, Lager- und Versorgungsräume sind im Sockel - sozusagen im Parkbogen Ost - herangeschoben.

Der Werkstattsockel ist $3 \mathrm{~m}$ eingerückt und mit großen verglasten Öffnungen versehen. So kann auch im Freibereich gearbeitet werden ohne dass notwendige Wege verstellt werden. Durch die großen Öffnungen entstehen hier Ladenfenster, die entlang des Sockels zum Flanieren einladen.

Diese lauten Räume werden im 1. Obergeschoss mit den gut zu erreichenden Räumen der Schule weitergeführt. Die eigentliche Schule beginnt also ab dem 1. OG und ist vom Parkbogen Ost zu erreichen. Im Norden kann das Dach der halb vergrabenen Turnhalle vom Parkbogen erreicht werden. Hier befinden sich Außensportanlagen. Eine 100m-Rennbahn und eine Weitsprunganlage finden auf dem Parkbogen entlang des Rad- und Fußwegs ihren Platz.

\section{RAUMORGANISATION VERTIKAL}

Die im Raumprogramm explizit aufgeführten Ganztags- und Inklusionsräume sowie der Schulclub sind dem Sporthallengebäude zugeordnet. Zusammen mit den darüberliegenden Musik-Räumen kann hier ein ganztätiges Angebot im Bereich, Tanz, Musik, Ergotherapie und Jugendarbeit stattfinden.

Der im Norden des Areals befindliche Sport- und Pädagogikbereich und der im Süden anschließende Lernatelier-Trakt sind durch das Freinetzentrum miteinander verbunden. Dieses ist vom 1. - 4. OG (sowie Dachterrasse) über der Mensa angeordnet und mit einer Rampe erschlossen. Entweder können die Sitzplätze der Mensa im 1. OG weitergeführt werden oder der Raum als Treffpunkt zum Lernen oder Spielen genutzt werden. Im 2. OG des Freinetzentrums ist die Mediathek bzw., Bibliothek mit extra Informatik- und Programmierraum sowie möglichen Redaktionsräumen einer Schulzeitung. Im 3. OG befindet sich der Schulrat-Raum. Entlang des Oberlichts der Rampenerschließung steht ein runder Tisch an dem bis zu 40 Personen Platz finden können.
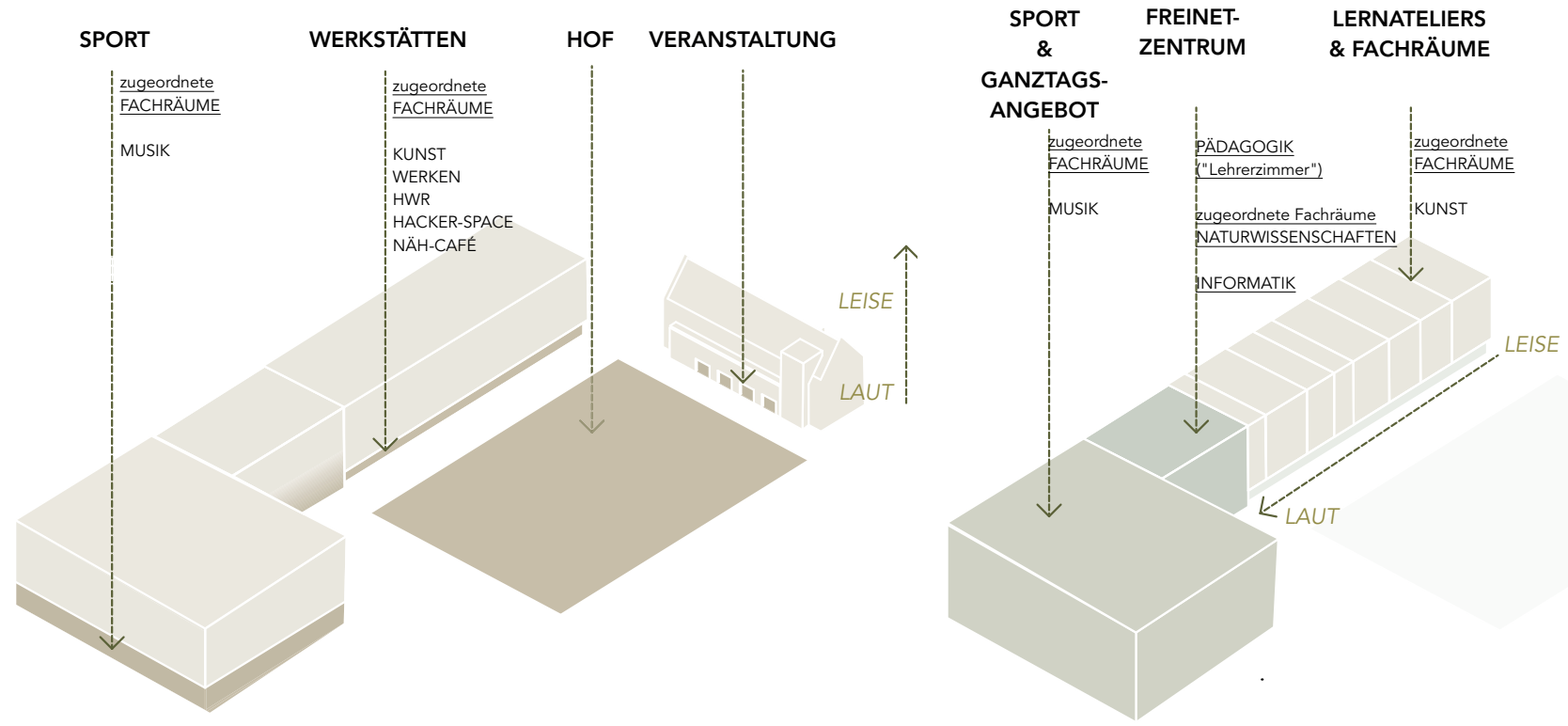

OSTWACHE 


\section{RAUMORGANISATION CLUSTER \& KLASSENRAUM-PLUS}

Der Schulriegel ist in Clustern organisiert. Auf jedem Geschoss sind drei Cluster zu finden, zwischen die Cluster sind verschiedene Fachräume und Sanitärräume geschaltet.

Während im 1. OG noch verschiedene Büro- und Beratungsräume der Lehrer_innen zwischen Schulclusterräumen und Freinet-Zentrum vermitteln, schließen sich auf jedem Geschoss 1.-4 OG Lernateliers und Unterrichtsräume an. Diese werden im 1. und 2. OG noch den Kunsträumen und im 3. 4. OG mit den naturwissenschaftlichen Fachräumen voneinander getrennt. Physik, Biologie- und Chemieräume sind gehen teilweise über zwei Geschosse verteilt, damit sie aufgrund ihrer Größe einen angenehmen Deckenhöhe bieten. Hier sind ggf. Tribünenmöblierungen möglich.

Die Lernateliers und Differenzierungsräume sind im Cluster organisiert. Jeweils 4 Lernateliers, als Klassen, teilen sich einen Differenzierungsraum und ggf. einen Vorbereitungsraum für die Lehrer_innen. Die Lernateliers- und Differenzierungsräume sind zusammenschaltbar, aber bewusst als abgeschlossene Räume entworfen. Eine Klasse hat hier vor allem für die partitipativeren Slots wie z.B. Morgenrunde oder stille Arbeit einen vertrauensvollen und abgeschlossenen Raum.

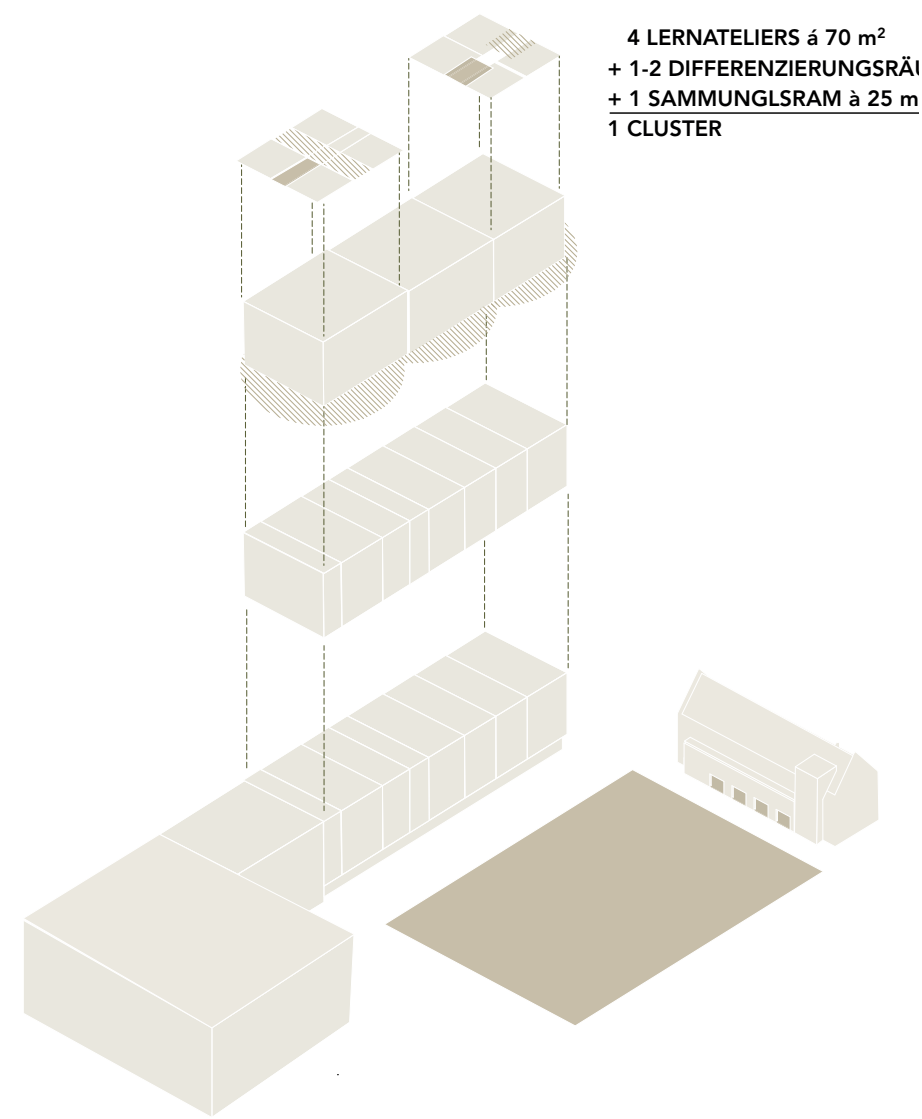




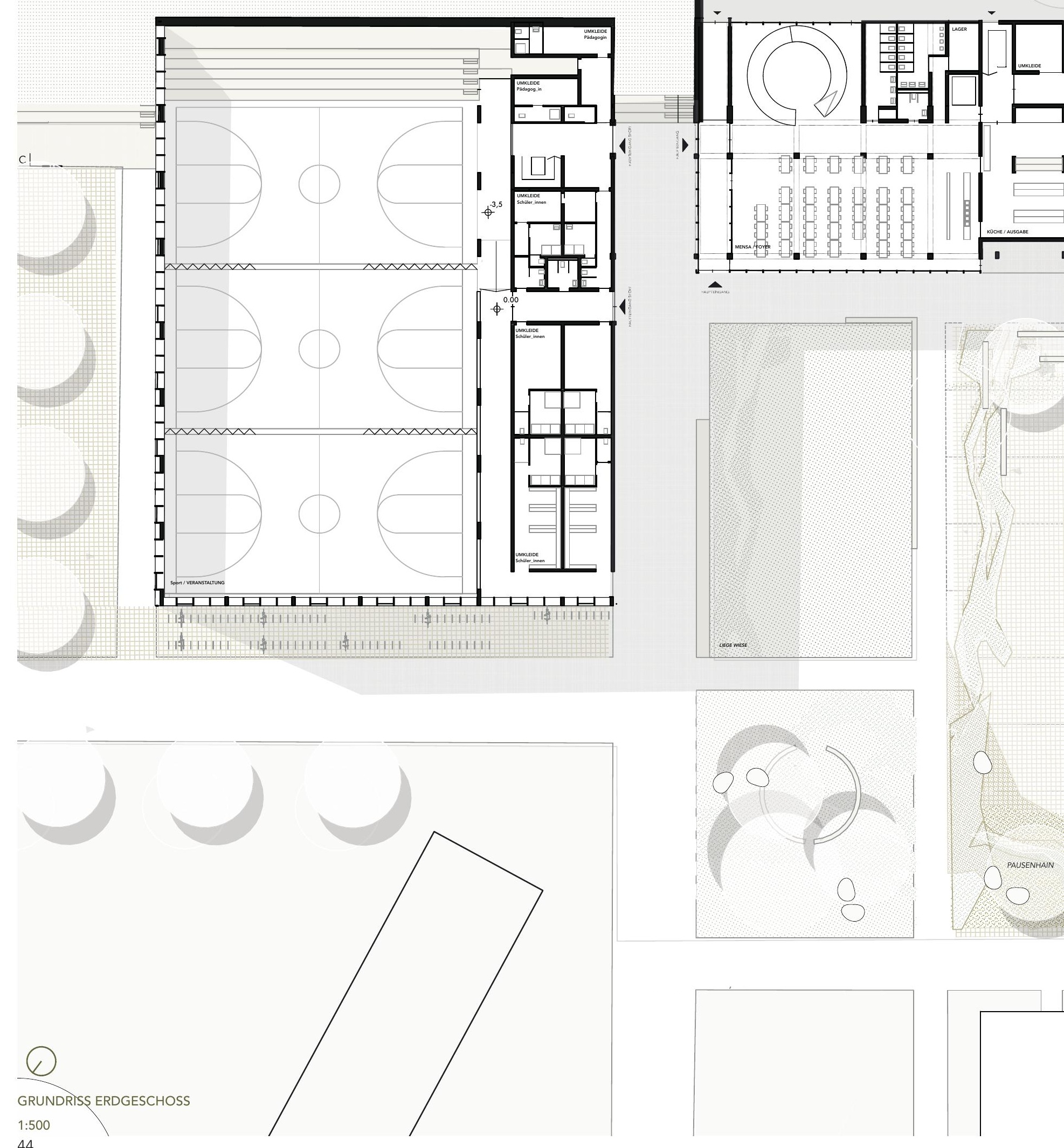




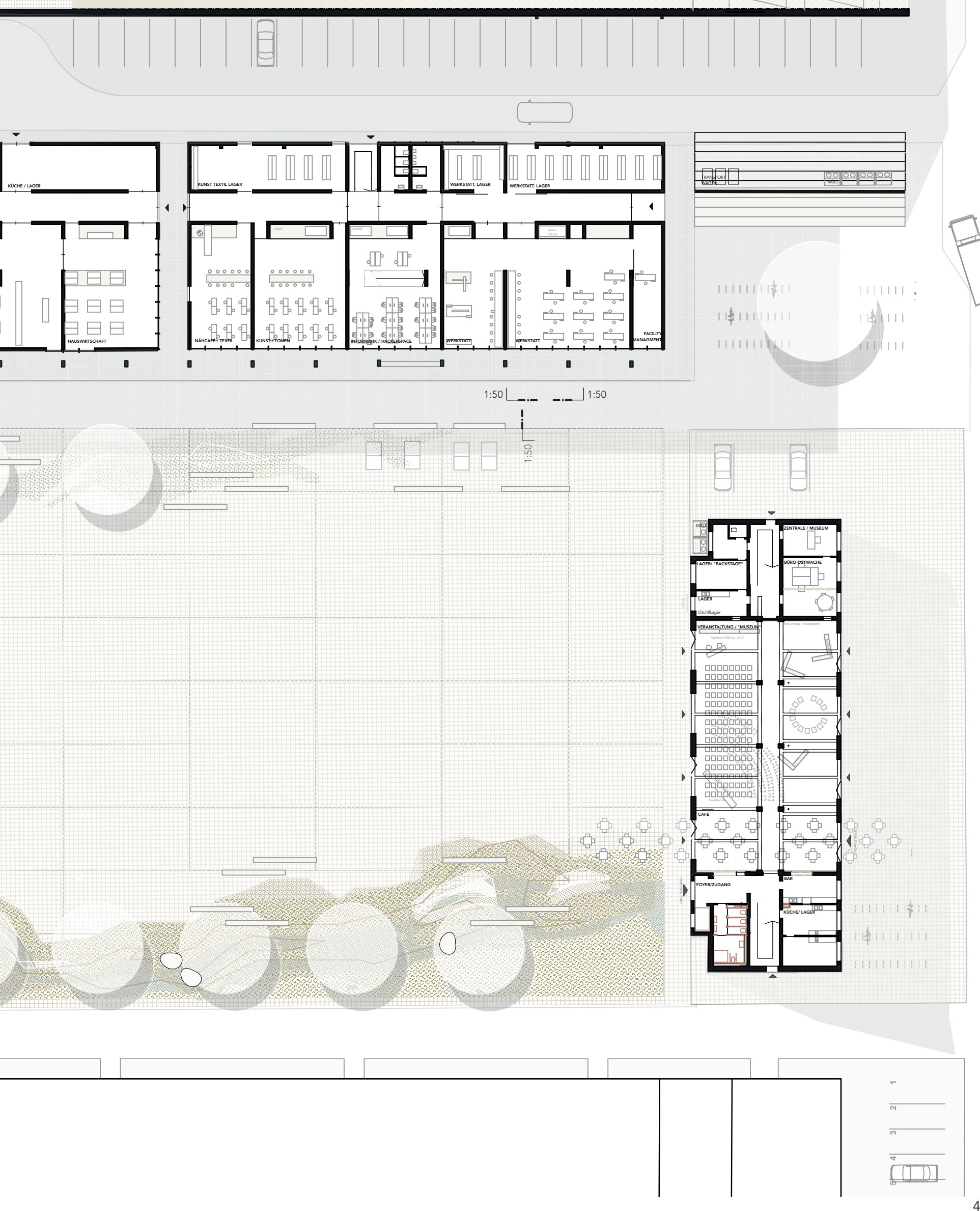



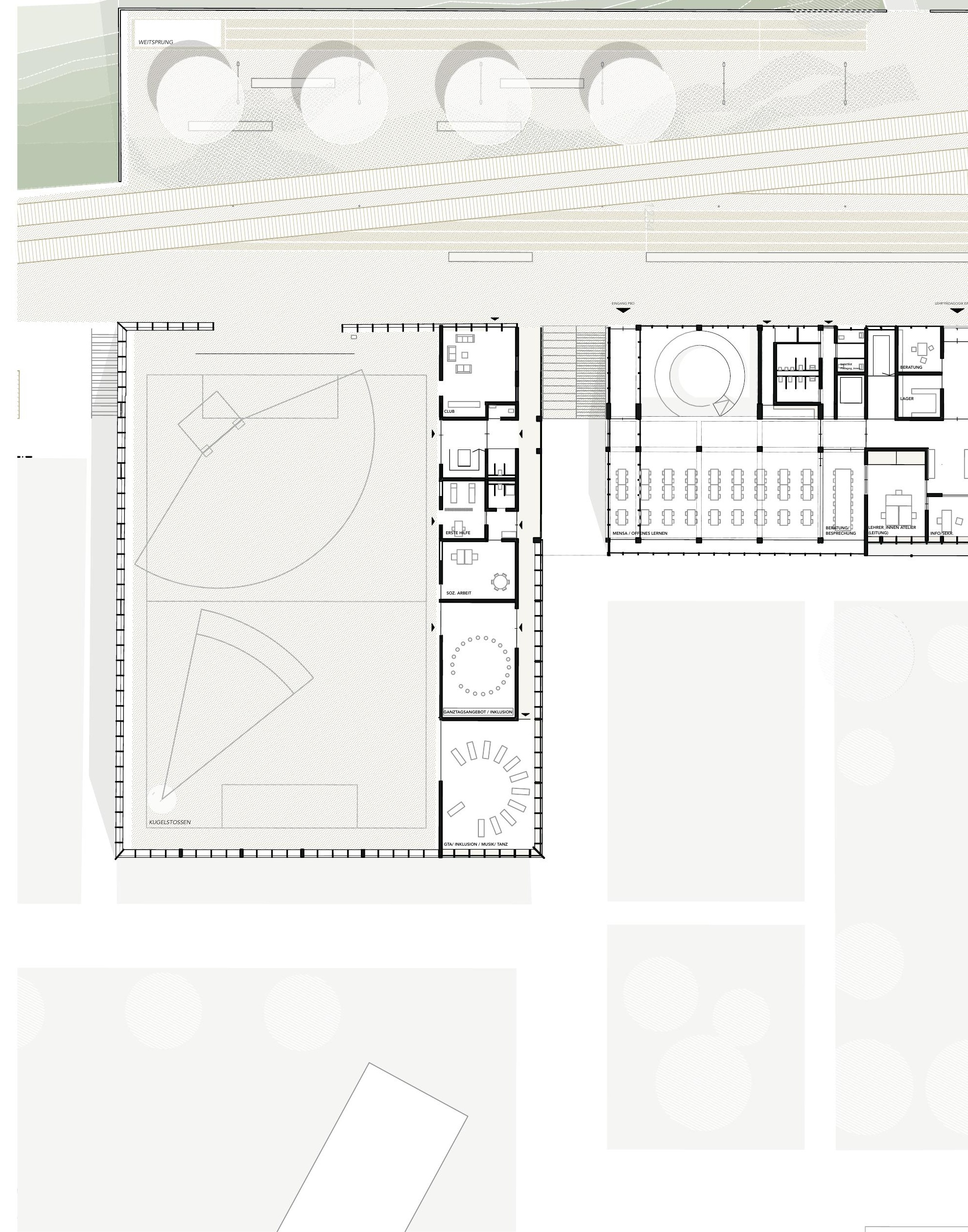

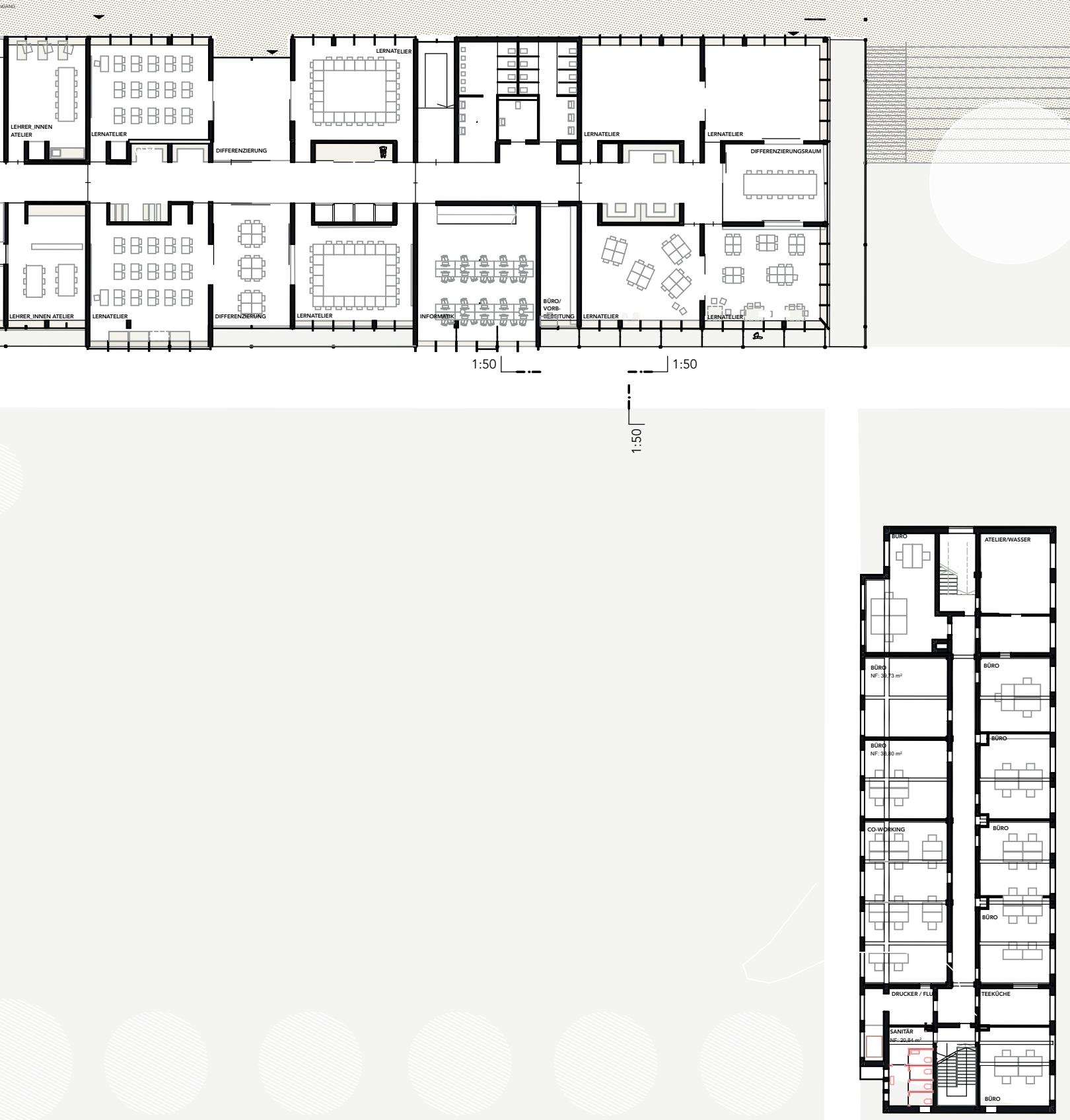

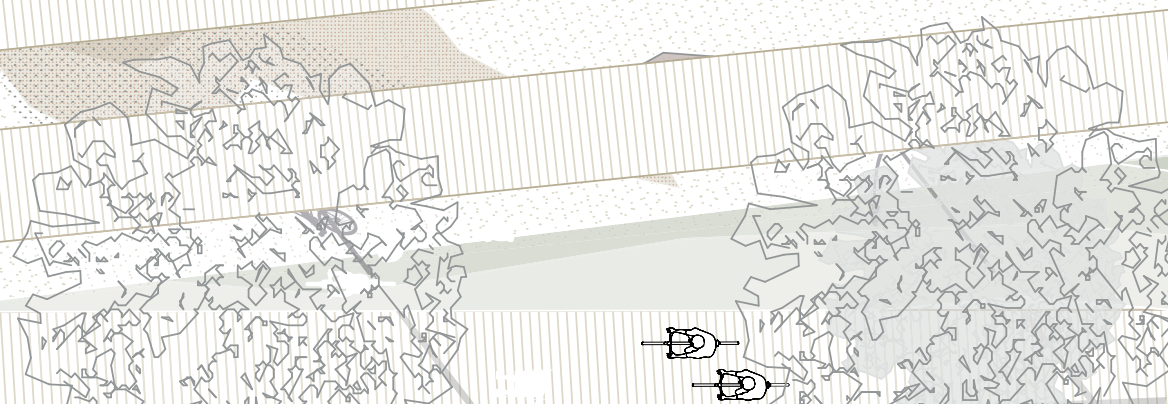

$42+10 ; 2$
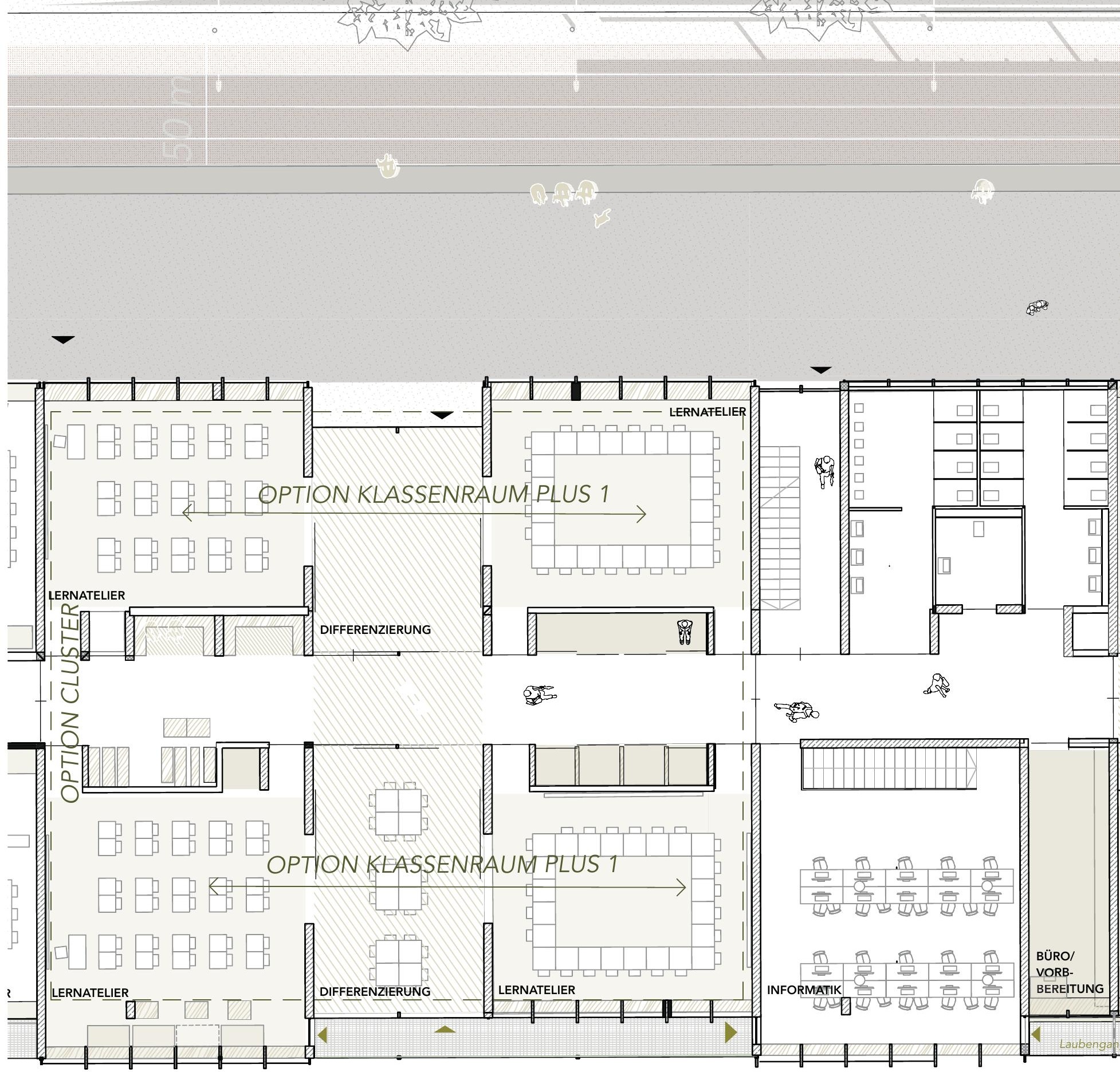

OPTION CLUSTER + KLASSENRAUM + 1

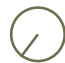

GRUNDRISS AUSSCHNITT 1. OG

/ RÄUME / M 1:500 


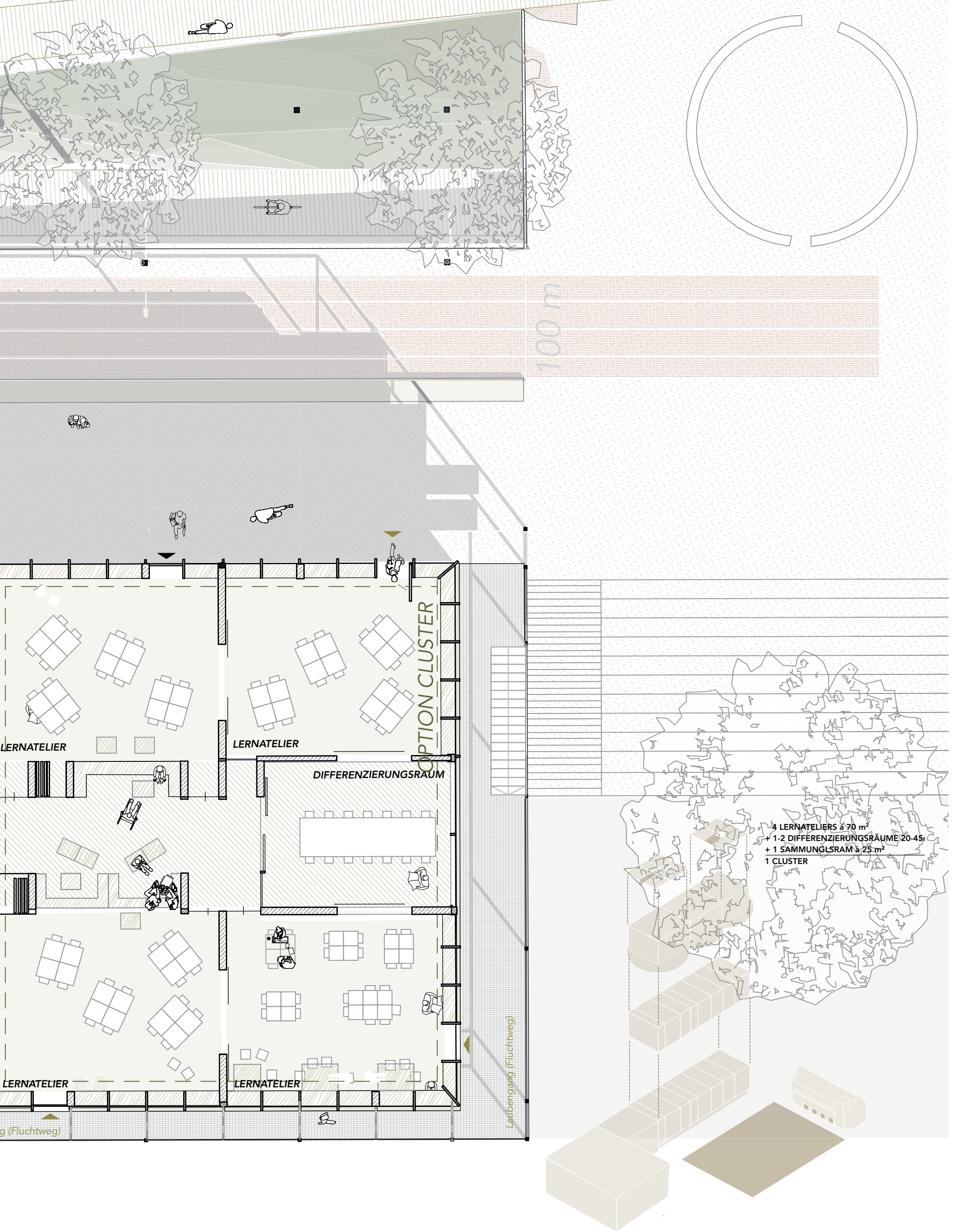


ANMERKUNGEN

ZUM BRANDSCHUTZ

Das Gebäude ist in verschiedene Brandabschnitte geteilt. Der Erste Rettungsweg ist über den Flur und die Treppenhäuser angelegt. Der zweite Rettungsweg führt entweder über Laubgänge oder die Halle (Mensa/Freinetzentrum).

ANMERKUNGEN

TECHNIK

Technische Räume sind im

Kellergeschoss über das

Foyer/Mensa oder den Spor-

triegel zu rerreichen.
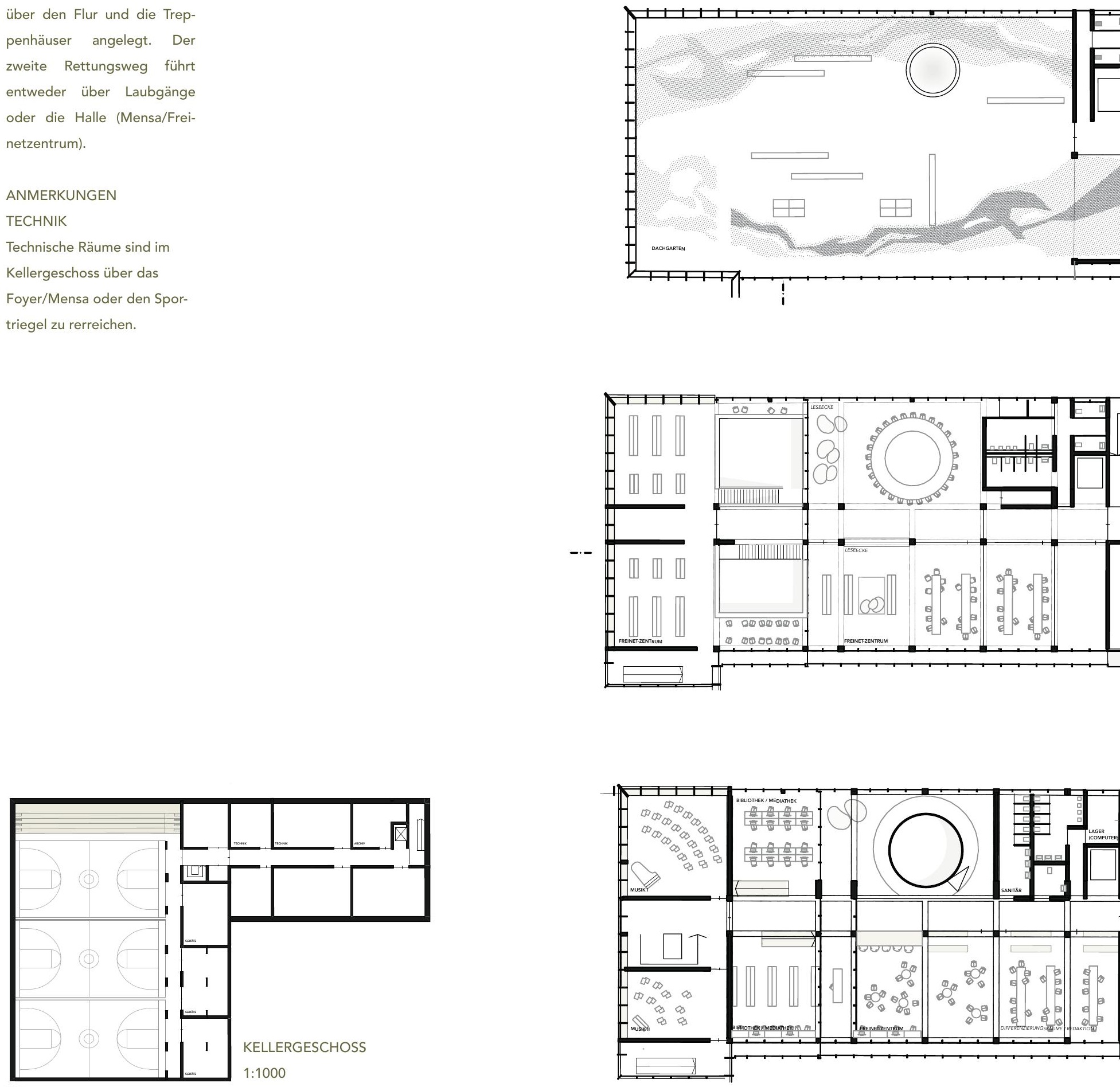
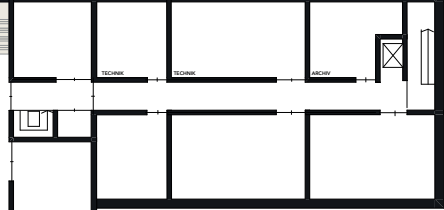

I I

I

KELLERGESCHOSS

$1: 1000$
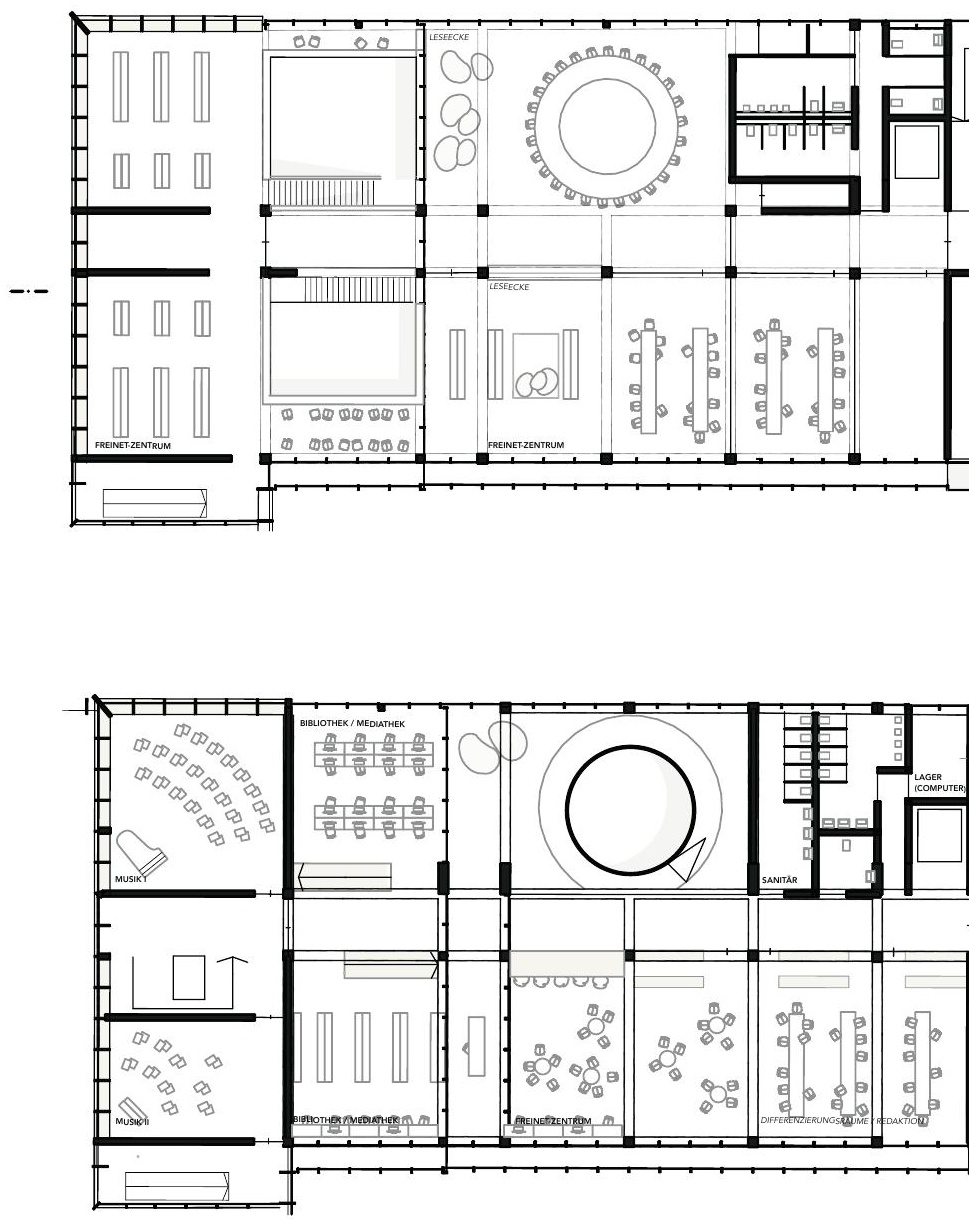


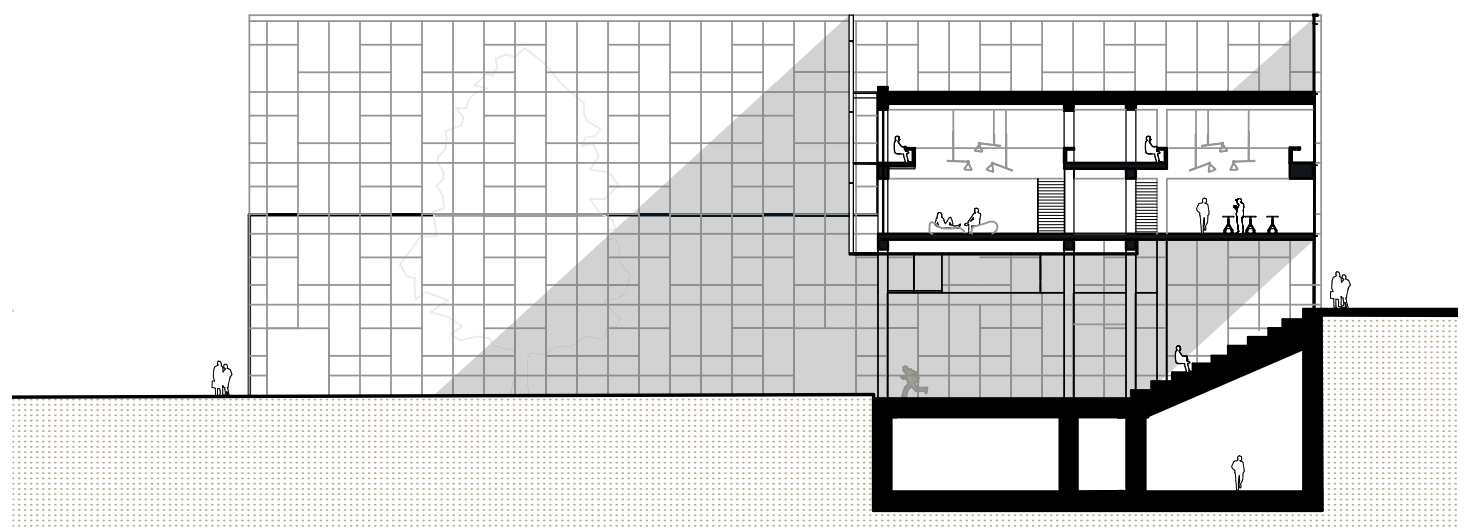

QUER SCHNITT

M 1:500

(

GRUNDRISS 4. OG M 1:500

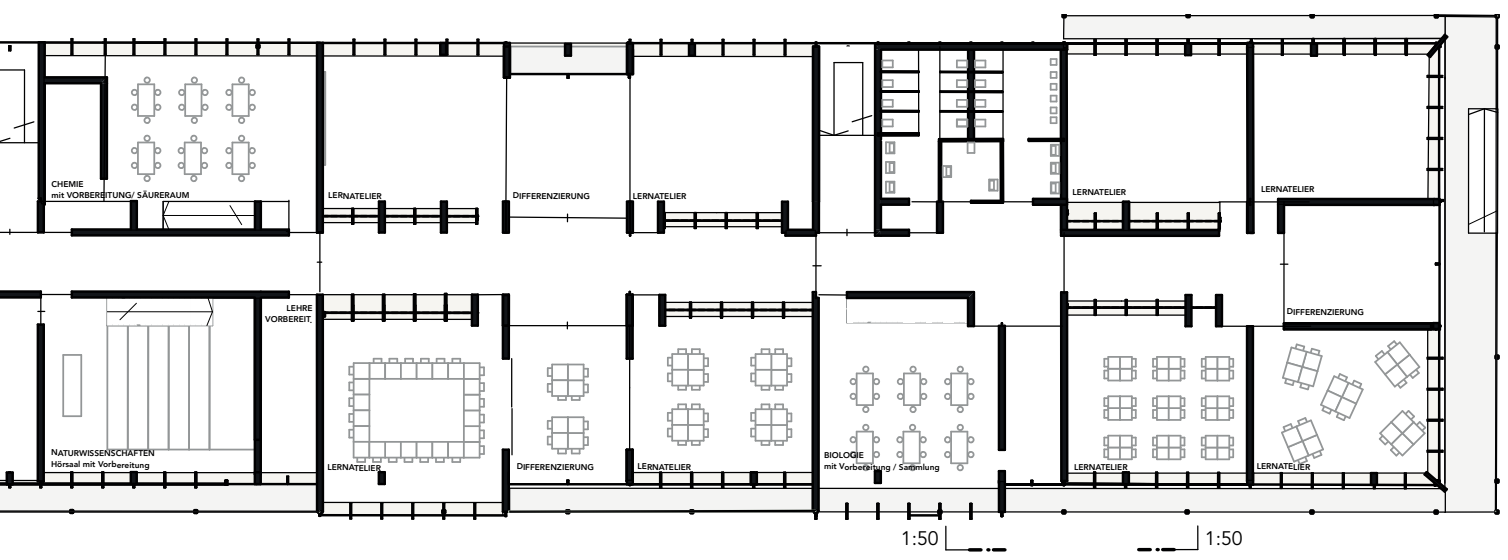

GRUNDRISS 3.OG M 1:500

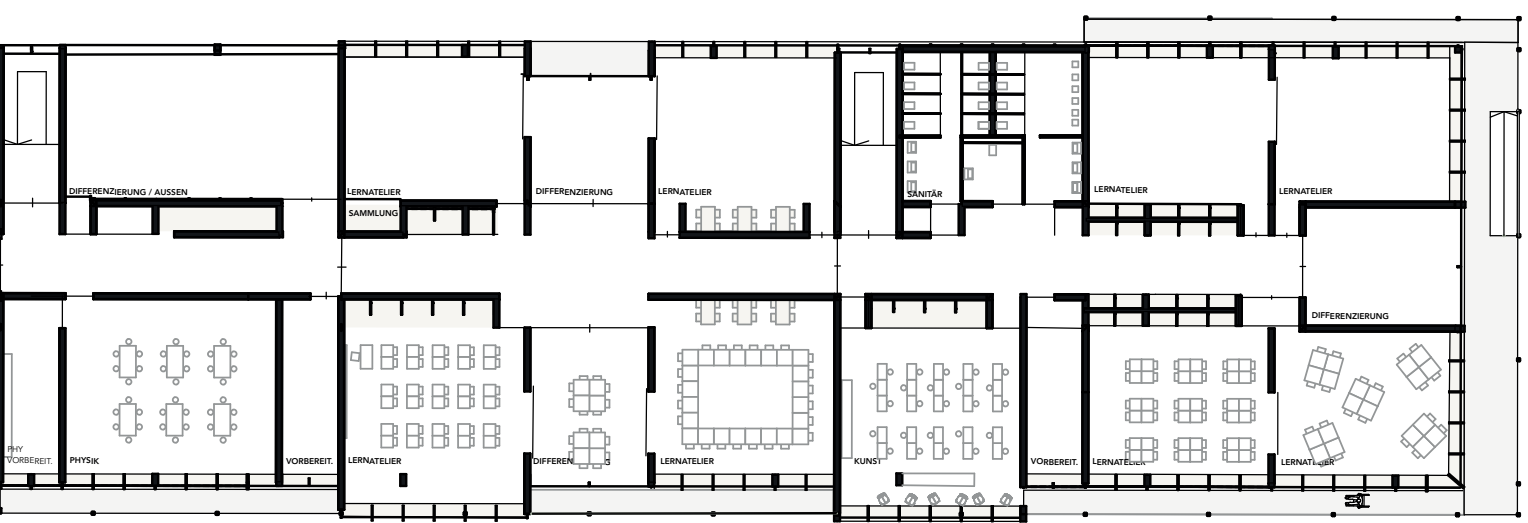

GRUNDRISS 2. OG M 1:500 
5.4

\section{RASTER, TRAGWERK, KONSTRUKTION}

\section{DER FLUR ZWISCHEN DEN SCHEIBENSTÜTZEN}

Der Neubau beruht auf einem Konstruktionsraster von 6,30 Meter bzw. ein oder zwei kleinere davon (3,15m und 1,575). Auf diesem quadratischen Raster lassen sich Lernalteliers von ca. 70m2 und die maximal 9 Meter tief sind, Fachräume von über $80 \mathrm{~m} 2$ und die notwendigen Flure gut organisieren. Das Raster wurde aus dem angenommenen der Feuerwache entnommen, um im Erdgeschoss ähnliche Öffnungen und Dimensionen, wie die der vier Einfahrten der Löschfahrzeuge zu erreichen.

Die Schule wird über einen Mittelgang erschlossen. Rechts und Links des Flures sind Stützen, die als 1,50 m tiefe Scheiben ausgebildet sind. Die Scheibenstützen auf der Ostflurseite sind grundständig - stehen also in jedem Geschoss übereinander, während sie auf der Westseite des Flures wechseln können. Die gesamte Flurzone hat eine Breite von 6,3 Metern, wobei die Räume zwischen den Stützen auch den Räumen zugeschrieben sind. Hier entstehen Leseecken und Nischen, Raum für Sammlungen (Lehrmittel) oder ggf. Treppenerschleißung für Räume, die über zwei Geschosse erschlossen werden.

Da diese Nischen mal den Lernalteliers und mal dem Flur zugeordnet sind, entsteht zwar ein langer, aber mäandernder Flur, der durch die durchgesteckten Differenzierungsräume, die zum Flur hin verglast sind, belichtet wird. Das Freinetzentrum ist als Stahlskelett auf dem gleichen Raster ausgebildet. Die öffenen und großen Räume ver-

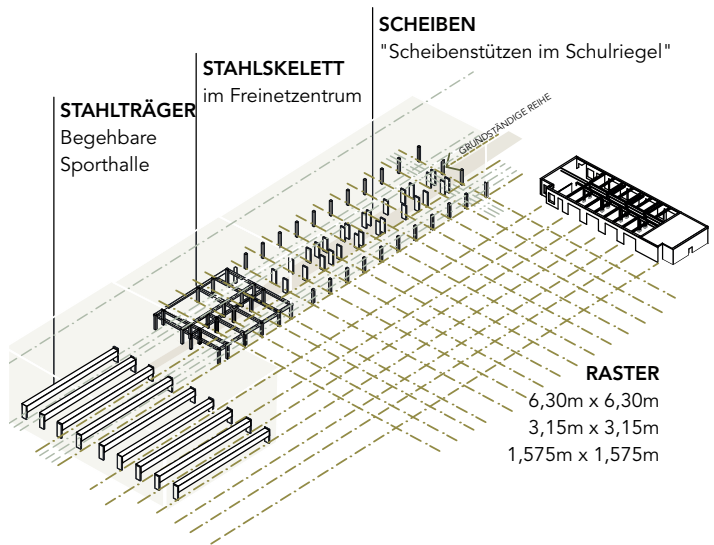

langen eine große Spannweite. Optisch entsteht auch so ein anderes Fassadenbild zum Schulriegel.

Der Rasterbau ermöglicht die Vorfertigung von Bauteilen und somit einen schnellen Bau. Das Raster findet sich im Roh- sowie in den Leichtbauelementen wieder.

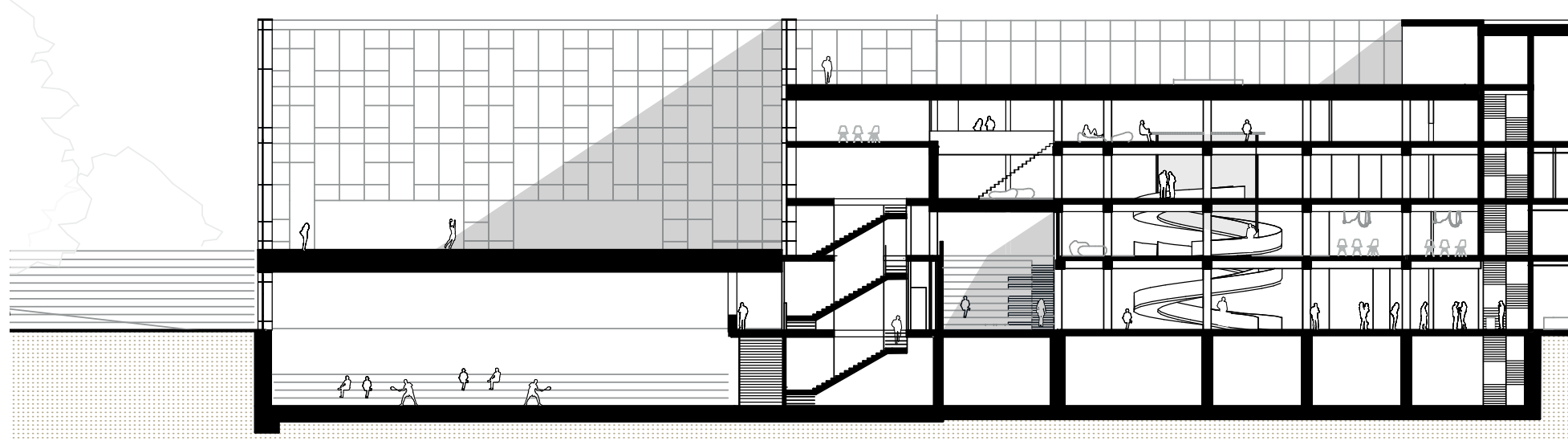


5.5

\section{FASSADE/ ANSICHTEN}
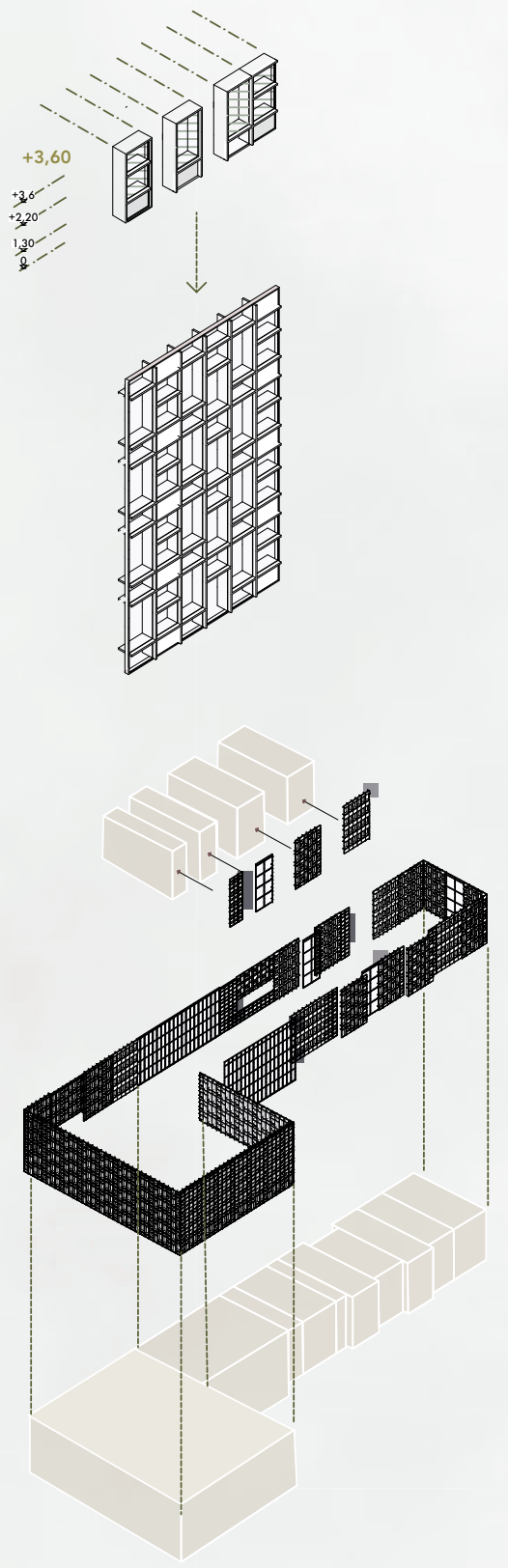

Die Pfosten-Riegel-Fassade beruht auf einem wiederkehrenden System von 3,60m (Geschosshöhe) mal 1,575m (Abstand im Raster): Die Riegel sind auf dem Raster $(1,575 \mathrm{~m})$ angeordnet, während die Pfosten auf drei fixen Höhen sitzen können. Sie wechseln je nach Fassadenteil. Die Fassade des Riegels wird aufgelockert. Das gleiche Fassadensystem wird in verschiedenen Ausführungen vor die übereinanderliegen Räume gehängt. Ähnlich wie die Fassaden von Blockrandbebauung der Gründerzeit, wird der lange Baukörper durch die Parzellierung gegliedert und aufgelockert. Vorbild dabei war das Projekt "Lokdepot" des Berliner Architektenbüros Robertneun (Kleinen 2014)

Dabei sind Pfosten und Riegel bewusst nicht filigran ausgebildet, sondern werden mit $15 \mathrm{~cm}$ dicken Profilen ein Schattenbild auf die Paneele und verbergen gleichzeitig die Sonnenschutzrollos.

Für diese Arbeit wurden drei verschiedene Varianten des Systems entwickelt, die zwar gleich gegliedert und gerastert sind, aber je nach Nutzung im Innenraum verschiedene Füllungen der Panels beinhalten können. Darüber hinaus wechseln gefüllte und nicht gefüllte Panele ab.

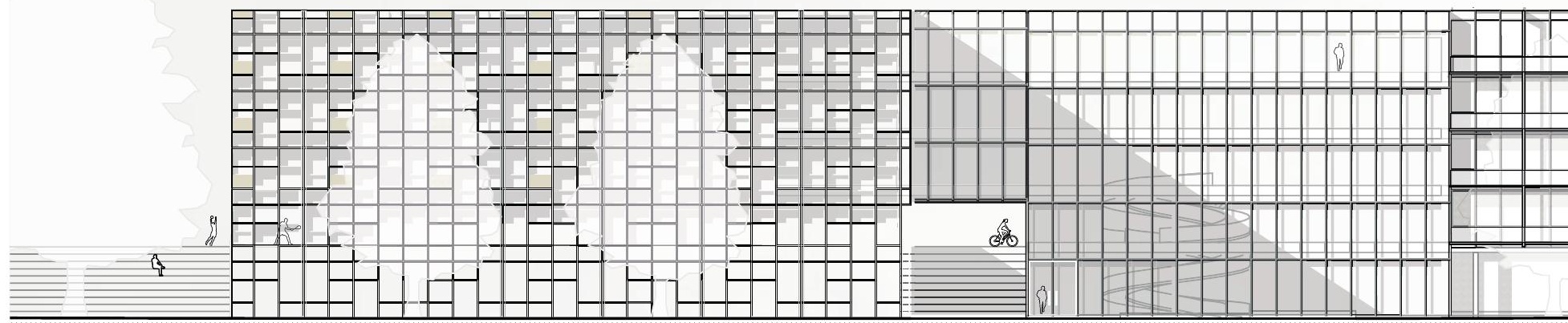



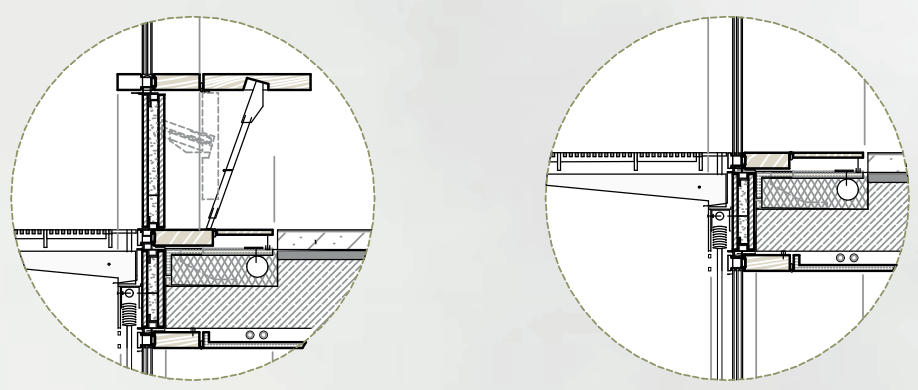

TEXTILBETON

FASSADENELEMENT

$15 \mathrm{~mm}$ Textilbeton

$5 \mathrm{~mm} \quad$ Luftschicht

$25 \mathrm{~mm} \quad$ Vakuumpaneel

$25 \mathrm{~mm} \quad$ Vakuum Panee

$5 \mathrm{~mm} \quad$ Luftschicht

$30 \mathrm{~mm}$ Textilbeton

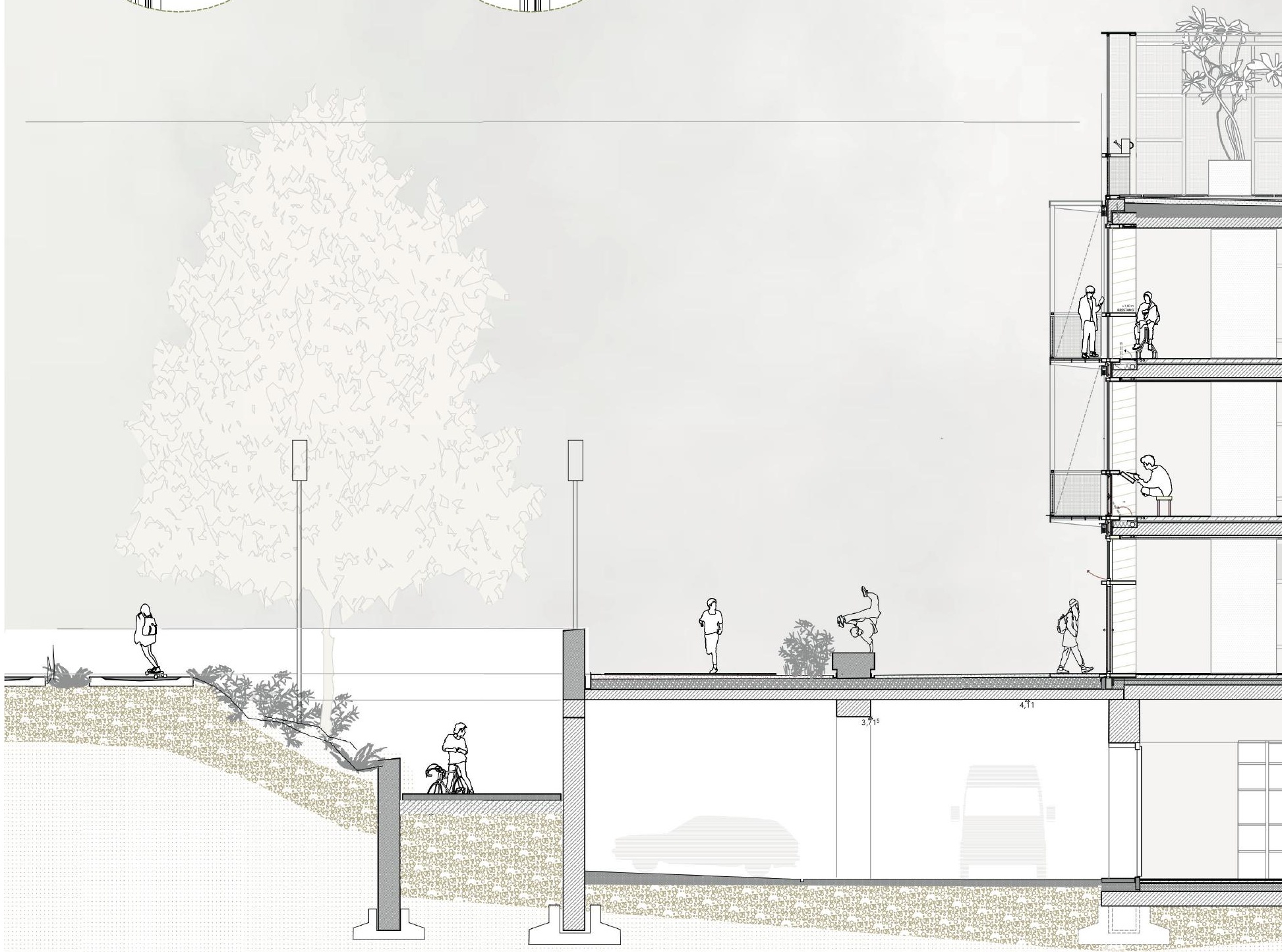




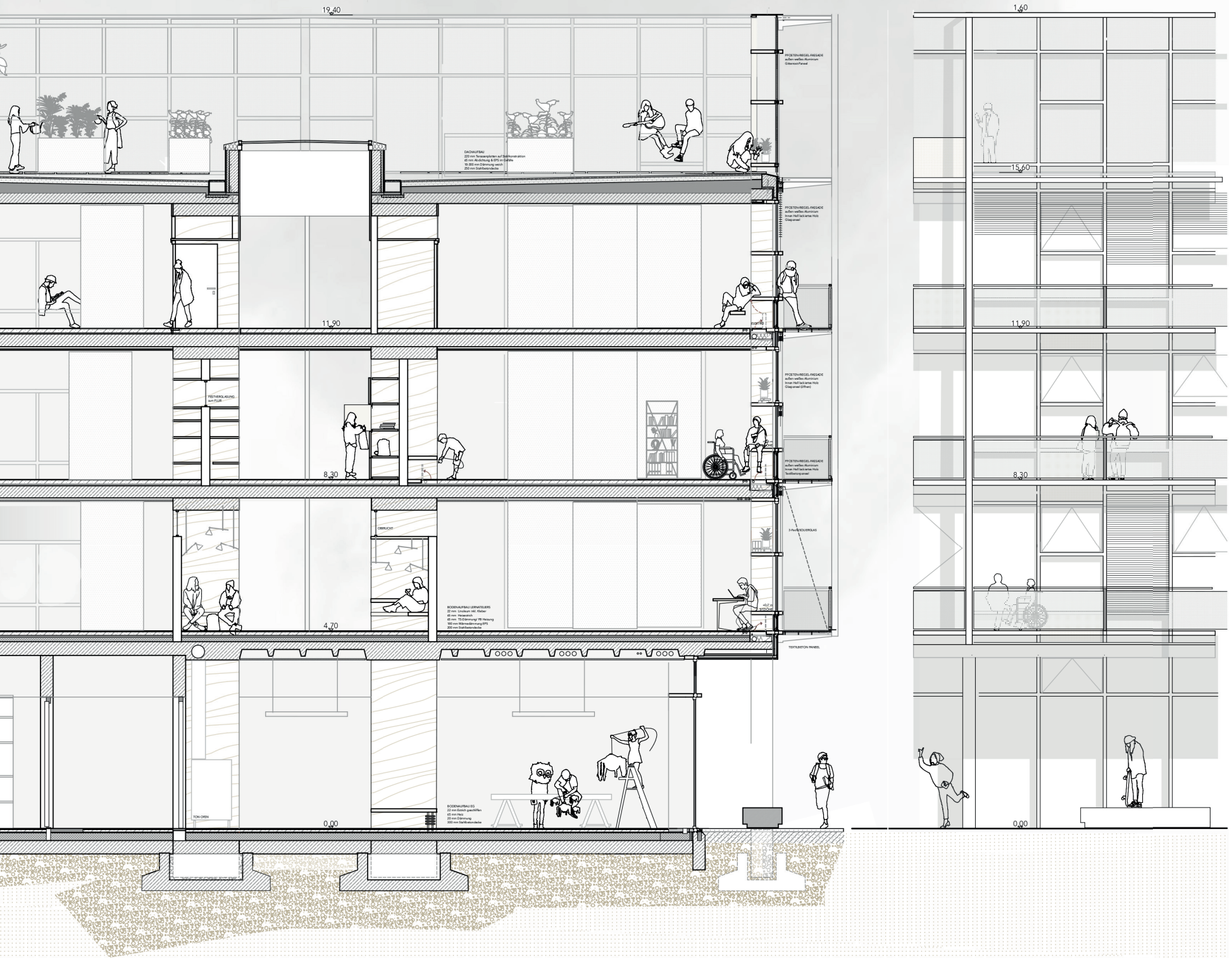




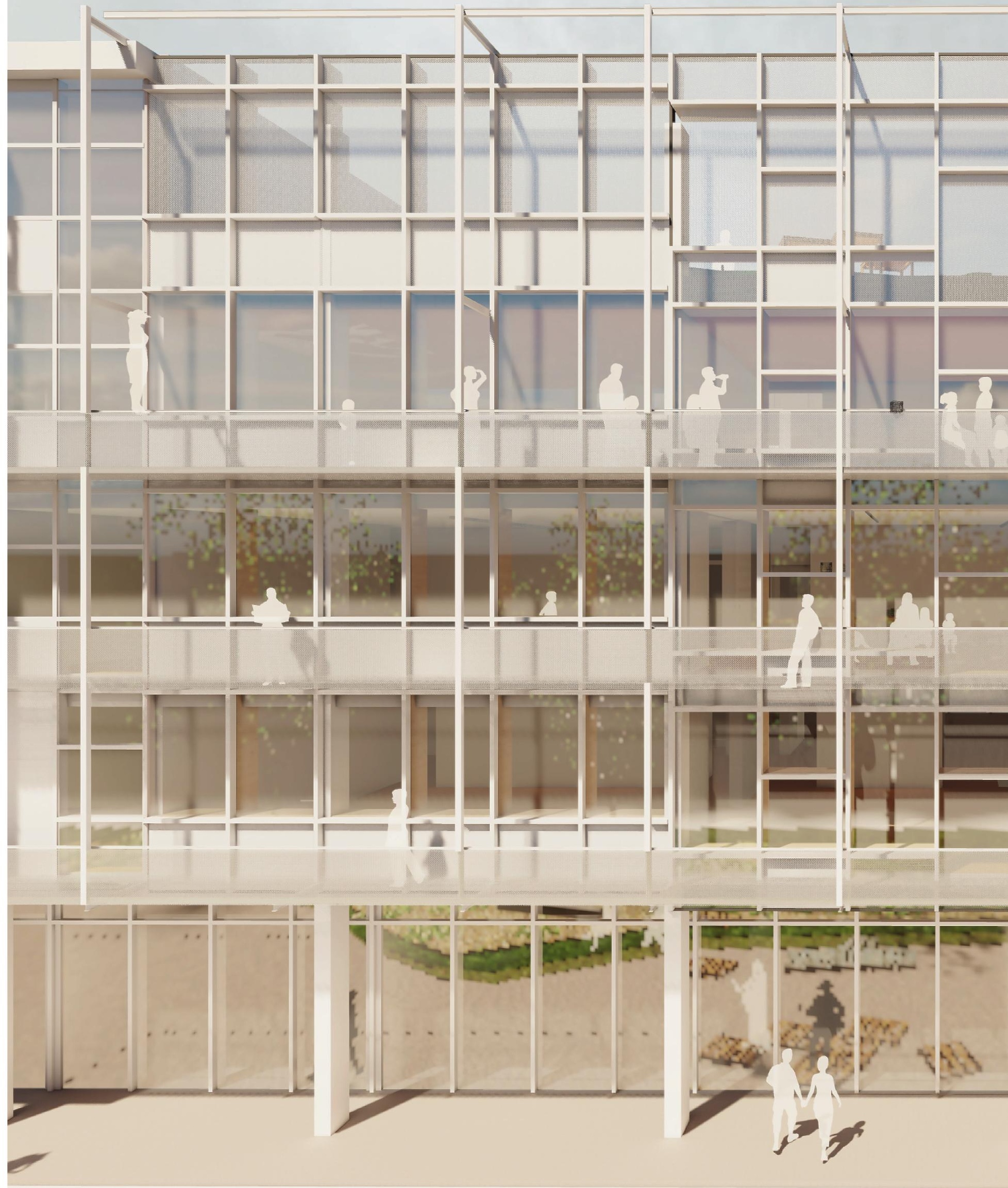



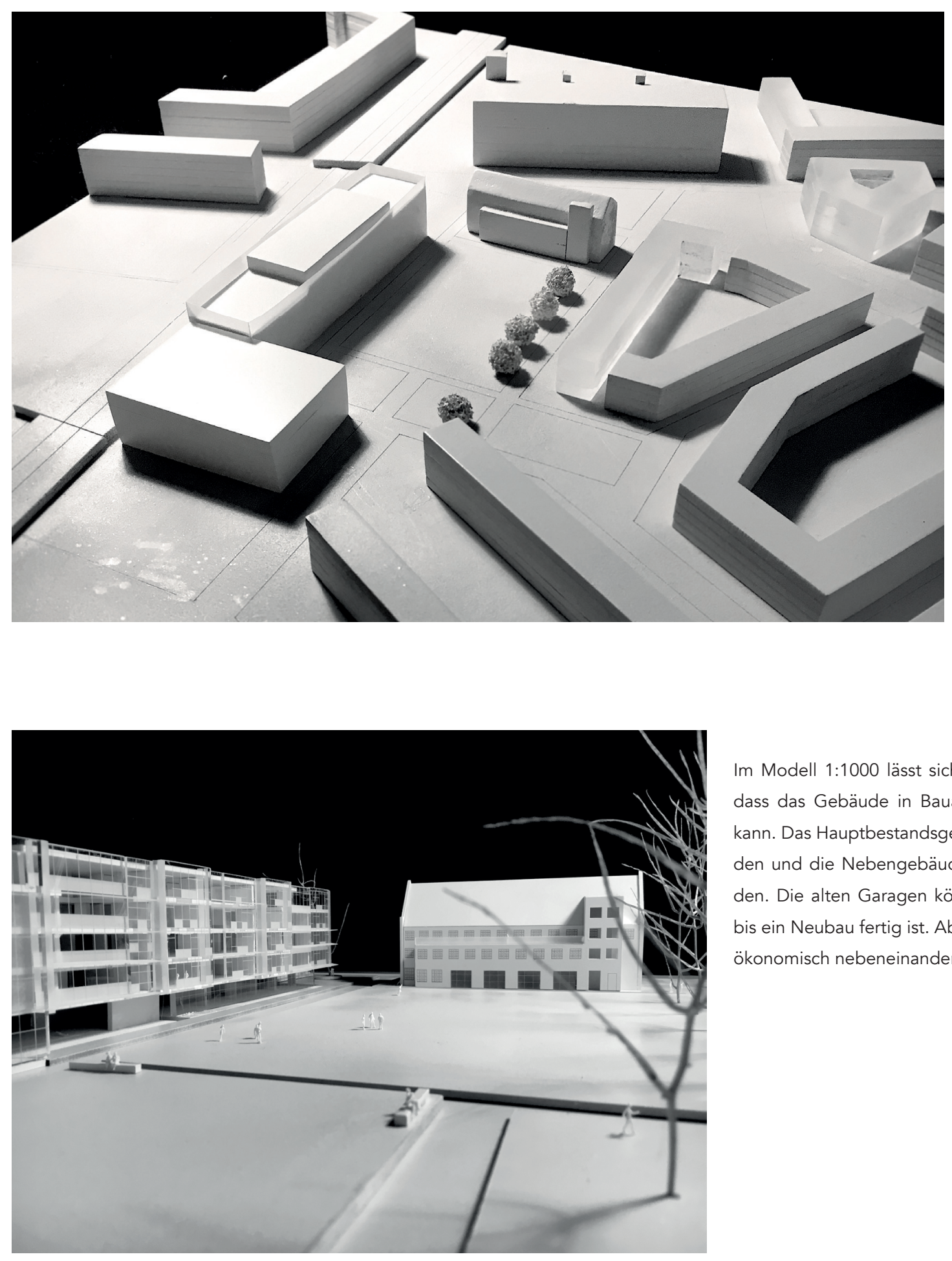

Im Modell 1:1000 lässt sich noch einmal verdeutlichen, dass das Gebäude in Bauabschnitten realisiert werden kann. Das Hauptbestandsgebäude kann jetzt saniert werden und die Nebengebäude ggf. zwischengenutzt werden. Die alten Garagen können als Werkstätten dienen bis ein Neubau fertig ist. Abriss und Neubau können hier ökonomisch nebeneinander stattfinden.

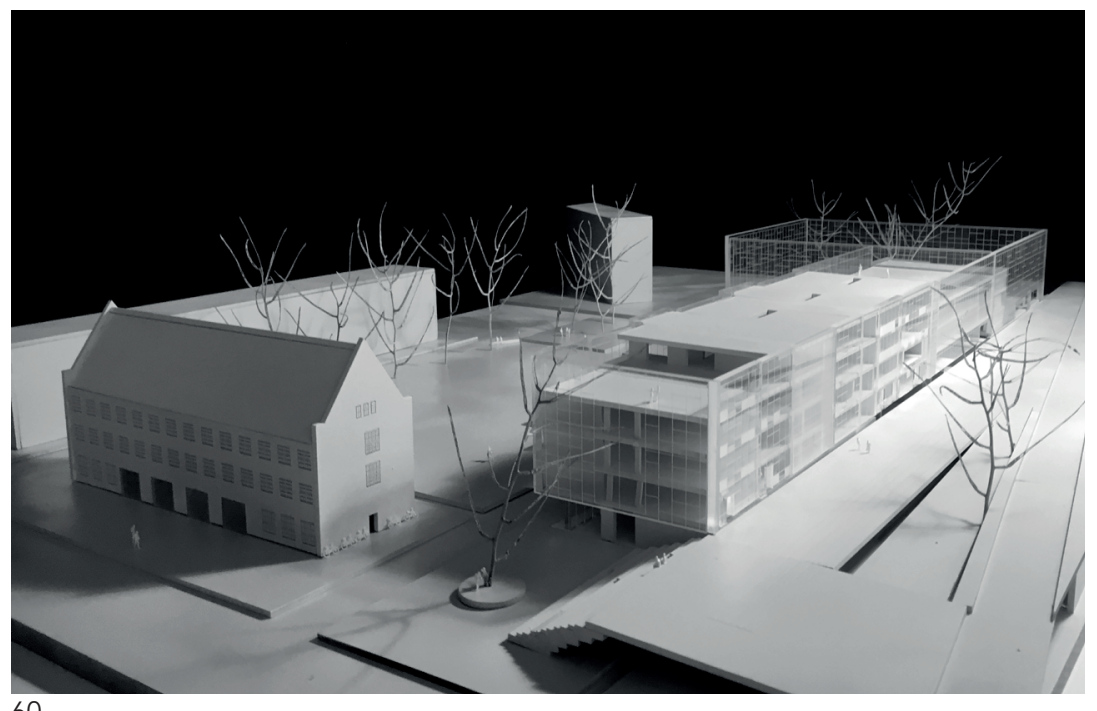


MODELLE
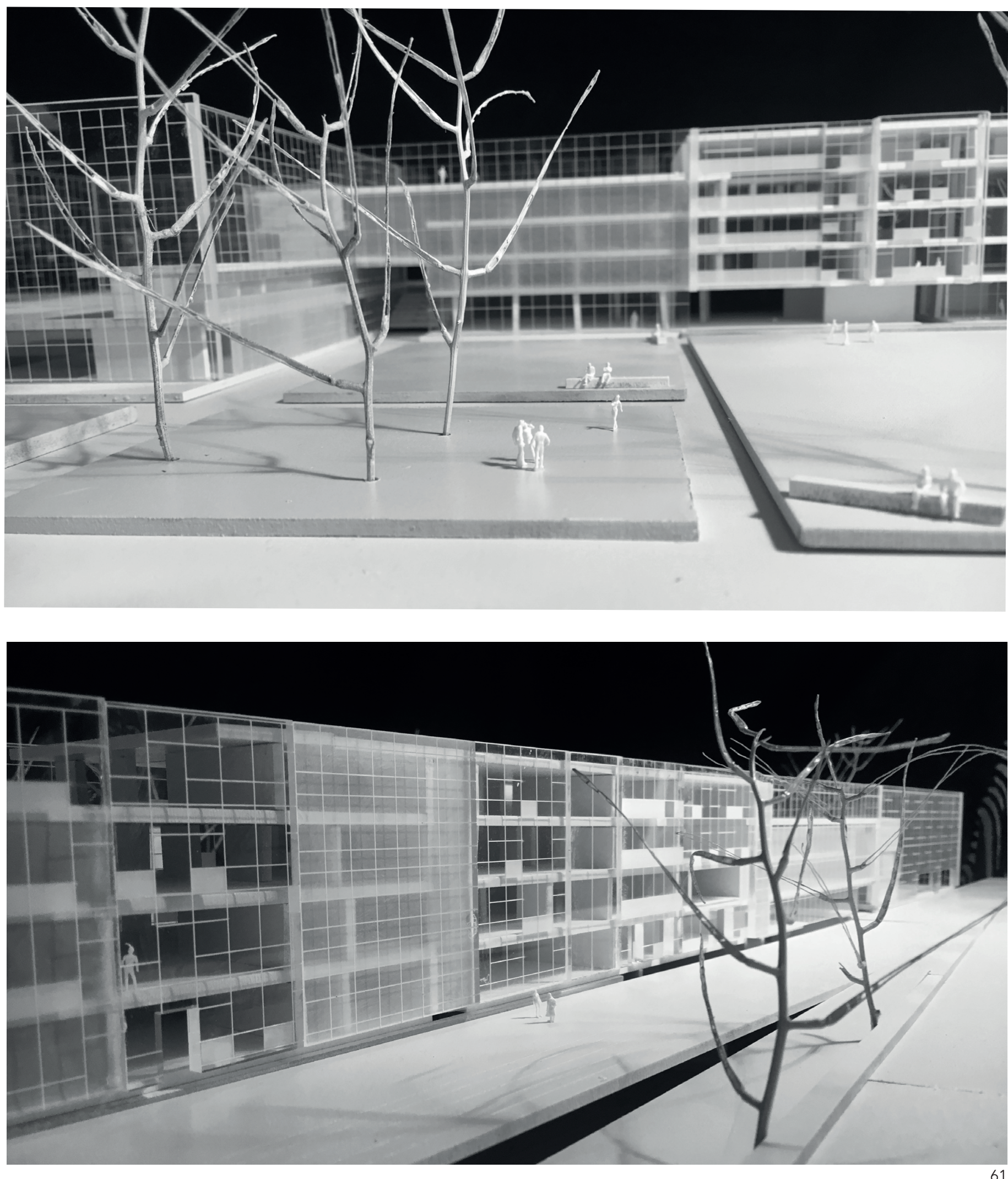


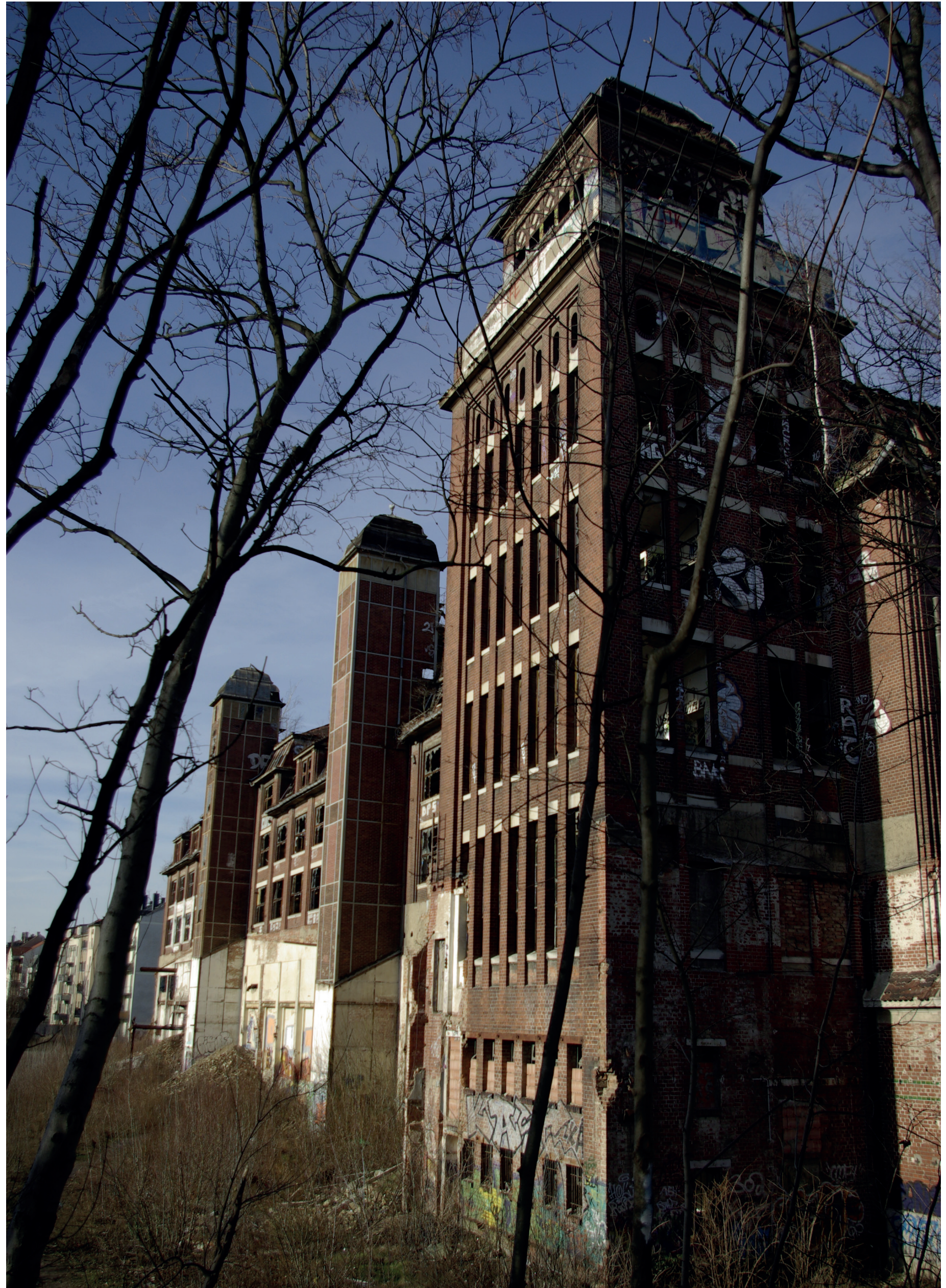




\section{WENN DREI SICH STREITEN...}

Und nun?

Sind alle zufrieden - die Stadt Leipzig bekommt eine Schule und die Ostwache kann als Nachbarschaftszentrum eröffnen.

Noch nicht ganz: Ziel der Arbeit war es durch die Nutzungsergänzung einen Treffpunkt für Anger-Crottendorf zu schaffen. (These I). Davon ist bereits jetzt schon auszugehen. Auch ohne Schulneubau wird die Feuerwache voraussichtlich ein lebendiger Ort im Leipziger Osten. Allein die Interessensbekundung zukünftiger Nutzer_innen spricht zumindest für einen gut vermieteten Ort.

DOI - Kapitel 6: http://doi.org/10.33968/9783966270144-06 
„Also, eine Schule darf da auf keinen Fall hin".

Mitglied des Ostwache e.V.
Die Feuerwache kann vermutlich auch ohne eine Schule am Ort funktionieren. Würde sie auch auf eine gemeinsame Hofnutzung verzichten und beispielsweise den Platz vor der Ostwache ( ${ }_{\text {"Crotti }}{ }^{\prime}$ ) nutzen, müsste man nichts miteinander zutun haben.

Jedoch sind auch Synergieeffekte sinnvoll. Das Raumprogramm von Schule und Nachbarschaftszentrum lässt sich aufgrund des Schwerpunkts der sozialen und kulturellen Nutzung gut miteinander verbinden. Eine Schule am Standort könnte sogar noch einen jungen und aktiven Ort schaffen. Neben den Synergieeffekten, wie des Ausbaus des öffentlichen Nahverkehrs, eine ganztätige Nutzung von gestalteten und halböffentlichen Freiräumen, eine Sporthalle im Stadtteil, die sogar für den Vereinssport genutzt werden kann.

Dafür muss sich nicht das Konzept der Ostwache, sondern das der Standartschule ändern. In staatlicher Trägerschaft deutscher Schulen sind solche Nutzungsmischungen selten. Deshalb wurde ein alternatives pädagogisches Schulkonzept vorgeschlagen. Jedoch wurde das Raumprogramm nur teilweise ergänzt - die Baumasse und Ausstattung lässt eine Schule in freier und öffentlicher Trägerschaft zu.

Dafür können, wie im Entwurf vorgeschlagen, zwar verschiedene Räume abgeschlossen, jedoch sollte der Schulhof frei zugänglich sein.

Der pädagogische Ansatz "Stadt als Schule” macht die Synergie der verschiedenen Akteure möglich. Wenn die Räume des Nachbarschaftszentrums und die der Schule gemeinsam und ganztags genutzt werden können, wird ein neuer Treffpunkt in, mit und für Anger-Crottendorf entstehen (These III).

Als ich schlussendlich meinen Entwurf auf der Weihnachtsfeier des Ostwache e.V. den dort Engagierten vorstellen konnte, kamen schell Diskussionen auf. Nachdem aus dem Arbeitsmodell für alle ersichtlich wurde, dass darin ein Bauvolumen einer mindestens 4-Zügigen Schule vorgesehen ist, war eines der Vereinsmitglieder des Ostwache e.V. spontan davon überzeugt, dass hier auf ihrem Grundstück auf gar keinen Fall eine Schule entstehen sollte. Vom städtebaulichen Entwurf waren einige vorerst also nicht zu überzeugen - ein zu großer Körper neben „ihrer" Feuerwache.

Insgesamt hat die kurze und herzliche Zusammenarbeit mit dem Verein meine Motivation, als Architektin arbeiten zu wollen wieder einmal bestärkt. Denn neben der Skepsis den Schulneubeu betreffend, sind gleichzeitig viele der entwickelten Ideen, wie bspw. den Schlauchturm als Aufzug oder den Platz vor der Feuerwache zu nutzen, auch sehr gut aufgenommen worden. Es ist eine besondere Bestätigung, festzustellen, dass diese Masterarbeit für die Menschen vor Ort relevant war.

Des Weiteren meldete sich während der Bearbeitungszeit ein Elternvertreter der Freien Schule Leipzig bei mir. Die Schule sucht einen neuen Standort und die Stadt Leipzig hat den Kontakt an mich weitervermittelt. Der Standort und das Konzept der Freien Schule und das der Ostwache können meines Erachtens durchaus zusammen gedacht werden - Die Stadt Leipzig müsste, was ihre Anforderungen an die zukünftige Schule, besonders was die Zahl der Schüler_innen und dem entsprechend die Baumasse, auf einen möglichen alternativen Schulträger zugehen. Vierzügig sind alternative Schulen momentan noch nicht häufig umgesetzt worden.

Zu Beginn der Arbeit hatte ich die Erwartung, dass ich während des Entwicklung des Entwurfs häufig mit dem Verein zusammenarbeiten werden müsse und diese Zusammenarbeit einen der Schwerpunkte meiner Arbeit darstellen würde. Im Laufe der Bearbeitung wurde deutlich, dass der Verein seit 2015 bereits einen großen Teil an Vorarbeit geleistet hatte und ich lediglich klassische planerische Aufgaben übernehmen konnte wie die Sanitärplanung oder Brandschutzkonzepte vorzuschlagen. Der intensivste Kontakt zum Ostwache e.V. bestand dabei derweilen zu Noriko Minkus, mit deren Hilfe sich die Bearbeitung des Entwurfs für die Feuerwache schnell abschließen ließ. Als selbstständig arbeitende Architektin hat sie ihre fachlichen Einschätzungen mit mir geteilt und 
hat zudem gleichzeitig auch die ökonomischen Grenzen des Vereins im Blick. Durch die Zugewandtheit und Professionalität des Kontaktes zu Noriko Minkus konnte ich sehr von ihr profitieren. Insgesamt sind dadurch jedoch auch viele Termine entstanden, was es mir erschwert hat zusätzlich die Zweitbetreuung durch Ronald Scherzer in Anspruch zu nehmen.

Der Schwerpunkt meiner Arbeit - die Verbindung von Schule und Nachbarschaftszentrum - hat sich erst während der Arbeit an der Problemstellung herausgestellt. Während der Recherche hat sich meiner Ansicht nach verdeutlicht, dass Schulen und Schulneubauten sich öffnen müssen, und davon profitieren näher an der Stadtgesellschaft zu lehren und zu lernen. So entstehen Freiräume für Jugendliche in der Stadt die auch ganztags genutzt werden. So entstehen für alle neue Perspektiven.

\section{... FREUT SICH DER VIERTE}

Wenn drei sich streiten, freut sich der Vierte. Denn während die drei Akteure in einem Nutzungskonflikt um eine städtische Liegenschaft stehen, bleibt das Grundstück der alten Karl-Krause Fabrik weiter unberührt. Das Objekt liegt seit mehreren Jahren brach. Der Verkauf an einen privaten Investor und die etwaige Planungen haben noch keine Veränderung gebracht. Wahrscheinlich scheint, dass darauf spekuliert wird, das Grundstück bald wieder zu einem höheren Preis verkaufen zu können.

Auch auf diesem Areal der Karl-Krause-Fabrik wäre es denkbar, einen Bildungsstandort zu etablieren. Eine Sanierung des mittlerweile sehr beschädigten Gebäudes wird sich vermutlich bald nicht mehr lohnen. Der in dieser Arbeit entworfene Schulneubau fände entlang des Parkbogens oder auch an anderer Stelle des Bogens sicherlich auch einen guten Standort.

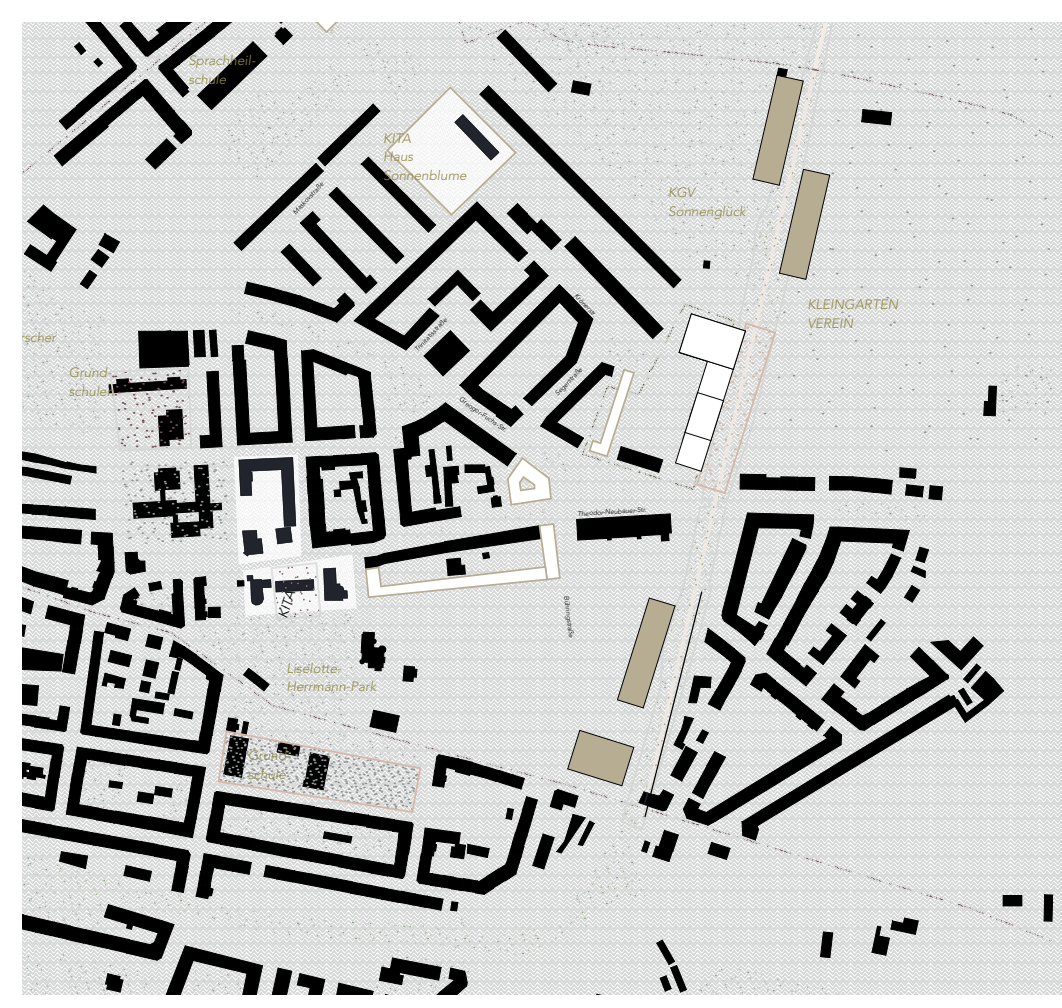




\section{QUELLEN}

Alphabetisch, nicht nach Art soritert
Briel, C./Krüger, H. (1999): Anger-Crottendorf : Eine historische und städtebauliche Studie /. Leipzig [BUCH].

Bruns, A. (2011): Demokratie und soziale Gerechtigkeit. Die pädagogischen Konzepte von Célestin Freinet und Paulo Freire im Vergleich. 2., bearbeitet. Oldeburg. $[\mathrm{BUCH}]$

Bundesverband der Freien Alternativschulen (2011): Frei wovon? Frei wozu? - Die Freien Alternativschulen -- eine Standortbestimmung. https://www.youtube.com/ watch?v=2zAmzHWjb-E (8. Januar 2019). [FILM]

Burow, O.-A. (2018): Lernen von morgen. https://www. deutschlandfunknova.de/ (8. Januar 2019). [VORTRAG].

Dietrich, I. (Hrsg.) (1995): Handbuch Freinet-Pädagogik: eine praxisbezogene Einführung. Weinheim Basel. $[\mathrm{BUCH}]$

Dolphin Trust GmbH (2017): Die ehemalige Fabrikhalle des Kombinats Polygraph Leipzig. In: Immo Anleger. http://www.immo-anleger.de/die-ehemalige-fabrikhalle-des-kombinats-polygraph-leipzig/ (18. Oktober 2018). [WEB]

Försterling, M. (2018): Feuerwache. Gespräch mit Sachbearbeiterin ASW, Eigene Notizen, September 2018. [GESPRÄCH]

Glänzel, H. (2012): Die "Natürliche"(Lern-)Methode. In: Hansen-Schaberg, I. (Hrsg.): Freinet-Pädagogik. Baltmannsweiler, S. 170-190. [BUCH]

Grothe, L. (2018): Zusammen lernen - kreuzer online. In: kreuzer online. https://kreuzer-leipzig.de/2018/11/27/zusammen-lernen/ (03.02.2019). [ZEITUNG]

Hansen-Schaberg, I. (2012): Praxis und Theorie in der Freinet Pädagogik. In: Freinet-Pädagogik. 2., überarbeitet. Baltmannsweiler, (= Reformpädagische Schulkonzepte). [BUCH]

Simon, J.; Simon, T. (2013): Stadt als Schule? Zum Zusammenhang von Schul(raum)entgrenzung und inklusiven Schulentwicklungsprozessen. In: Zeitschrift für Inklusion, 0 Jg., H. 2. [ZEITSCHRIFT]

Kahl, R. (2004): Treibhäuser der Zulunft. Wie in Deutschland Schulen gelingen. FILM https://www.youtube.com/ watch?v=foxcULxYcUs (8. Januar 2019). [FILM]

Kleinen, D. (2014): BAUWELT - Am Lokdepot. https://www.bauwelt.de/themen/bauten/Am-Lokdepot-Park-am-Gleisdreieck-Berlin-Robertneun-2154590. html (24. Januar 2019). [ZEITSCHRIFT]
Kovermann, B. (2012): Der Klassenrat: Demokratie mit Jugendlichen im Schulalltag vorbereiten. In: Hansen-Schaberg, I. (Hrsg.). 2., überarbeitet. Baltmannsweiler, S. 244-278. [BUCH]

Landesamt für Denkmalpflege Sachsen (2018): Liste der Kulturdenkmale in Anger-Crottendorf. In: Wikipedia. https://de.wikipedia.org/w/index.php?title=Liste_der_Kulturdenkmale_in_Anger-Crottendorf\&oldid=178500883 (12. September 2018). [WIKIPEDIA]

Leipziger Internet Zeitung/Freitag, M. (2016): Alte Feuerwache Ost: Achtung, der Bürger meldet sich zu Wort + Interview. In: L-IZ.de. https://www.l-iz.de/politik/engagement/2016/12/alte-feuerwache-ost-achtung-der-buerger-meldet-sich-zu-wort-interview-161651 (27. August 2018). [ZEITUNG]

LPG, L. L. P. mbH/Drescher, S./Schröder, R./Weber, A. (2017): Grobscreening von Teilräumen der Stadtteile Reudnitz-Thonberg, Anger-Crottendorf, Neustadt-Neuschönefeld, und Volkmarsdorf der Stadt Leipzig im Hinblick auf städtebauliche Räume bei denen Abzeichnende Städtebauliche Aufwertungen der Wohngebiete im Zusammenhang mit Verdrängungszendenzen der angetammten Bevölkerung stehen. LPG Landesweite Planungsgesellschaft mbH Geschäftsführer Roland Schröder Gaudystraße 12. [STUDIE]

Luckmann, H. (2018): Schulplanung an der Feuerwache. Telefonat, eigene Notizen, September 2018. [GESPRÄCH]

Montagsstiftung/Bund deutscher Architekten, B./Nerband Bildung und Erziehung, V. (Hrsg.) (2013): Leitlinien für Leistungsfähige Schulbauten in Deutschland. abrufbar unter: https://www.vbe.de/fileadmin/user_upload/VBE/ Service/Publikationen/2017_06_20_Schulbauleitlinien. pdf) (18. August 2019). [BUCH]

Müller-Barion, M. (2008): Der dritte Pädagoge. In: www. fr.de. https://www.fr.de/rhein-main/blaulicht-sti879542/ dritte-paedagoge-11588655.html (30. Januar 2019). [ZEITUNG]

Ostwache Leipzig e.V. (2018a): Ostwache Leipzig. http://ostwache.org/ (27. August 2018). [KONZEPT]

Ostwache Leipzig e.V. (2018b): Erstes Gespräch zur bearbeitung einer Masterarbeit. [GESPRÄCH]

Ostwache Leipzig e.V. (2017): Konzept. in: Ostwache.org; http://ostwache.org/wp-content/uploads/ sites/52/2016/08/Ostwache-2016.12-Konzept.pdf 


\section{(03.02.2019) [KONZEPT]}

Schlemminger, M. (2005): Glossar zur Freinet-Pädagogik. In: Riemer, M. (Hrsg.): Praxishilfen Freinet-Pädagogik. Bad Heilbrunn, S. 233 - 252. [BUCH]

Seehausen, F. (2015): Die Fabrikgebäude. In: Brahm, D. (Hrsg.): Kirsten \& Nather: Wohn- und Fabrikationsgebäude zweier West-Berliner Architekten. Ostfildern, S 180-217. [BUCH]

Stadt Leipzig, ASW (2018a): Parkbogen Ost - von Bahnflächen zum grünen Aktivband. In: leipzig.de. https://www. leipzig.de/bauen-und-wohnen/stadterneuerung-in-leipzig/stadterneuerungsprojekte/parkbogen-ost/ (18. Oktober 2018). [WEB]

Stadt Leipzig, ASW (2018b): Quartiersschule Leipziger Osten. In: leipzig.de. https://www.leipzig.de/bauen-und-wohnen/stadterneuerung-in-leipzig/stadterneuerungsprojekte/quartiersschule-leipziger-osten/ (18. Oktober 2018). [WEB]

Stadt Leipzig, Amt für Statistik \& Wahlen (2018): Statistischer Quartalsbericht II /2018. [STUDIE]

Werner, F. (2011): Raum vor Ort. Eine exemplarische Untersuchung von Raumkonstitutionen an einem Leipziger Stadtteil (Magisterarbeit). Leipzig. [ABSCHLUSSARBEIT]

STAFFAGE / Texturen in Visualisierungen: toffu.com, Lumion; Alle Grafiken mit ArchiCAD Graphisoft und LUMI$\mathrm{ON}$ erstellt.

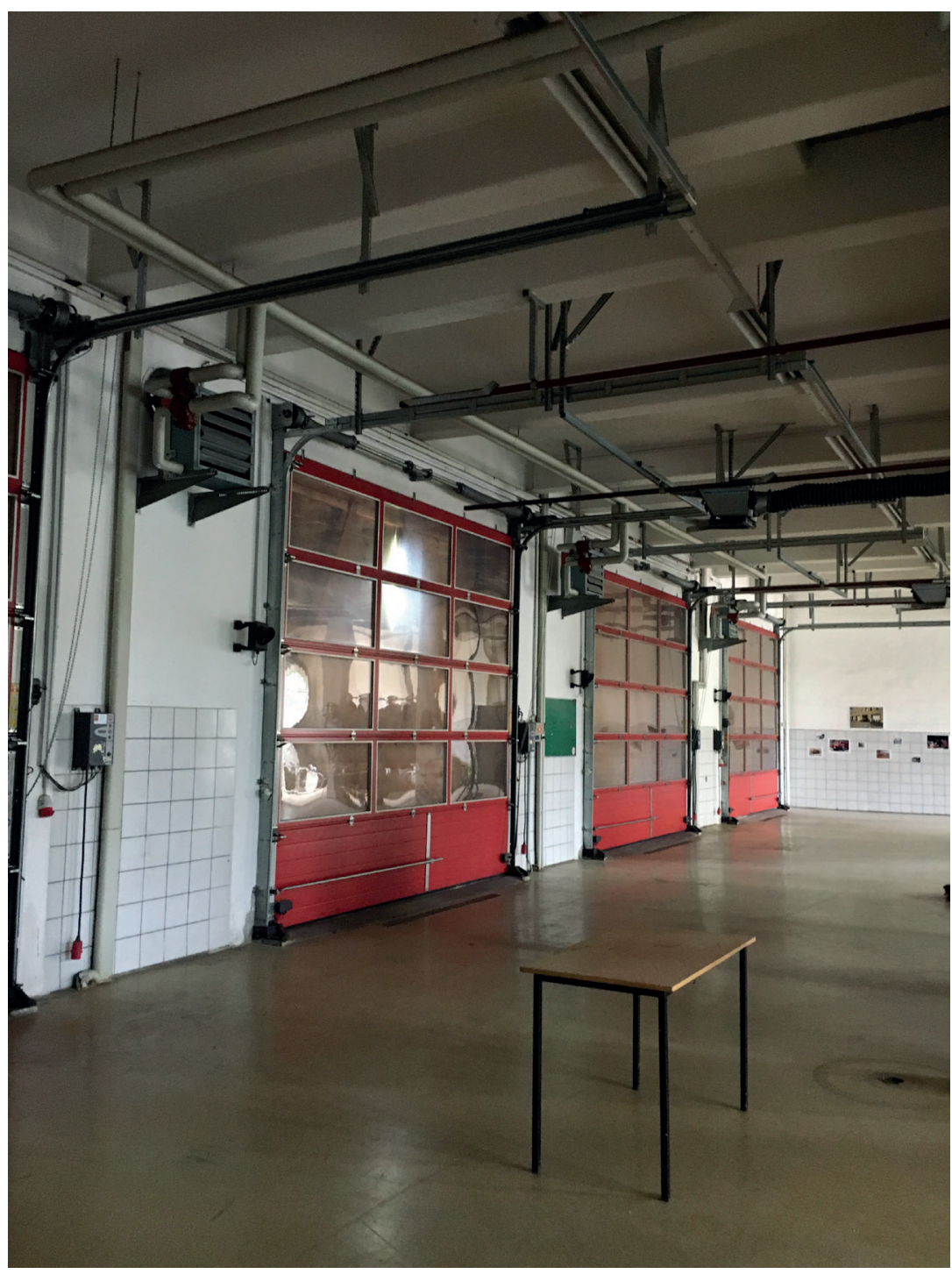


